Portland State University

PDXScholar

$1-1-1985$

\title{
Growing old and going straight: examining the role of age in criminal career termination
}

Annette I. Jolin

Portland State University

Follow this and additional works at: https://pdxscholar.library.pdx.edu/open_access_etds Let us know how access to this document benefits you.

\section{Recommended Citation}

Jolin, Annette I., "Growing old and going straight: examining the role of age in criminal career termination" (1985). Dissertations and Theses. Paper 66.

https://doi.org/10.15760/etd.66

This Dissertation is brought to you for free and open access. It has been accepted for inclusion in Dissertations and Theses by an authorized administrator of PDXScholar. Please contact us if we can make this document more accessible: pdxscholar@pdx.edu. 


\section{GROWING OLD AND GOING STRAIGHT: EXAMINING THE ROLE OF AGE IN CRIMINAL CAREER TERMINATION}

by

ANNETTE JOLIN

A dissertation submitted in partial fulfillment of the requirements for the degree of

\section{DOCTOR OF PHILOSOPHY in \\ URBAN STUDIES}

Portland State University

(C) 1985 Annette Jolin 
TO THE OFFICE OF GRADUATE STUDIES AND RESEARCH:

The members of the Committee approve the dissertation of Annette Jolin presented May 31, 1985.

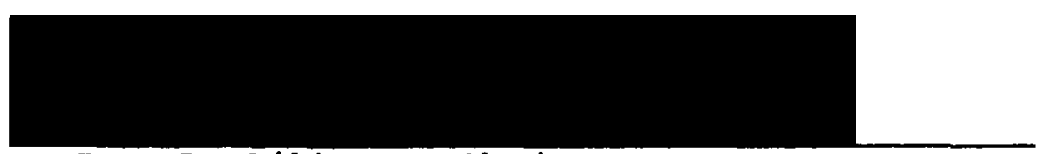

Don C. Gibbons, Chairman
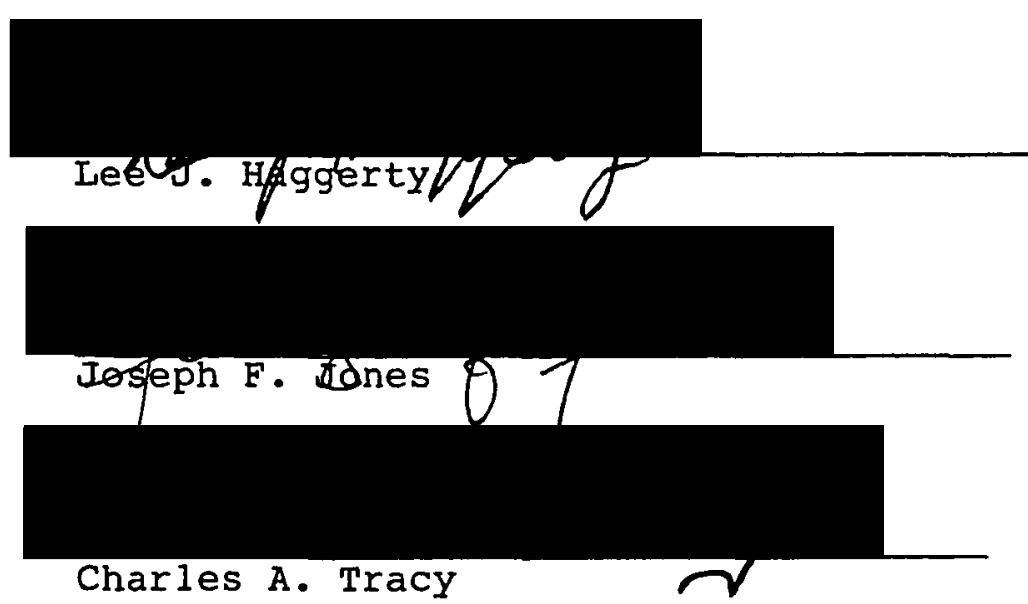

APPROVED :

Kenneth J. Dueker, Acting Dean, School of Ûrban and Public Affairs

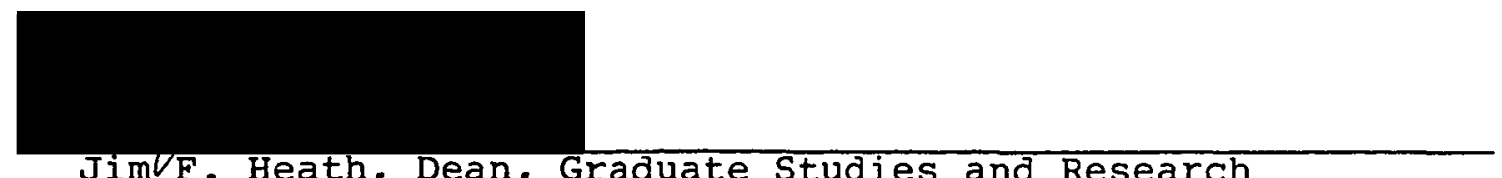

JimVF. Heath, Dean, Graduate Studies and Research 
AN ABSTRACT OF THE DISSERTATION OF Annette Jolin for the Doctor of Philosophy in Urban Studies presented May 31 , 1985.

Title: Growing old and Going Straight: Examining the Role of Age in Criminal Career Termination.

APPROVED BY MEMBERS OF THE DISSERTATION COMMITTEE:

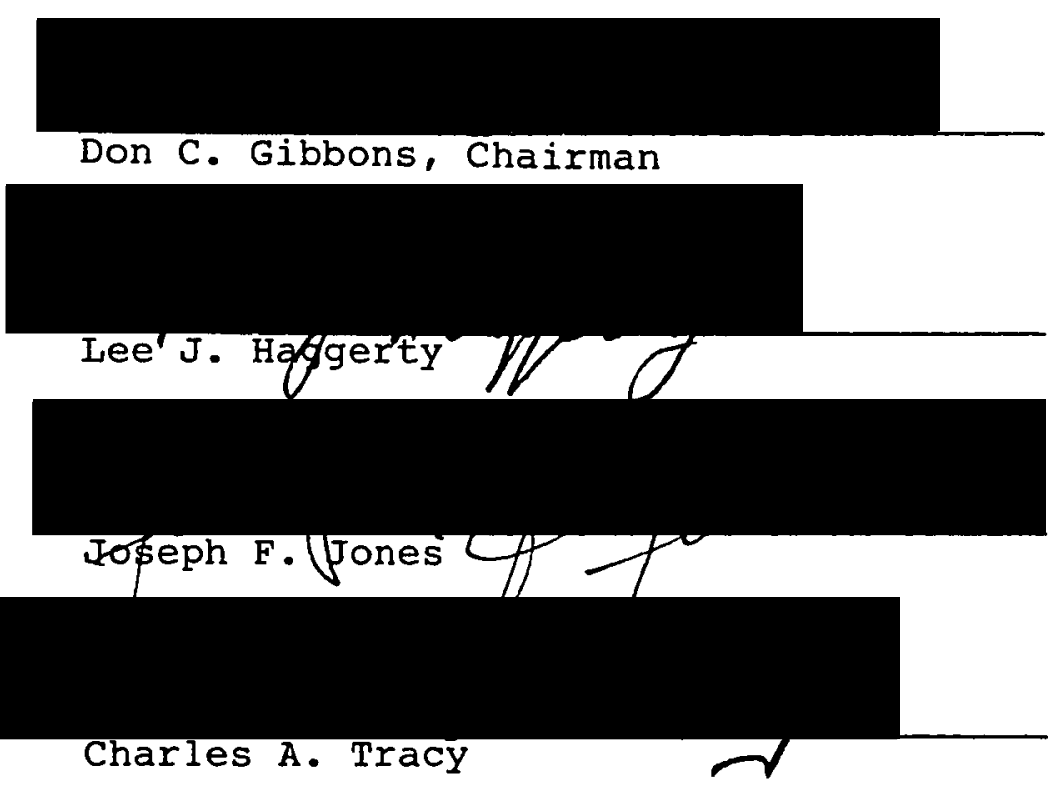

Why do men appear to desist from ordinary street crime by approximately age forty? Criminologists, who first noted the existence of a relationship between increasing age and decreasing crime as far back as 1833, have done little to investigate the reason for such desistance. Concepts such as "maturational reform," "maturing," and "burnout" have 
been used in reference to the phenomenon, but the concepts themselves have remained rather hollow, at best vaguely suggesting developmental unfolding or capitulating.

This study was designed to investigate mid-life desistance from crime as a function of general mid-life change. Adult developmental theory postulates that major occupational or lifestyle changes occur during mid-life, more so than during other developmental periods in adulthood. Such changes are said to occur in conjunction with specific transitional processes experienced by the middle-aged male. The abandonment of a criminal career at mic-life is viewed as a significant occupational and lifestyle change. It is examined in relation to the postulated transitional processes affecting aspects of the life areas of work and social relationships, as well as health and psychological well-being.

Structured interviews were conducted with a small group of former career criminals and a small group of currentlyimprisoned middle-aged career offenders. Career offenders were compared with middle-aged general population men, and former career offenders were compared with imprisoned career offenders. Limitations of the research design and the sampling methods are also discussed.

The findings suggest that middle-aged career offenders, regardless of whether they have terminated their criminai 
careers or are still imprisoned, in large part resemble general population men in terms of mid-life concerns. A comparative analysis of ex-offender and inmate responses suggests that while the men resemble each other closely in the area of mid-life concerns, successiul change away from a criminal career at mid-life means that mid-life developmental tasks must be accompanied by relatively welldeveloped social relationships and the ability to gain control of drug and alcohol problems. 


\section{ACKNOWLEDGMENTS}

My gratitude is due a number of people, each of whom gave generously to make this project possible.

I want to thank the men who, as participants, must remain nameless. They gave their time, experience, and knowledge in the true spirit of generosity.

I want to thank Dr. Don C. Gibbons, whose unerring guidance and extraordinary dedication have been with this project from its inception.

I want to thank Dr. Joseph F. Jones, Dr. Lee J. Haggerty, and Dr. Charles A. Tracy for lending perspective and for showing considerable patience.

I want to thank the state of oregon corrections Division for its extensive technical support of this project and the U.S. Department of Justice for its financial support in the form of Graduate Research Fellowship Grant 010-G51.

I want to thank my children, Marc and Andrea, who gave understanding and tolerance to a cause of uncertain rewards. 
TABLE OF CONTENTS

PAGE

ACKNOWLEDGMENTS . . . . . . . . . . . . . . . iii

LIST OF TABLES . . . . . . . . . . . . . . . viii

CHAPTER

I MATURATION FROM CRIME . . . . . . . . . 1

The Relationship Between Age and

Crime . . . . . . . . . . 6

Age and Crime: Empirical

Evidence

Age and Crime: Anecdotal

Evidence

Explaining the Criminality:

Criminological Explanations . . . . 10

A Theoretical Approach to

Maturational Reform... . . . . 14

I.evinson's Mid-Life Theory

Tamir: Men in Their Forties

I I AN EXAMINATION OF AGE-RELATED CHANGES IN CRIMINAL BEHAVIOR: METHOD . . . . • . • 46

Procedure . . . . . . . . . 46

Ex-Offender Participants

Inmate Participants

Instrument.$\cdot \cdot \cdot \cdot \cdot \cdot \cdot \cdot \cdot \cdot \cdot$

Social Background Questions

Criminal History Questions

Life Satisfaction Questions

Social Psychological

Development Questions

Social Desirability Questions 
Ex-Offender and Inmate Social Background Characteristics . . . .

Criminal Histories Juvenile Offense Backgrounds Involvement with the Criminal Justice System

Use of Accomplices in the Commission of crime Perceived Success in Crime Going Straight: Inmates and Ex-offenders Looking Back

III WORK, SOCIAL RELATIONSHIPS, AND SOCIAL WELL-BEING IN THE LIFE OF CAREER OFFENDERS

The Data

Work Relationships . . . . . . 80

Social Relationships . . . . . . 85

Marriage

Fatherhood

Friends

Psychological Well-Being at Mid-Life 95

Self-Esteem

Zest

Psychological Immobilization

Drinking Problems

Drug Use

Summary

Value orientation

Conclusions . . . . . . . . 109

IV THE MID-LIEE TRANSITION IN THE LIFE OF THE EX-OFFENDER • • • • • • • • • • • • • • • 113

Reappraising Life Before Middle Age - 114

Planning a New Life Structure During the Mid-Life Transition . . . . . 116

The Young/Old Polarity at Mid-Life • 119 


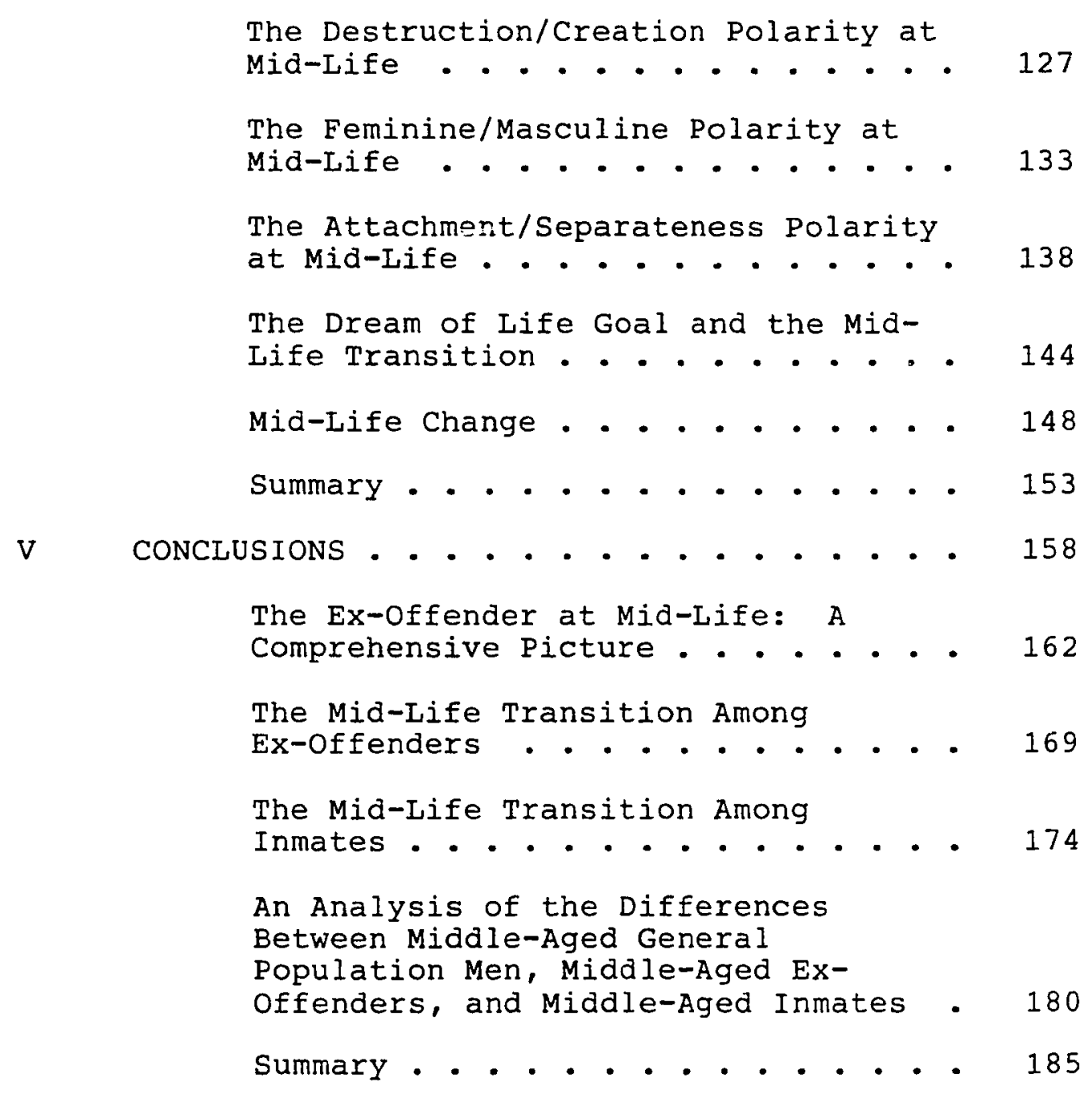

REFERENCES • . . . . . . . . . . . . . . 187

APPENDIX A: ADVERTISEMENT FOR THE STUDY . . . . . . . 193

APPENDIX B: INFORMED CONSENT . . . • . . . . . . 195

APPENDIX C: MATRIX APPLICATION-MULTIPLE OFFENSE • • 197

APPENDIX D: SOLICITATION LETTER . . . . . . . . • . 199

APPENDIX E: THANK-YOU LETTER . . . . . . . . . . 201

APPENDIX F : BACKGROUND CHARACTERISTICS . . . . . . 203 
vii

PAGE

APPENDIX G: CRIMINAL HISTORY QUESTIONS . . . . . . 206 APPENDIX H: SATISFACTION •. . . . . . . . . . 213 APPENDIX I : SOCIAL PSYCHOLOGICAL DEVELOPMENT • • • 222 APPENDIX J: SOCIAL DESIRABILITY INDEX . . . . . 228 


\section{LIST OF TABLES}

TABLE

PAGE

Characteristics of Actual and Potential

Inmate Participants . . . . . . . . .

II Response Comparison of all Inmates Versus

Inmates without the High Scorers on the

Social Desirability Scale....... . 60

II Social Background Characteristics of

Ex-Offenders and Inmates . . . . . . . .

IV Reasons for Involvement in Crime,

Ex-Offenders vs. Inmates . . . . . . .

V Criminal Histories as Juveniles,

Ex-Offenders vs. Inmates . . . . . . 68

VI Involvement with the Criminal Justice

System, Ex-Offenders vs. Inmates . . . . 70

VII Crime with/Without Accomplices,

Ex-Offenders vs. Inmates . . . . . . 73

$\begin{array}{ll}\text { VIII } & \text { Retrospective Impressions of Going } \\ & \text { Straight, Ex-Offenders vs. Inmates . . . } 75\end{array}$

IX Aspects of Work . . . . . . . . . . 83

$X$ Social Relationships: Marriage,

Parenthood, and Friendship . . . . . 87-89

XI Self-Esteem . . . . . . . . . . . 93

XII Zest or Absence of Depression . . . . . 98

XIII Psychological Immobilization . . . . . 101

XIV Alcohol and Drug Use . . . . . . . 103

XV Orientation . . . . . . . . . . 107

XVI Health . . . . . . . . . . . . 123 
TABLE

PAGE

XVII The Young/old Polarity at Mid-Life . . . 125

XVIII The Destruction/Creation Polarity at Mid-

Life . . . . . . . . . . . . 130

XIX The Feminine/Masculine Polarity at Mid-Life . . . . . . . . . . 135-6

$\mathrm{xX}$ The Importance of Becoming a Mentor at Mid-Life . . . . . . . . . . . . 139

XXI The Attachment/Separateness Polarity at Mid-Life .............. 143

XXII The Importance of the Dream of Life-Goal in Mid-Life . . . . . . . . . . . . 146

XXXIII Mid-Life Change: Summarized Responses to Open-ended Questions . . . . . . . 150 


\title{
CHAPTER I
}

\section{MATURATION FROM CRIME}

\begin{abstract}
Many of us are aware that in our society, criminal offenses, at least predatory offenses, are committed disproportionately by young people, more specifically by young men. Less than fifteen percent of the general public will ever be arrested for the commission of a serious offense, and more than half of those arrested once will never be arrested again. Only about five percent of the population as a whole will show the beginnings of serious involvement in predatory crime.

Serious lawbreaking tends to have its beginnings relatively early in life; in fact, the earlier it begins and the more serious it is at that point, the greater the chance of adult criminal behavior (Petersilia, 1980). Once begun, criminal activity tends to be maintained primarily for economic reasons, including drug- and/or alcohol-related ones. With advancing age, however, criminal offenses decline in frequency until such time that a clear "career termination" (Petersilia, 1980) can often be observed on the part of many lawbreakers.
\end{abstract}


Research efforts on offender careers have focused predominantly on the identification of variables which are predictive of criminal career onset or of differing degrees of involvement in persistent crime. Criminologists, psychologists, and scientists from several other disciplines have attempted to identify social-structural, personality, cultural and/or genetic characteristics that account for or predict criminality, while studies such as the Rand investigations of offenders have tried to differentiate "low rate" and "high rate" career criminals. By contrast, questions that ask why increasing age is accompanied by a decline in criminality and what accounts for the termination of criminal careers, have received very little attention until quite recently. Joan Petersilia (1980) has asserted:

Career termination is another area in which further research is needed. Little is known about the distinguishing characteristics of active criminals who shift completely into lawful pursuits. For occasional offenders this transition may represent a significant event; but for active offenders it may represent a significant departure in attitude, behavior, and social contacts (p. 373).

This transition from involvement in lawbreaking to desistance from criminality has variously been referred to as "maturational reform" (Matza, 1964), "burn-out" (von Hirsch, 1981), or simply maturing or aging. For example, David Matza (1964) used the term "maturational reform" in reference to the fact that only a small fraction of 
delinquent youths become adult criminals. Similarly, Andrew von Hirsch (1981) asserted that we currently have a

certain number of people in prison who would deserve to be there because they had an extensive record of violence, but who would no longer be dangerous. They may, for example, have 'burnt out' due to aging or maturing (p. 88).

Kenneth Polk et al. (1981: 303) examined maturational reform for the cohort of the Marion County Youth Study. More accurately, Polk et al. Iimited the discussion to "desistance" or "reform" and deliberately sidestepped the complex and problematical issue of "maturation."

It is argued that maturational reform (Matza, 1964) leads to or causes desistance; thus, by focusing on the behavioral phenomenon of desistance from crime, Polk et al. did not address how desistance came about. To invoke the concept of maturation--the emergence of personal and behavioral characteristics through growth processes (Webster, 1973)--evidence must be provided to show that desistance from crime is associated with changes in internal growth patterns. Thus it must be shown, first, that the person has stopped committing crime and second, that before he stopped committing crime, he "matured." While the Polk et al. research did not address the issue of maturation

Desistance refers to the discontinuation of criminal behavior by a given offender. 
and instead focused primarily on the extinction of offense behavior that accompanies age, an attempt was made nevertheless to explain desistance in terms of such adolescent background factors as family support, school success, and peer involvement. The findings indicated that

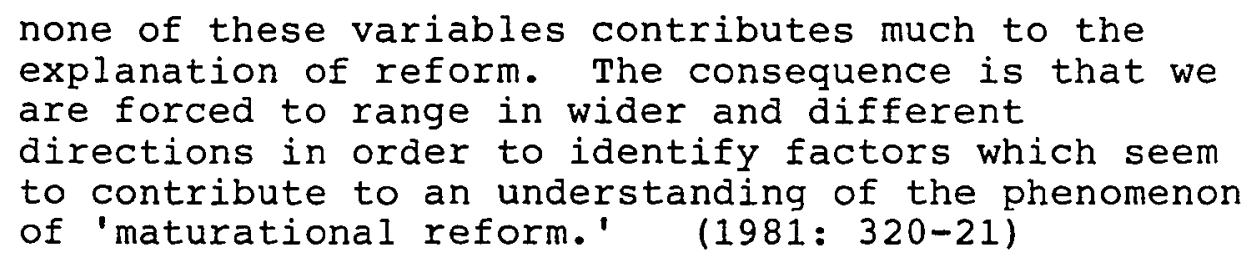

Samuel Bazemore (1982) re-examined the Marion County Youth Study data to assess the possible effect of social labeling on desistance. He, too, avoided specifying the nature of maturational reform itself. Bazemore found, contrary to his expectations, that those juveniles who had accepted and internalized delinquent labels were no less likely to reform than were those juveniles who had not internalized delinquent labels.

In still another study, Neal Shover (1983) examined property offenders in the later stages of their careers in an attempt to identify the contingencies surrounding the maturational or burnout process. Shover's findings linked desistance from property crime to a change in contingencies (for example tiredness, identity shift, ties to other persons, etc.) surrounding the commission of offenses by the aging criminal. 
Meisenhelder (1977) looked at "exiting from crime" as a natural career stage (321). He had obtained information from inmates presumed to be in the later stages of their criminal careers; and based on this information, he suggested that successful exiting was linked to the offenders' ability to establish a bond to the conventional world (331) and to the increasing threat that doing more time represented to these men. The central thrust of these observations on maturational reform and kindred concepts is that, in the work of Polk et al. as well as in the writings of those who speak of "burnout," "maturation," and the like, these concepts are invoked to account for desistance from lawbreaking, but the ingredients or indicators of maturation or burnout remain largely unspecified. Put still another way, the evidence for maturation tends to be largely the same data on desistance that the concept is intended to explain.

The central goal of the current study is to provide some substance to the notion of maturational reform by identifying some of the dimensions of the phenomenon. assuming for the moment that it can be shown to exist. It proposes to pursue the dimensions of maturation somewhat further than they have been studied to date. However, before turning to a more detailed explication of the study 
at hand, some further attention to the age-crime relationship is in order.

\section{THE RELATIONSHIP BETWEEN AGE AND CRIME}

\section{Age and Crime: Empirical Evidence}

The most consistent and extensive records on crime in America are published annually by the Federal Bureau of Investigation (FBI). Police agencies across the country report crime occurrence figures, arrest data, and other statistics to the FBI, which, in turn, assembles these data in the form of an annual report, Crime in the U.S.: Uniform Crime Reports.

According to these official statistics, the age-related pattern of crime participation appears to be rather consistent over time. In 1970, youths between the ages of 15 and 19 were responsible for 26 percent of all arrests, and in 1980 this age group accounted for 27 percent of all arrests. In general, participation in conventional crime rises with age, peaks in adolescence or young adulthood, and declines with increasing age, but some variation in this pattern occurs when different offenses are examined.

\footnotetext{
The use of the word "crime" in this study refers to "garden variety" or predatory crime only. Generally speaking, this means the exclusion of white collar crime, organized crime, etc.
} 
David Greenberg (1983), for example, delineated three broad offense categories within which to examine age relationships. For burglary, theft, vandalism, etc., the official records reflected peak involvement during ages 15 to 19, followed by rapid decline with age; for homicides, rapes, assaults, etc., involvement was greatest during ages 17 to 21 , followed by a less rapid decline; for fraud, embezzlement and sex- and alcohol-related offenses, involvement was greatest during ages 21 to 22 , followed by a slow decline.

The way in which age-crime data are collected may further influence findings. Greenberg (1983) pointed out that a comparison of cross-sectional and cohort data

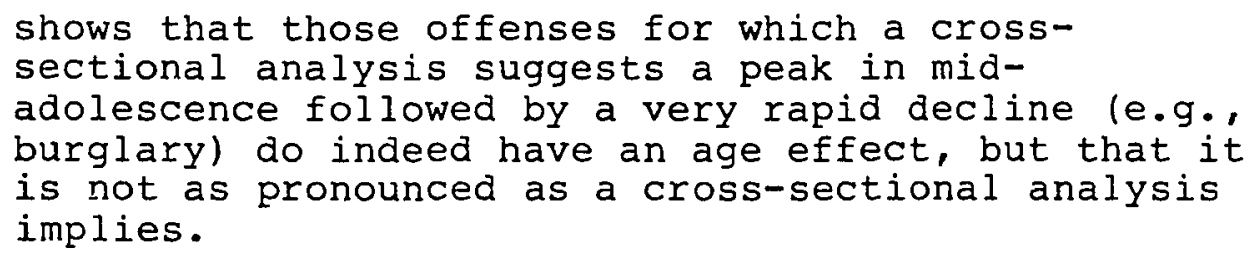

Miller et al. (1982) in a longitudinal study of violent offenders' arrest records, also pointed to the variability in the age-crime relationship. However, these patterns do not fundamentally contradict those that are shown by FBI index arrest figures.

Additional statistical evidence came from a study by Robins (1966) who examined the relationship between antisocial adult behavior and deviant behavior in childhood. 
Robins reported that the median age at which her subjects gave up or markedly decreased their anti-social behavior was 35. Also, the Polk et al. (1981) study followed a cohort of Marion County youths from 1958 to 1979. The authors concluded that

the persistence of the basic pattern of extinction when status offenders are removed suggests that there is probably a real and substantial break in offense behavior beyond age 18. (1981: 311)

Regrettably, Polk et al. followed their cohort only to age 28 and thus provided only limited insight into adult offense behavior. Earlier, the Glueck's (1937: 105) had attempted to identify the relative contribution of various factors leading to the termination of criminal careers and concluded that aging was "the only one [factor] which emerges as significant in the reformation process."

\section{Age and Crime: Anecdotal Evidence}

Clues as to the processes underlying the statistical evidence on maturation can be found in such case history accounts as ex-prisoner Malcolm Braly's Ealse Starts (1976). Braly's first encounter with the California Department of Corrections took place at age 18. He took stock of his life twenty years later and reported: 
- . in the last twenty years I had been free ten months between Preston and the Nevada prison, free eighteen months between my first and second jolts, and free eleven months between the second and third. A month better than two and a half years (331).

He referred to this time, which ended with his final discharge from the Department of Corrections shortly after his fortieth birthday, as his grossly extended adolescence. He wrote False Starts almost ten years later and concluded: ". the pattern is clearly broken" (374). In his discussion of career termination Gibbons (1977) pointed out that John Irwin's book the Felon (1970) provided one of the best analyses of desistance from criminality following an extensive criminal career (251). Irwin's information was based upon interviews with fifteen offenders who had remained out of prison for many years, along with his own insights gleaned as an ex-felon.

Reports of declining criminality with age have also come from correctional workers. Braly quoted his san Quentin psychologist as saying

You are older. This seems to work for some. You see how the Gods churn away your life... . And the immortal child begins to yield to the mortal adult (1976: 221).

A long-time West Coast professional criminal, Harry King, described the process of discontinuing a life in crime: 
I really don't know why I went straight. I just decided that after I got out. It wasn't fear of . the law, it isn't fear of the penitentiary, 'cause I've sat down and thought it out very seriously, but I just had enough of it, that's all. The last time I was in the penitentiary I guess I was making a change then and didn't realize it (1972: $158)$.

Taken together, the statistical, case history and autobiographical information indicates that past a given age in the lives of persons who have been involved in officially-recognized criminal activity, reduction or discontinuation of criminality often occurs. The exact point in time or age at which desistance takes place appears to vary somewhat from individual to individual, as well as differing for groups of persons who have committed similar offenses (Greenberg, 1983). However, criminological explanations for this phenomenon have been sparse. Indeed, Matza (1964), in an early attempt to deal with the phenomenon, noted that while criminological theories fail to account for maturational reform psychological and biological theories do not do much better.

\section{EXPLAINING THE CRIMINALITY: CRIMINOLOGICAL EXPLANATIONS}

Criminologists have had a great deal to say about factors and processes which may impel individuals into initial acts of lawbreaking and deviance. For example, Sutherland's theory of differential association has much to 
offer when one wishes to examine why one person commits a crime and another does not. According to sutherland, the first individual has been exposed to an excess of definitions favoring violations of the law, while the latter has encountered an excess of definitions not favorable to crime. But once crime has been learned, do the same mechanisms remain in effect? If so, how can one explain cases such as Malcolm Braly, who spent most of his adult life in prison but who ultimately ceased his criminal acts? Where did he encounter definitions unfavorable to crime, and why did it take 16 years of incarceration to tip the balance in favor of lawful behavior?

Another currently popular formulation regarding deviance and criminality is the social labeling perspective. The central thrust of this perspective is that when real or putative rulebreakers and lawbreakers are singled out by social audiences and tagged with negative social labels, many of them are driven, as a result, further into deviant careers-what Lemert has termed "secondary deviation" (1972: 219).

Perhaps such processes do occur fairly frequently, but desistance or witharawal from criminality also occurs. Labeling theory and labeling theorists have had relatively little to say about discontinuance of deviance on the part of identified deviants or lawbreakers. On this point, 
Bazemore (1982) has supplied empirical evidence of the labeling perspective's limited power. Although labeling arguments would predict that those juveniles who accept and internalize delinquent labels are less likely than those who reject them to reform, his data did not support this contention.

In summary, criminologists who have focused on crime patterns and criminal careers have concentrated their attention upon etiology, that is, explanations for why some individuals become engaged in lawbreaking and acquire criminal status while others do not. Much less attention has been given to those who, once having embarked upon misconduct, "reform" or desist from lawbreaking. Further, the available evidence indicates that involvement in and desistance from criminality show an age patterning, with high involvement in lawbreaking by young persons often being followed by disengagement from criminality at later points in the life course. Although these relationships are somewhat varied, with certain kinds of lawbreakers desisting from criminality at an earlier or later point in life than is true of other groups of offenders, desistance from crime apparently takes place on the part of most offenders as they approach middle age.

How is desistance to be explained? Is there some kind of underlying phenomenon that can be identified as 
"maturational reform" which explains termination of criminal involvement? And, if so, what are the dimensions of this phenomenon?

Perhaps maturational reform on the part of criminal offenders is largely a reflection of age-related changes in general that characterize human behavior. Perhaps there is a common life course experienced by most adults in our society which manifests itself in the form of desistance from criminality on the part of lawbreakers, and in the form of scaled-down ambitions, growing conservatism, and the like on the part of nonoffenders. Put another way, it might be argued that social maturation is a general process underlying both desistance from criminality and somewhat parallel life changes among nonoffenders.

Until quite recently, students of human behavior have virtually ignored the possibility that adulthood is made up of a series of stages in life that involve changes and reorganization both within the person and between persons and their environment. Childhood, adolescence, and old age have typically been defined as major age categories, while "adulthood" has been viewed as an undifferentiated period to be passed through by the adult who has emerged from adulescence and who will ultimately pass into old age. However, the argument advanced here is that "adulthood" commonly consists of a series of life changes and 
adjustments. Further, these changes that occur to adults generally may have much to do with maturational experiences on the part of lawbreakers.

The discussion of adult development in this study will be restricted to adulthood changes in men because 1) male offenders are responsible for the vast majority of criminal offenses, and 2) the adult life course of men and women appears to proceed along different lines (Tamir, 1982; Levinson et al., 1978).

\section{A THEORETICAL APFROÃCH TO MATURATIONAL REFORM}

This study is based upon the premise that a substantial number of men whose lives are characterized by career-like criminal involvement discontinue it around age 40 . In a study primarily designed to examine career criminals, Layan and Greenfeld found the vast majority of inmates who were incarcerated either during or after their fortieth year to have been incarcerated for the first time in their lives. Furthermore, these authors' data indicated that "among those with a prior incarceration, their criminal career had

Career-like refers to movement within an occupational system and with respect to criminals draws an analogy between the lives of deviants and nondeviants (Best, 1982). 
spanned only about two years" (1983: 5). By implication, then, a great number of those persons who had been heavily involved in predatory crime throughout their early adulthood did not re-enter prison past their fortieth birthday.

Findings such as those raise two basic questions: 1)

What are the factors that account for the apparent termination of a criminal career around age 40? 2) What are these "ex-career criminals" doing now that they have seemingly discontinued activities that previously must have occupied much of their time and attention?

Answers to both these questions will be sought in this study. The major focus, however, will rest with efforts to determine the ingredients of "maturational reform," a label given to the apparent mid-life discontinuation of criminal careers. Therefore, the primary task is to determine what factors accompany this apparent major change in the middleaged criminal's life.

With the exception of linking age to desistance from crime, criminological research has virtually ignored the middle-aged criminal. Anecdotal evidence supplied primarily by ex-offenders such as Braly (1976), King (1972), and Irwin (1970) has shed more light on the ingredients of maturational reform than has research evidence. The only study to date that specifically addressed factors associated with the mid-life discontinuation of criminal careers was 
that of Shover (1983), who has linked the desistance from property crime to a change in contingencies surrounding the commission of offenses.

An examination of these admittedly sparse items in the literature on maturational reform and its associated factors suggested that some of the same social-psychological

processes that accompany mid-life change in the noncriminal adult male also occurred in the middle-aged career criminal. For example, Levinson et al. (1978), one of the foremost theoreticians in the area of adulthood development and midlife change, postulated that a reappraisal of one's life becomes one of the primary concerns during mid-life. Malcolm Braly's (1976) autobiographical accounts of his criminal career appears to describe a pattern similar to the one Levinson et al. (1978) describe as mid-life reappraisal. Braly ultimately concluded that the last twenty years of his life constituted a grossly extended adolescence (331). Braly's account paralleled another central idea in Levinson's theory, namely the middle-aged man's unique confrontation with mortality--with time running out. Braly recalled, "I had always had my real life to look forward to. Now it seems it might well be behind me" (1976: 362). Neal Shover (1983) conducted an empirical examination of maturation or burnout in property offenders. His findings paralleled Levinson's findings obtained from nonoffenders. 
Both authors implicated man's changing relationship to himself and to his surroundings as central elements in the process of maturation.

In view of the following considerations it appears appropriate to conduct the search for elements associated with maturational reform within the theoretical framework of adul thood development:

\footnotetext{
- Criminological theory does not address mid-life desistance from crime;

- Social psychological theory does identify elements associated with mid-life changes in nonoffenders; evidence exists linking mid-life experiences of nonoffenders to those of offenders.

- This study seeks to identify elements associated with mid-life desistance from crime;
}

While a number of authors (Erikson, 1963; Brim \& Wheeler, 1966; Neugarten, 1968; Sheehy, 1974; Gould, 1978) have addressed adulthood developmental issues, Levinson et al. (1978) have to date presented one of the most comprehensive theoretical approaches. It is for this reason that their theory is utilized in this study.

Another author, Lois Tamir, has quite recently conducted an empirical study of men in their forties. Tamir's work represented in many ways a test of the concrete implications 
of Levinson's theoretical conceptualizations about the midlife changes that have been implicated by Levinson et al. The inclusion of the Tamir study is therefore viewed as desirable for purposes of this study. A more thorough review of Levinson's as well as Tamir's work will be presented in the pages that follow.

\section{Levinson's Mid-Life Transition Theory}

Daniel Levinson was one of the pioneers in examining the psychological development of men in early adulthood and mid-life. Levinson et al. (1974) have made it their main theoretical goal to formulate a social-psychological conceptualization of the life course and its accompanying developmental periods. Rather than focusing on developmental variations within individuals or within groups of individuals, the authors were primarily concerned with "relatively universal, genotypic, age-linked adult developmental periods within which variations occur" (Levinson, et al., 1974: 244; emphasis in the original).

In their totality, these periods neither represent a mere unfolding of internal forces, nor are they stages in a progressive career sequence. Instead, Levinson et al. set forth a conceptualization of aduit male developmental periods that encompasses wide variations of biological, psychological, cultural, social-structural, and socialpsychological occurrences (244-245). The developmental 
periods, according to Levinson et al., are times of relative stability in a man's life. He is busy establishing a life structure that provides a viable link between himself and the wider adult wor? d.

The life structure concept encompasses both external and internal aspects of an individual. External life structure elements are, among others, life style, roles, memberships and interests--in short, "the particular way in which [the individual] is plugged into society" (247). Internal aspects of a life structure are reflected in the meanings the individual gives to the external elements, as well as in inner identities, core values, etc. External as well as internal qualities are said to shape the individual's engagement in the world, which, in turn, influences the qualities themselves (247).

The termination of one developmental period and the onset of the next one are linked by a transitional period. For some individuals, this transition may involve considerable turmoil, while for others it may involve a more quiet reassessment. In either event, the transition

is marked by important changes in the life structure and internal commitments, and presages the next stage in development (245).

While the authors concern themselves with the adult life span as a whole, they give special attention to the mid-life 
transition. This transition begins and ends, they say, several years on either side of age forty (244).

One of the first tasks to be confronted during the midlife transition entails reappraising the past. "Deillusionment" emerges as a major factor during this time. The authors argue that much of a man's early adulthood is based on illusions about both the world and the self in the world. A reappraisal of long-held assumptions and beliefs shows many not to be true and in neer of change. This reduction of illusions is called "de-illusionment." This process has diverse outcomes; some men feel a great loss, others feel great freedom (1978: 192-193).

Gradually, the focus of the mid-life transition shifts from evaluating the past to anticipating the future. During this time, many men make far-reaching changes in the external and internal aspects of the life structure. External changes include

divorce, remarriage, major shifts in occupation and life style, marked decline in the level of functioning, notable progress in creativity of in upward social mobility (194).

Aspects of the internal life structure that may change during this time are social outlook, personal values, one's feelings of responsibility toward society and one's feelings of responsibility toward oneself. While not all men make visible external changes, it is argued that attitudes toward 
the environment do change profoundly.

According to Levinson et al., all transition periods-infancy, pubescence, and mid-life transition--involve the developmental process of "individuation." Individuation refers to "changes in a person's relationship to himself and to the external world" (195). With each developmental period, a person establishes clearer boundaries between himself and the world. Through individuation a person becomes increasingly more independent and self-generating, thereby gaining the confidence and understanding that permit a strong attachment to the world. Individuation, these authors argue, occurs as a man confronts and reintegrates polarities in his life. Four such polarities must be confronted and reintegrated as part of the mid-life transitional task.

The Young/old polarity at mid-life demands that a man come to terms with feeling young and old at the same time. Levinson et al. argue that Young/old forces are present within the individual throughout the life cycle, yet, at each transition point they must be brought into a new balance. As one life structure or period of relative stability comes to an end and a new period is in the making, old thoughts and feelings such as "being in a rut,", "rotting," and "coming to the brink of death" (211-212) are confronted with young thoughts and feelings of "being 
reborn," "making a Eresh start," "discovering fresh possibilities in the self and new vistas in the world" (212)

During mid-life, some youthful qualities must be given up while others must be retained. Old qualities such as maturity, self-awareness and judgment can only be of value if they are infused with young qualities such as "energy, wonderment, capacity for foolishness and fancy" (212).

Attaining an age-appropriate balance, which is the developmental task at this point in life, is by no means easy. Examples of failing in this task can be found in the man of 40-50 who frantically pursues all those youthful activities he feels he missed as an adolescent, or in others who take on exaggerated versions of being old and begin to stagnate, "fighting a futile battle against emptiness and decline" (212) .

According to Levinson et al., one of the most disturbing aspects of the Young/old confrontation during the mid-life transition comes from a man's growing recognition of his own mortality and his strong wishes for immortality. Death is no longer an abstract event. Declining physical and psychological powers, more frequent illness and the death of others, more accidents, heart attacks, alcoholism, job failures, and troubles with teenage children all serve as powerful reminders of increased vulnerability and ultimate 
mortality.

The wish for immortality, the authors contend, is the primary motivator for the thorough reappraisal of life at age forty. "Beyond the concern for personal survival, there is the concern with meaning" (216). In this search for meaning, the middle-aged man discovers that his claim to immortality is intimately connected with the flow of generations. Hence concerns for enduring values form the framework within which he evaluates past actions and contemplates future commitments. The authors introduce the concept of "legacy" in this context.

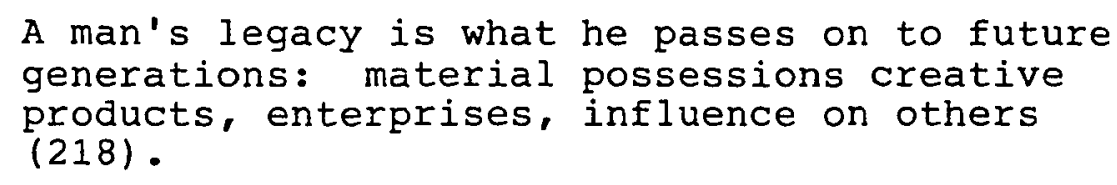

While the work of Levinson et al. indicates that men vary greatly in what they consider to be a legacy, it is ultimately their assessment of this legacy that determines for them the value of their life and their claim on immortality (218).

During the mid-life transition, a man must also confront and reintegrate the Destruction/Creation polarity. Some of the analytical work that must be done to accomplish this developmental task resembles that of the Young/old develupmental task. The authors argue that in connection with a man's growing awareness of his own mortality, he 
becomes increasingly aware of the destructive forces, both around him and within him. However, the confrontation with mortality simultaneously inspires his desire for immortality, which in turn spurs his efforts at creativity $(222-228)$.

A third polarity, the Masculine/Feminine polarity poses developmental challenges that are quite different from those of the two discussed so far. Levinson et al. explain that their usage of the words feminine and masculine goes beyond purely biological differences, encompassing social and psychological ones as well (228-229).

The authors offer the following line of reasoning for the existence of this developmental task. Growing up male means being taught gender-ar-ropriate behavior and feelings. Along with the development of a male identity, a boy also learns about femininity from his relationships with important females in his early life.

In the event that a boy actually behaves in a feminine way as a result of what he has learned, his environment generally responds quickly with efforts to suppress such behavior. Learned feminine feelings, on the other hand, unless they are openly expressed, are not subject to censure from the environment.

Therefore, a boy who is taught how to behave and feel like a boy also carries around with him feminine feelings 
and suppressed feminine behaviors. During adolescence and early adulthood his life structure dictates an almost exclusive concern with the attainment of manhood.

A young man struggling to sustain his manliness is frightened by feelings and interests that seem womanly. One result of this anxiety is that much of the self can not be lived out or even experienced in early adulthood (230).

The authors maintain that partial integration of the masculine and feminine takes place in the late teens and early twenties; however, a qualitatively new integration of the two does not emerge until the mid-life transition.

The developmental task is to come to terms in new ways with the basic meanings of masculinity and femininity (236).

The concrete expressions of this change, of course, vary with the individual. However, several broad shifts can be identified. Levinson et al. list a number of commonlyaccepted masculine and feminine characteristics and state that a successful completion of the mid-life transition task results in finding a balance between these tendencies in oneself.

Thus, if unadulterated masculinity dictates concerns with bodily prowess, toughness and stamina; the newlyintegrated Masculine/Feminine model dictates that frailty, weakness and vulnerability--traditional female 
characteristics--find a place in a man's self as well. Levinson et al. identify the unifying theme of masculine qualities to be doing, making, and having. In mid-life this theme is expanded to include feeling, creating, and being $(233-234)$.

The fourth and last polarity to be resolved during the mid-life transition involves Attachment/Separateness. Levinson et al. use the term "attachment" to refer to all the forces that connect a man to his environment. "To be attached is to be engaged, involved, needy, plugged in, seeking, rooted" (239). A man is attached when he tries to adapt, participate in, or master the world.

Separateness, on the other hand, refers to a man's primary involvement with "his inner world--a world of imagination, fantasy, play" (239). While separateness promotes individual growth and creative activity, it can be harmful if carried to the extreme. Schizophrenia, for example, is considered to be an extreme form of separateness.

Similarly, if a man becomes too attached, he jeopardizes inner growth and creative effort. The authors maintain that men must deal with the Attachment-Separateness issue at all times in their lives. During early adulthood, however, the "balance tilts strongly in the direction of attachment" (241). Men in their 20's and 30's are fully 
absorbed in their responsibilities toward occupational and family matters. During the mid-life transition, some of this attachment has to be loosened because the transitional tasks of de-illusionment and reappraisal demand that a man become more involved with himself, that he turn inward. Only then can he explore such questions as "What do I really want?" "How do I feel about my life?" "How shall I live in the future?: (241).

When this balance is found, a man will discover that he is less dependent upon external stimulation and that he places less value on possessions, rewards, and social approval.

He lives more in the present and gains more satisfaction from the process of living--from being rather than doing and having (242).

A dream, according to these authors, constitutes a man's "personal myth, an imagined drama in which he is the central character" (246). The dream's strong inspirational qualities can easily contribute to the tyranny of the dream. Thus, a man may feel compelled to live according to the illusory beliefs dictated by his dream. "Reducing this tyranny is a major task of the mid-life transition" (248). a man who has successfully accomplished this task will find it no longer essential to succeed, nor will he find it catastrophic to fail. Instead 
he will be able to enjoy the intrinsic values of his work and its meaning to himself (249), In other words, "he is more free to be himself and to work according to his own wishes and talents" (251).

Levinson et al. assert that being a mentor with young adults is one of the most important relationships a man can have at this time of his life (253). Mentoring is said to require a degree of successful mid-life individuation. It is through the task of mentoring that a man can satisfy his longing to be a part of the continuum of human life, $\mathrm{h}^{2}$ hile at the same time providing a great service to society at large (254).

Marital difficulties may have been present throughout a man's early adulthood but, according to Levinson et al., he is likely to give them serious consideration only in his late $30^{\prime} \mathrm{s}$. Only then may he question his own role in. contributing to these difficulties and his illusions about marriage. The outcome of this questioning can be divorce, an improved relationship, or lingering dissatisfaction.

The theoretical claims presented in the preceding pages are based upon research conducted by Levinson and his associates. Forty men ranging in ages from 35-45 participated in the study. All were American-born, and all lived in the eastern part of the United States. They varied in social class background, with 15 percent coming from poor 
urban or rural areas, 42 percent from working-class, 32 percent from comfortable middle class, and 10 percent from upper class backgrounds. Twelve percent of the participants were black, 70 percent had completed college, and six percent had not completed high school. All had been married at least once, and roughly 80 percent had children. Each participant belonged to one of the following four occupational groups: university biologists, industrial hourly workers, executives, and novelists.

The participant selection procedure varied for each of the occupational groups and did not constitute a representative or randomized process. Executives and workers came from two large companies. The biologists were from two Eastern universities. The novelists had each published at least two novels and had all indicated that their central identity was derived from being a novelist. Although the primary source of information was obtained from biographical interviews with each of the participants, other sources such as wives, home, and office visits were included as well. Levinson noted that "A biographical interview combines aspects of a research interview, a clinical interview and a conversation between friends" (15). The primary task of the interview was to construct a biographical account of a man's life. According to their preference, participants were 
interviewed either in their own home, at their work place, or at the researchers' office. Taped interviews generally lasted one hour and were conducted at weekly intervals over the course of 2 to 3 months. Roughly 300 pages of transcript were generated for each participant. In most cases a one-time followup interview was conducted two years after the initial contact. The authors do not describe how the information from these interviews was analyzed. They do, however, offer portions of the biographical materials to illustrate and support their theoretical contentions.

Other authors (Tamir, 1982; Vaillant, 1977; Inkeles and Smith, 1974; Neugarten, 1968; Erikson, 1963) also have asserted that adulthood is not merely a period in life that involves a number of life situations to be passed through by the unalteringly mature adult. Instead, they have suggested. that identifiable changes occur during adulthood. Some authors (Brim and Wheeler, 1966; Dannefer, 1984) have suggested a sociological approach to the study of adulthood change rather than the social-psychological one offered by Levinson et al. Brim and Wheeler (1966), for example, talk about changes that take place in the life course in general and in mid-life in particular as a function of socialization into an appropriate adult role:

learning certain attitudes during the formative middle years may lay the necessary basis for satisfactory socialization into the old-age role (23). 
Essential to the satisfactory performance of a role are three ingredients: knowledge of what is expected and what should be pursued; motivation to behave appropriately and to pursue designated values, and ability to carry out the behavior and to hold appropriate values (25-26). In the course of socialization, the content of these three elements changes; and these authors maintain that as the person gets older, there is a change, among others, from idealism to realism.

In addition to providing a different model for adulthood change from that of Levinson et al., these authors discuss how an individual is formed and changed by the processes of socialization and the impact of over-and under-socialized persons upon the very social system that is the basis for socialization in the first place.

Neugarten et al. (1964) support this view with their argument that culturally-induced age norms, which exist in the minds of most people, operate as a system of social control. Dannefer (1984), in an article entitled "Adult Development and Social Theory," cautioned that socialpsychological theories of adult development may be "obfuscating the extent to which life-course patterns are shaped by social forces" (111). He furthermore suggested that assumptions about the developmental unfolding of agerelated changes produced self-fulfilling prophecy findings. 
In contrast, sociological studies of age effects consider how institutional forces aictate what "normative" aging is and how age-related changes in individual characteristics are in fact influenced by institutional forces (112). While this study does not purport to settle theoretical issues pertaining to the relative impact of physiological and social-cultural forces on adult behavior, it does consider social context in the form of incarceration as a major factor in the aging process of the men being studied.

By far the best documented change occurring in adulthood is the transition to mid-life. This mid-life transitional period has also been hypothesized to be related to behavioral changes among officially identified criminals (Robins, 1966; Hare, 1978; Braly, 1976; Petersilia, 1980; Bittner \& Messinger, 1980). Accordingly, this life period warrants closer examination.

A recent work by Lois Tamix, Men in Their Forties (1982), provided not only an extensive literature review of men and middle age, but also included findings from her own exploratory study examining the "quality of life experience, work, family and social relationships in the lives of middle-aged men" (117). A detailed analysis of Tamir's study is presented below. 
Tamir: Men in Their Forties

Tamir argued that the development through the life span entails a process of continual change and reorganization. This process takes place within the individual, between individuals, and between individuals and their social environment (Tamir, 1982).

From a review of the literature on adult development, Tamir was led to conclude that middle age and its associated changes and reorganization occupies a distinctive place in adult development. ". - The transition to middle age constitutes a unique period of time in the adult life of the male" (emphasis in the original, 20). Tamir found, however, that no firm conclusions could be drawn because existing research evidence is sparse, ambiguous, and does not specifically focus on the middle age male. Thus, she proposed to conduct an empirical study guided by the hypothesis that, for males, middle age is a major transitional period that is "reflected in the quality of life experience, with repercussions in the worlds of work, family, and social relationships" (21).

Tamir analyzed secondary data obtained from an instrument that was originally used and designed for the 1976 Study of Modern Living carried out for the Research Center at the University of Michigan Institute for Social Research. This instrument was designed to assess the 
quality of life and its social indicators within the nation. The survey instrument was constructed so as to tap many dimensions of the quality of life.

A representative sample of adults aged 21 and older was selected through a multistage probability area sampling design. The respondents were asked to give information about 1) their feelings and sources of well being; 2) their social roles such as marriage, parenthood and work; 3) their social supports; 4) their values; 5) their help-seeking behavior; 6) their various symptoms and selected demographic information (23).

For purposes of her own study, Tamir selected men between the ages of $40-49$ as the major population for study and limited the focus to married men who were fathers. She offered the following argument for this choice: 1) men and women do not show the same adult developmental patterns, and 2) men who are both married and fathers proceed through a more conventional life cycle than do other males. Tamir's total sample $(\mathbb{N}=551)$ included currently-married fathers ranging in age from 25 to 69. Educational level was used as a proxy for social class, with the total sample divided into a college-educated group $(\mathrm{N}=211)$ and a noncollege-educated

It was not clear whether "being a father" meant that a child or children were presently living with the father. 
group $(N=338)($ see $26-27)$.

Tamir selected those items from the original "Modern Living" survey that seemed most relevant to mid-life transition. Based on face validity, items were grouped together and subjected to factor analysis. Items with loadings of .60 and above on a single factor were included in a given index. Each resulting variable, e.g., time orientation, zest, etc. then constituted a dependent variable. Each dependent variable was subsequently examined in its relation to the sole independent variable: age (grouped into five-year intervals). Whenever interval means were the same or nearly the same, age intervals were collapsed. Tamir used four statistical methods in the analysis of her data:

ANOVA: each dependent variable was subjected to a oneway ANOVA with age as independent variable.

Time Series Plot: the independent variable, age, was treated as a form of time series data, with each year between ages 25 and 69 constituting one case.

Contingency Tables were used in the analysis of nominal-level data.

The two groups did not equal 551 because educational status could not be determined in two cases. 
Chi-square analyses were employed to determine whether significant differences in responses existed among age groups.

Correlation Matrices: In an effort to detect possible interactions among variables, Tamir constructed correlation matrices. Obtained correlations of .30 and above were further subjected to comparisons between age groups, and their statistical significance was tested (29-35).

Tamir's main focus was on the general quality-of-life experience of men in their forties. Five dimensions of the quality-of-life experience were identified: Internal Psychological state, Psychological and Physical symptoms, Sources of Life Satisfaction, Time Orientation, Value Orientation. The dimensions Internal Psychological state, Psychological and Physical Symptoms, and Source of Life Satisfaction were designated indicators for Well-Being $(37-38)$.

No statistically-significant results were found for Happiness and Life Satisfaction. The data showed that both college and noncollege men between the ages of 40 and 49 were neither more nor less happy or satisfied than males of other ages. Tamir interpreted these results as possibly reflecting social desirability response tendencies, a male 
reluctance to indicate vulnerability, or a basic continuity of temperament throughout the life span.

The Zest, or absence of depression variable, showed college-educated men in their $40^{\prime} \mathrm{s}$ to have significantly less Zest than both noncollege-educated men in their $40^{\prime} \mathrm{s}$ and men of other age groups. Noncollege men in their $40^{\prime} \mathrm{s}$ showed significantly lower self-esteem than all other men in the sample. Based upon results obtained from the measures Zest and Self-Esteem Tamir suggested that men in their late $40^{\prime}$ 's experience a period of "inner examination . . that takes differing forms, dependent upon social background" (45). Hence, lower zest in college educated men may be the result of self-examination based upon a comparison with others $(42-46)$.

Under the "Symptoms" heading, Tamir discussed findings from four composite measures: Psychological Immobilization, Drinking Problems, Psychological Anxieties, and Physical III Health. College-educated men aged 45-49 displayed significantly more symptoms of psychological immobilization than other men. Also, college-educated men in their late $40^{\prime}$ s indicated significantly more problems related to the consumption of alcohol than did other men. However, the data on Psychological Anxiety showed no significant differences between age groups or educational levels. Finally, Tamir interpreted the significant findings on 
the Physical Ill Health measure as indicative of decreasing physical health on the age continuum rather than as a characteristic of the $40^{\prime} \mathrm{s}$. Responses to a question about drug and medication use showed college-educated men in their $40^{\prime}$ 's to use more drugs and medicines in an effort to combat worries, nervousness or tension.

Sources of Life Satisfaction information was obtained by asking directly how much satisfaction someone derived from leisure activities, housework, job, marriage, and parenthood. Satisfaction derived from leisure activities or work around the house did not discriminate among age or educational groups. However, satisfaction derived from work was significantly greater for noncollege men aged 45-49 than for all other age groups. Satisfaction derived from marriage for men in their early $40^{\prime} \mathrm{s}$ was significantly less than for men in other age groups. Yet, starting in their middle 40's, men seemed to derive significantly more satisfaction from their marriage than men of other age groups. This pattern was the same for college-educated respondents, but the findings were not statistically significant. Satisfaction derived from parenthood was significantly less for all men in their early 40's.

The Time Orientation variable yielded statisticallysignificant results for non-college men in their 40 's. These men significantly decreased their expectations for 
greater happiness in the future and increased their expectations that things would remain much the same. The same significance pattern emerged for college-educated men; however, it manifested itself only in the latter half of the 40 's. For both educational groups, Tamir found men in their 40 's to view past, present, and future as much the same $(58-61)$.

The Value Orientation variable yielded significant responses. College-educated men in their late 40's overwhelmingly attributed the highest value (from a choice of nine) to self-respect. Noncollege-educated men showed the same pattern to a lesser degree. Tamir offered the following:

- . the self is chosen as the judge of one's own behaviors, attitudes, and accomplishments. Perhaps this is linked to the process of turning inward at midale age... (63).

A desire for warm relationships emerged as the second most important value for these men.

A good portion of Tamir's survey was devoted to an examination of the meaning of work in the life of middleaged men. Six measures were used for this purpose: Job Satisfaction, Work Commitment, Perceived Job Clout, Perceived Job Relations, and Motives at Work.

Job Satisfaction was found to increase dramatically for men in their 40's regardless of educational background (72). 
Tamir's explanation of this finding is that men in their 40 's may voice satisfaction for a variety of reasons. Some may indeed be satisfied for they have reached their goals, while other may have learned to accept their limitations and therefore have reconciled themselves to not having realized their dreams.

Men in their early $40^{\prime}$ s were significantly more likely to consider switching jobs than were other men, a pattern particularly evident among noncollege-educated men. Tamir suggested that noncollege men are traditionally employed in job with little job flexibility. Thus, at 40 a man may come to the realization that ". . this is his last chance for a break--now or never" (75).

The findings from the work-related measures led Tamir to conclude:

Overall, it is likely that by middle age, whether successful or not or well educated or not, men psychologically disengage themselves from the work arena or at least begin to question the value of work in their lives (93).

Social relationships was another life arena in which Tamir examined men in their $40^{\prime} \mathrm{s}$ compared with men in all other age groups. In general, she found few differences attributable to age. For example, the findings indicated that the number of neighbors a man interacted with was unrelated to his age. Similarly, relationships between men 
and their relatives and friends did not change during their $40^{\prime} \mathrm{s}$. Overall Tamir concluded:

Middle aged men reveal no unique characteristics in measures of the frequency of their exchanges with others and the quality of these social encounters (109).

While the analysis of social relatedness in and of itself failed to differentiate middle-aged men from others, an analysis of an interaction effect of social relatedness and psychological well-being yielded quite different results, particularly for the noncollege-educated men.

Without social relatedness these men exhibited low self-esteem, while conversely, close social connectedness was associated with high self-esteem. Those who were most lacking in zest visited least with neighbors, and those who frequently discussed their problems with relatives and friends were the most anxious (110-111).

Tamir argued the fact that social relatedness is so closely related to the lower class self-esteem implies that these men based their self-estimation upon comparisons with others. Therefore, they were especially likely to question their own worth when they were unable to sustain general social relationships (112).

Results from the social relatedness index revealed a general picture of noncollege-educated males in their $40^{\prime} \mathrm{s}$ exhibiting increased sensitivity to feelings of social 
connectedness. Thus, Tamir reported that

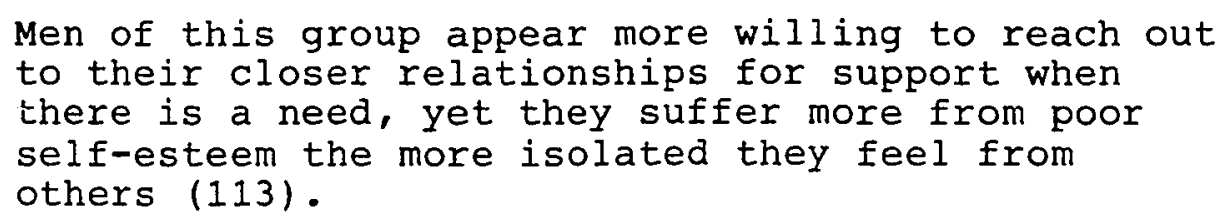

The college group showed similar interaction patterns for social relationships and psychological well being; however, this group relied more heavily on satisfactions derived from marriage than upon general social relationships.

We can draw the following picture of the middle-aged American male who has not gone to college from Tamir's findings: In spite of being more satisfied with work than at any other time in his life, he shows low self-esteem, low expectations for greater happiness in the future, and is likely to consider switching jobs. At least in his early 40 's he derives little satisfaction from marriage and children, and any satisfaction he does derive from work does not seem to increase his sense of well being. He places greatest value on security and warm relationships with others, and his self-esteem is closely connected to his social relationships. Whether or not he seeks out social contacts depends on how depressed he feels; and if he has problems, he is more likely than ever before to seek help from relatives and friends.

A somewhat different picture emerged for the college- 
educated American male in his $40^{\prime} \mathrm{s}$. Like his less educated counterpart, the college-educated male is more satisfied with his job, has more job clout, and evaluates his work performance more positively than those of similar education but of different ages. Still, he foresees no increased happiness in the future, is more likely to consider switching jobs, and finds that the satisfaction he derives from work is less related to his sense of well-being than ever before. Power is now an important motivating force in his work. In his early $40^{\prime} \mathrm{s}$, his satisfaction from marriage is lower than ever before; in his later $40^{\prime} \mathrm{s}$, the reverse is true. Satisfaction from parenthood is at an all-time low for men in their early $40^{\prime} \mathrm{s}$. In spite of the fact that they place greatest value on self-respect and a desire for warm relationships, they report being troubled by drinking and other drug problems and are likely to feel more immobilized than at any other time in their lives.

In Tamir's words,

Middle-aged men feel, act, and react in a manner different from men at other ages, be they older or younger. No doubt, there are basic continuities in life experience from youth to old age, but men in their 40's are men in transition, shedding the final vestiges of young adulthood and coming to accept a stage in life with responsibilities to significant others, to society, but ultimately to themselves (177).

What then is the outcome of this transition? Tamir states: 
At worst, a sense of resignation . . when hopes of breakthrough success clearly come to a halt with the recognition by the middle-aged man that future growth can only come from within. At best, a sense of wisdom begins to thrive at this time of life, a wisdom that comes with perfection of skills, confrontation of life's contradictions, the passing on of well-learned knowledge of upcoming generations, and fulfiliment of the human need to affiliate with others (117).

Because the above-mentioned studies document the occurrence of a mid-life transition for men in general, one can hypothesize that officially-identified criminals share some of the same experiences during this life period. Available evidence is extremely sparse and does little more than point out behavioral changes, such as desistance from criminal behavior.

Thus, Robins (1966) asserted that while decreases in anti-social behavior can be identified in every age group, they most often occur between ages 30 and 40 . Malcolm Braly (1976) stated in anticipation of his discharge from the California Correctional Department; "Discharge is eighteen months away. And during that eighteen months I would turn forty." Bittner and Messinger (1980) offered findings in support of Braly's statements when they reported that violent criminal careers tend to be extinguished at age 35 to 40 .

The current study will examine which, if any, variables can be identified and described that account for the agecrime desistance relationship. It asks whether there are 
characteristics associated with the social process of aging in general that might assist in an understanding of this empirical relationship. Social psychologists (Erikson, 1968; Levinson, 1974; Gould, 1978; Tamir, 1982) have noted the occurrence of behavior, attitudinal and status changes in adult persons, but very few criminologists (Irwin, 1974; Meisenhelder, 1977; Polk et al., 1981; Bazemore, 1982; and Shover, 1983) have searched for parallel developments among offenders.

Basically, this dissertation will explore the following questions: Do significant behavioral, status or attitudinal changes occur among middle-aged career offenders? Are there age-specific change patterns that lead to the termination of criminal careers? 


\section{CHAPTER II}

AN EXAMINATION OF AGE-RELATED CHANGES IN CRIMINAL BEHAVIOR: METHOD

\section{PROCEDURE}

Two groups of men were interviewed for this study, one consisting of 19 ex-offenders and the other of 30 oregon State Penitentiary (OSP) inmates.

\section{Ex-Offender Participants}

Identifying and locating ex-offender participants presented one of the major problems in carrying out this research. Ex-offenders had to meet the following characteristics for selection into the study: (1) must be male; (2) must be at least 35 years old; (3) must have demonstrated serious, career-like involvement in crime; (4) must have been free of any misdemeanor or felony arrests (excluding minor traffic offenses) for at least five years; and (5) must have been free of any supervision from the corrections division for at least five years.

‡

All procedures used in the selection and interview processes were approved by the Human subjects Research Review Committee at Portland State University. 
The criterion of five arrest-free years meant that potential participants had to be free citizens whose last involvement with any part of the corrections system must have been at least five years prior to the interview.

In order to identify potential ex-offender participants, referrals were solicited from persons who were thought to be likely to know of suitable candidates. Such persons included people involved in offender counseling, parole and probation officers, and finally, ex-offender participants who had already been interviewed. Additionally, a flyer asking for research participants (see Appendix A) was widely distributed in Portland's Skid Road community.

Generally, anyone who met the selection criteria and who was willing to submit to a personal interview was included in the study. This procedure constitutes what Kerlinger (1973) refers to as "accidental" sampling and Biernacki and Waldorf (1981) as "snowball sampling." There are obvious problems with it. One significant problem is that ex-offenders who can be located and who agree to be interviewed may differ from ex-offenders who cannot be located or who do not agree to be interviewed. Consequently, information obtained from this group may differ from what might have been obtained if all, or at least a random selection, of ex-offenders had been included. Any 
findings derived from this "accidental" sample must

therefore be regarded with due caution and in full awareness of the possible bias. However, other sources of bias, such as researcher selection preference (Backstrom \& Hursh, 1963; Babbie, 1973), were controlled for in that each exoffender who was located, who indicated a willingness to participate in the study, and who met the study selection criteria was included.

All initial contacts with potential participants were made by the referral source. Only after the person had given his permission to be contacted was his identity disclosed to the researcher.

of 31 individuals who were referred as potential participants, 20 were ultimately interviewed. Most of those not selected were excluded because they failed to meet the selection criteria. Three could not be reached, even after six attempts were made to get in touch with them.

One of the 20 ex-offender participants had to be excluded from the study when it became known that he had been arrested and convicted of a misdemeanor offense four years prior to the interview and thus did not meet the five year arrest-free minimum criterion. Computer record checks of the 19 remaining ex-offenders verified their selfreported absence of arrests.

One participant, a rather well-known local ex-felon, 
reported at the time of the interview that a computerized search of his criminal record would fail to document any criminal involvement because his Chicago-based family had. paid money to have his records removed. Indeed, the search for recorded evidence of his criminal involvement failed to produce any.

The decision to include this participant was based on the following considerations: (1) his extensive and detailed knowledge of correctional facilities and practices; (2) the widespread knowledge of his past criminal involvement by local criminal justice officials; (3) his unhesitating willingness to participate in this study; and (4) a score on the Social Desirability Index that gave little indication of pretense. According to the ex-offenders' preferences, ten of the interviews took place at the participants' residences, eight at the researcher's office, and two at the participants' places of business. All interviews were conducted by the researcher personally. They ranged in time from two to four hours, and the men were offered $\$ 15$ for their time. While some accepted the offered monetary compensation, most demurred and indicated that they welcomed the opportunity to

Each interview included six questions on a Social Desirability Index. Low scores indicated that the participant was not motivated to present a sociallydesirable profile. 
let someone know that a "successful" termination of a life of crime is possible. All of the ex-orfenders indicated a desire to see the completed study or at least a summary of it.

At the outset of each interview, the interviewer explained the purpose of the study, the voluntary nature of participation in it, and the measures taken to insure confidentiality of the participants' information.

Each person was asked to read an Informed Consent letter (see Appendix B). The participant's signature was required at the bottom of the letter before the interview was conducted.

The interviewer read the questions aloud, and the interviewee selected his responses from several alternatives on a 5" x 3" response category card. On occasion, a participant embellished or qualified his response, and this additional information was noted on the interview schedule. The men varied considerably in how much additional information they supplied. It is this fact that primarily accounts for the variation in length of the interviews. After all questions had been answered, the ex-offenders

One participant did not know how to read. In his case, the questions as well as the response categories and the the consent letter were read aloud by the interviewer. 
were asked to respond to portions of the questionnaire a second time. This time, however, they were instructed that responses should reflect, as closely as possible, how each might have answered these questions during their last incarceration.

\section{Inmate Participants}

Even though this study focused on men who had discontinued their criminal careers, a decision was made to include inmates for two reasons: (1) to allow comparisons between men who, at similar stages in their adult lives and with similar criminal career patterns, have terminated their careers versus those who have not done so; (2) to ascertain whether the midlife transitional tasks identified by Levinson et al. (1978) are accomplished similarly by middleaged ex-offenders and by inmates.

*

Permission to conduct interviews with inmates at the Oregon State Penitentiary was obtained from the oregon Department of Human Resources-Corrections Division. A written application was submitted, together with the research proposal, to the Corrections Division Research Committee for review. That Committee made the determination that the study was within the statutory research guidelines of the Corrections Division, and thus the study was approved in accordance with ORS 179.040 . Once this permission had been granted, the researcher was assigned to a liaison person in each of the relevant internal divisions within the Corrections Division. 
Oregon State Penitentiary inmate participants were selected on the basis of the following criteria: (1) must be male; (2) must be at least 35 years old; and (3) must have demonstrated serious, career-like involvement in crime.

"Career-like" was defined as a Criminal History Risk score of 3 or less (see Appendix C). The Criminal History Risk score is a standard measure utilized by the oregon State Board of Parole to determine inmate eligibility for parole. Total scores can range from 0 , indicative of the poorest possible prognosis for a successful parole, to a score of 11, which signifies the best risk.

The total risk score for an individual inmate is calculated from the combined scores on six factors. These factors are: prior felony and misdemeanor convictions; prior incarcerations; verified number of conviction-free years in the community; age at the time when the crime leading to the current incarceration was committed; parole, probation, or court custody violations in conjunction with the present incarceration; and finally the presence or absence of an admitted or documented heroin or opiate derivative abuse problem.

There are, of course, numerous ways in which six assessment categories can yield an individual's cumulative risk score of three or less. Four of the six factors assess criminal involvement directly. A low risk score is 
therefore a reasonably good indicator of substantial criminal involvement. For example, to get a Criminal History Risk score of three, an inmate with no custody violations and no drug problems must have had four or more prior misdemeanor or felony convictions, fewer than three years of conviction-free time preceding the current incarceration, and must have been between 21 and 26 years old at the time he committed the crime leading to the present incarceration.

Inmates meeting the criteria for participation in the study were selected from the most current roster of OSP residents. The roster is updated monthly by the corrections Division and contains inmate names, birthdates, and Criminal History Risk scores, among other information. The entire list of OSP inmates was screened. Inmates fitting the selection criteria numbered 105 and were placed in a pool of potential participants. A letter was sent to each of these persons briefly explaining the nature of the study and asking for their voluntary participation (see Appendix D). Inmates were asked to indicate their willingness to participate in the study by signing and returning the letter to the researcher's OSP liaison.

Thirty-one inmates returned signed copies of the letter. Each subsequently received notice of the scheduled interview. One inmate died just prior to the interview; 
another arrived for the interview but then declined to participate, while yet another who had not returned a signed copy of his letter contacted the interviewer in person and asked to be scheduled for an interview. In the end, 30 inmates completed the interview.

Table I compares some of the characteristics of potential and actual inmate participants. A comparison of inmates who volunteered for the interview with those who chose not to participate indicated that inmates who participated were slightly older and that they had somewhat lower Criminal History Risk scores, indicating a relatively more serious involvement in crime. Also, more of the participating inmates were serving current sentences for crimes against persons.

All interviews took place in a small, enclosed interview room inside the OSP. Consent procedures and verbal instructions were identical for the ex-offender and for the inmate participants.

In general, the same questions were asked of the inmates that had been asked of the ex-offenders, except that questions such as one about the participants' type of residence were excluded from the inmate interviews. Similarly, inmates were not asked to repeat portions of the questionnaire to elicit information about previous incarcerations. 
TABLE I

CHARACTERISTICS OF ACTUAL AND POTENTIAL INMATE PARTICIPANTS

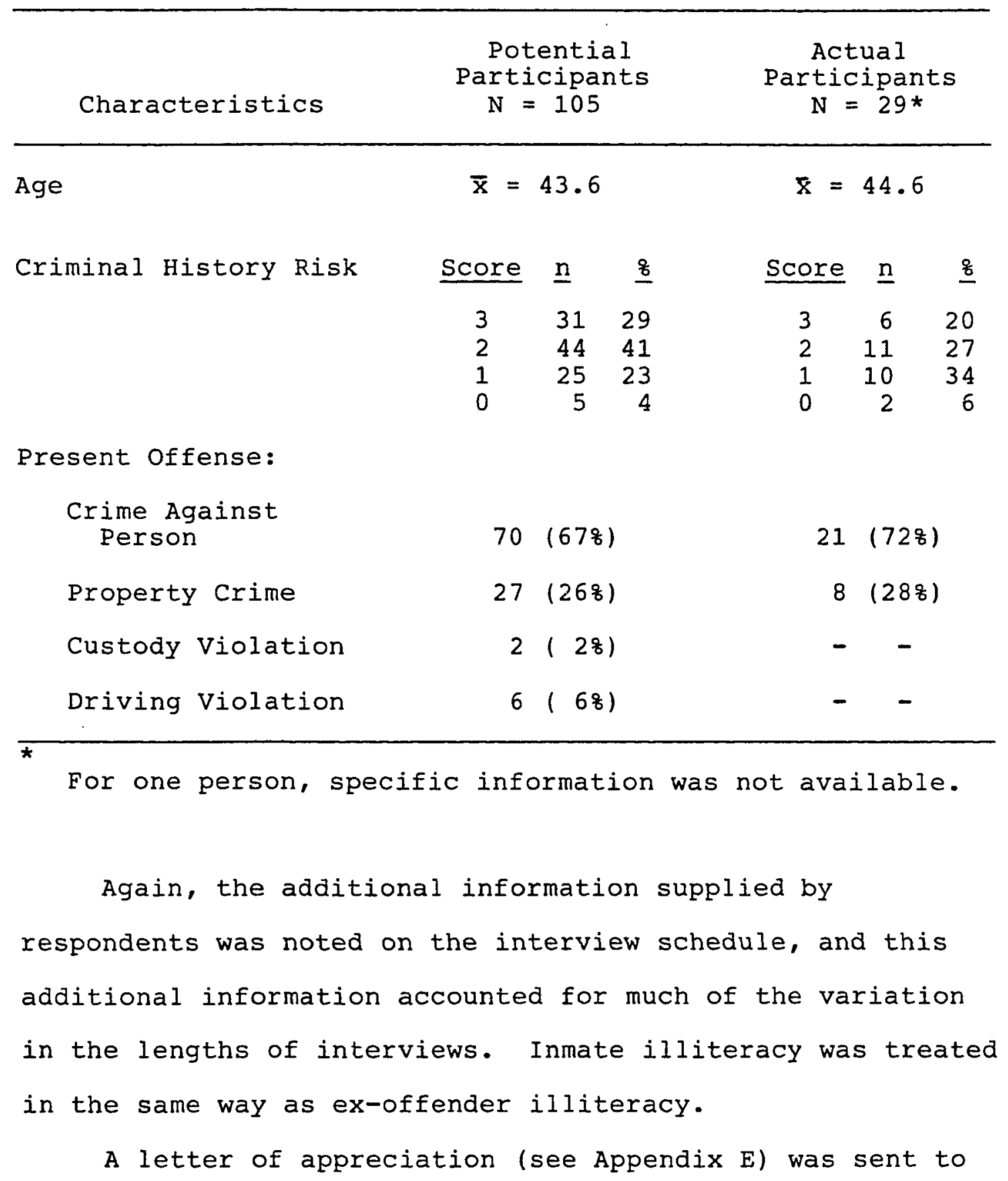


each inmate participant. Inmates received no monetary compensation for their participation. Most of them indicated a desire to see the completed study or a summary of it.

\section{INSTRUMENT}

The instrument used for this study consisted of four parts, only one of which was developed specifically for this study.

Social Background Questions

Part A included standard background questions. Its purpose was to compare respondents on such variables as age, race, marital status, education, income, religious affiliation, residence, and membership in organizations (see Appendix F) .

Criminal History Questions

Part $B$ asked questions about the participants' criminal backgrounds. These had been selected from the Rand Corporation's "Second Inmate Survey" published in Varieties of Criminal Behavior (Chaiken and Chaiken, 1982). Participants were asked about their criminal involvement as juveniles, as well as about their incarceration and drug use histories. Three questions asked them to predict the likelihood of their continued involvement in crime. One 
additional predictive question was specifically constructed for the present study. Furthermore, three questions were added to obtain information abouth the participation of accomplices in the commission of crimes (see Appendix G).

\section{Life Satisfaction Questions}

Questions in this section were drawn from an instrument used by Lois Tamir in her study of men in mid-life. The questionnaire and her findings were published in her book, Men in Their Forties (1982). Survey questions covered a wide range of topics ". . including social roles, mental health, and coping strategies" (22). The questions had been developed by Douvan et al. (1976) to tap a variety of dimensions of the quality of life. Questions, both openand close-ended, were designed to evaluate

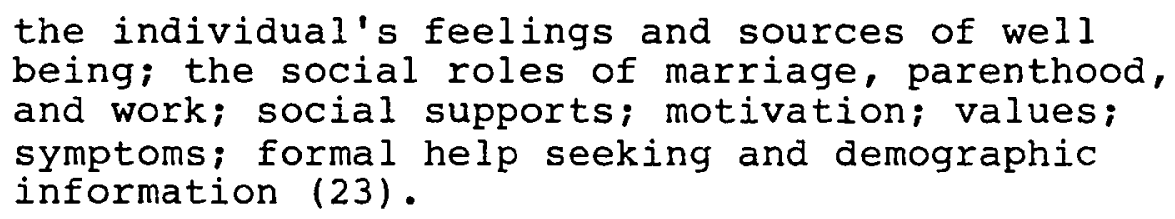

The survey constituted a multi-criterion approach to assessing mental health, an individual's sources of strength, and coping mechanisms. In her findings, Tamir (1982) reported that men in their forties differed from older or younger men on several dimensions. Only those questions that were found to differentiate middle-aged men from others were incorporated in Part $C$ of the instrument 
(see Appendix H) .

\section{Social Psychological Development Questions}

Part $D$ was developed specifically for this study. The items were based upon Levinson's (1978) conceptualizations of adult developmental tasks involved in the male mid-life transition. Levinson (1978) postulates major mid-life tasks that revolve around a man's changing position viz-à-viz four fundamental polarities.

Several items were constructed for each of the dimensions in Levinson's formulation. Part $D$ of the instrument was pretested on a convenience sample of 27 men. Following a factor analysis of the pretest data, all 26 items were retained for Part $D$ of the instrument. It should be noted, however, that the Attachment/Separateness and Male/Female dimensions are not entirely independent.

Several open-ended questions reflecting Levinson's developmental concerns of middle age comprised the remainder of Part D (see Appendix I).

\section{Social Desirability Questions}

A six-question standard Social Desirability Index was included to give some indication of whether the participating men wished above all to appear socially acceptable (see Appendix J).

The Social Desirability Index consisted of six 
questions, yielding scores ranging from zero to six. A score of zero indicated that none of the questions was answered in such a way as to suggest that the respondent wished to present a socially-desirable image. A score of six, on the other hand, could be interpreted to mean that the respondent wished to present a socially-desirable image. Hence, a high score could cast doubt on the validity of all responses by a given participant.

Because scores ranging from zero to four were found in roughly similar proportions in both the ex-offender and the inmate groups, responses were not questioned for participants in that range. Scores above four were obtained only from inmate participants.

Following is an analysis of inmate response patterns both with and without the four high scorers. A decision was made not to exclude these persons from the study. Table II compares both groups on several variables and shows virtually no differences in the responses.

\section{EX-OFFENDER AND INMATE SOCIAL BACKGROUND CHARACTERISTICS}

Differences between ex-offender and inmate social background characteristics may point to concrete

Tamir (1982) notes that men with less formal education tend to give more socially-desirable responses. Note in Table III that the inmates as a group have less formal education than the ex-offenders. 
TABLE II

RESPONSE COMPARISON OF ALL INMATES VERSUS INMATES WITHOUT THE HIGH SCORERS ON THE SOCIAL DESIRABILITY SCALE**

$\begin{array}{lcc} & \text { All } & \begin{array}{c}\text { Inmates without } \\ \text { the High SD } \\ \text { Scorers } \\ \text { Characteristics }\end{array} \\ \mathrm{N}=26\end{array}$

Social Background:

$\begin{array}{lrr}\text { Age } & \bar{x}=45 & \bar{x}=45 \\ \text { Marital status: } & 8(278) & 7(268) \\ \quad \text { Married } & 19(638) & 19(738) \\ \quad \text { Divorced } & 19(638) & 15(58 \%) \\ \text { Education HS or less } & 12(458) & 10(438) \\ \text { Income } \$ 10,000 \text { or less } & \end{array}$

Criminal History:

Age at first arrest

Total \# of arrests

\# of times in prison

\# of felony convictions

$\begin{array}{rlr}\bar{x}=15 & \bar{x}=15 \\ \bar{x}=13 & \bar{x}=13 \\ \bar{x}=4 & \bar{x}=4 \\ \bar{x}=3 & \bar{x}=3\end{array}$

Life Satisfaction:

Zest

Self-esteem

Alcohol Problems

Anxiety

$\begin{array}{rlr}\bar{x} & =22 & \bar{x}=21 \\ \bar{x}=14 & \bar{x}=14 \\ \bar{x}=7 & \bar{x}=7 \\ \bar{x}=10 & \bar{x}=11\end{array}$

Adult Development:

Young-old

Male-female

Attachment-separateness

Destruction-creation

$\begin{array}{ll}\overline{\mathrm{x}}=14 & \overline{\mathrm{x}}=14 \\ \overline{\mathrm{x}}=18 & \overline{\mathrm{x}}=18 \\ \overline{\mathrm{x}}=10 & \overline{\mathrm{x}}=10 \\ \overline{\mathrm{x}}=12 & \overline{\mathrm{x}}=12\end{array}$

Numbers are rounded to the nearest whole. 
manifestations of possible social psychological factors associated with desistance from crime. On the other hand, adult developmental arguments used to explain mid-life changes in career criminals may well be strengthened if the two groups of men show few differences on social background characteristics. For these reasons, a brief discussion highlighting the differences and similarities in ex-offender and inmate social background characteristics will be presented in the following pages.

Table III depicts ex-offender and inmate social background characteristics. It can be seen that the exoffenders differed most notably on Marital status, Education, Income, Type of Employment, and Group Membership. Approximately one-third of the ex-offenders were divorced at the time of the interview; nearly twice as many of the inmates were divorced. Levinson et al. (1978) and Tamir (1982) both suggest that close personal relationships become important aspects of the middle aged man's life. Shover (1983) went further in noting that for his group of ex-offenders, the establishment of "a mutually-satisfying relationship with a woman" became an "important factor in the transformation of their career line" (213).

On the other hand, it was not certain how much weight should be given to the fact that so many of the inmates were divorced. Most inmates indicated that marriages generally 
TABLE III

SOCIAL BACKGROUIND CHARACTERISTICS OF EX-OFFEWERS AND IINMATES

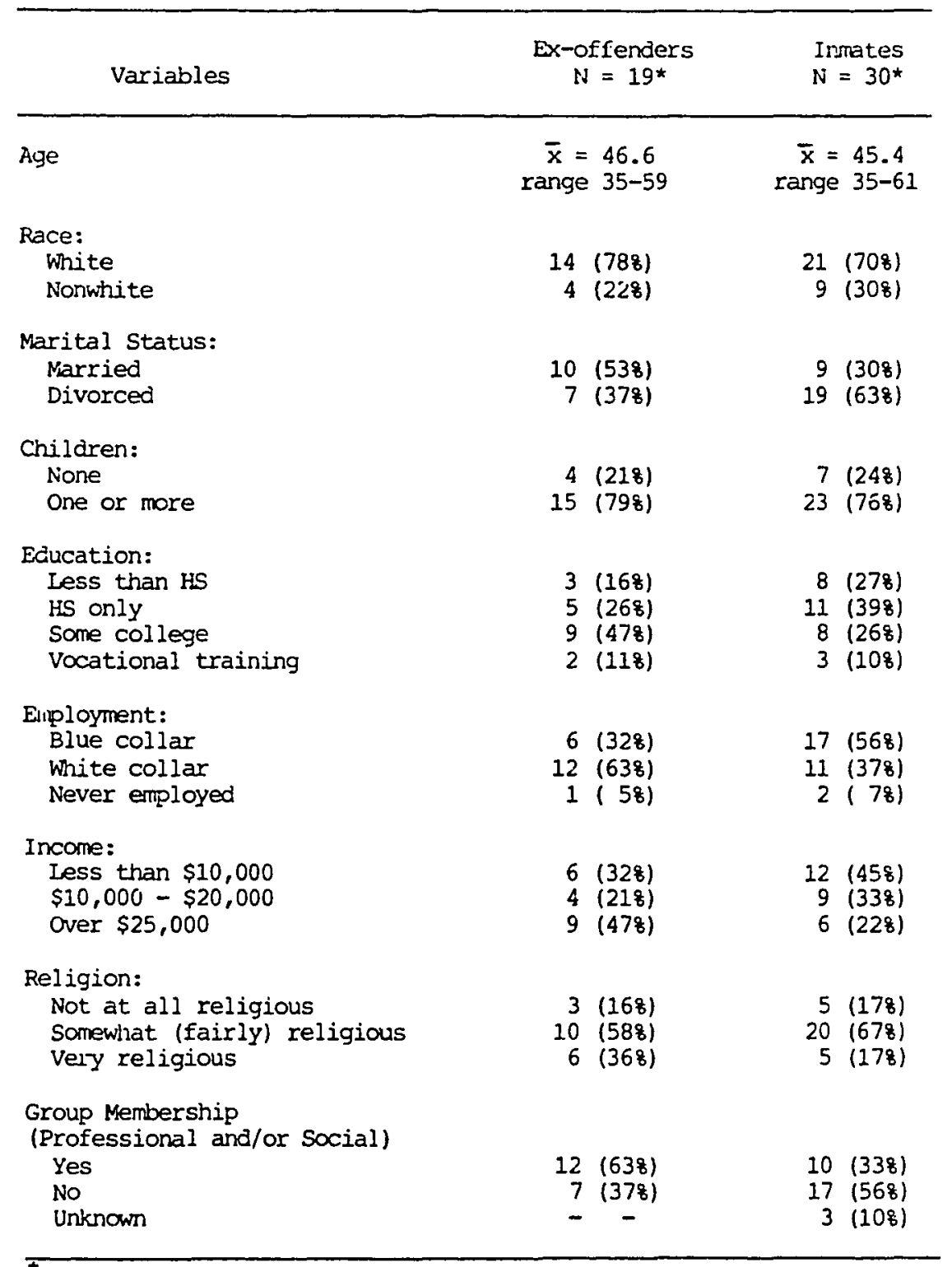

The N's for each group of respondents may not always add up to 19 or 30 respectj.vely, either because respondents failed to answer a given question, or because subcategories of variables were onitted from presentation in this table. 
don't withstand incarceration (Cordilia, 1983: 31). Because most of the inmates interviewed for this study were serving relatively long sentences, the status of being divorced may have been incidental to their incarceration rather than a preferred state.

Nearly half of the ex-offenders reported having at least some college education. The same was true for only one-third of the incarcerated men. In evaluating this difference, it should be noted that the ex-offenders, who are approximately the same age as the inmates, had at a minimum spent the last five years as free citizens. This same factor, namely having had more available time in which to develop skills, may be related to the differences in white collar vs. blue collar employment reported by the two groups. Consistent with education and employment information was the fact that the ex-offenders reported somewhat higher income levels than did the inmates. Two-thirds of the ex-offenders reported belonging to some sort of social or professional organization. Of the inmates, only one-third acknowledged membership in such organizations, either on the outside or within the OSP. This appears to lend some support to Irwin (1974) who Iinked termination from criminal careers to several factors, among

Income figures for inmates were reported for the time prior to their present incarceration. 
them "extravocational, extradomestic activities" (p. 203) such as sports and hobbies. Shover (1983), on the other hand, found little support for Irwin's extravocational Eactor.

The ratio of white to nonwhite men was nearly identical in both groups, as was the percentage of men who were fathers. Likewise, religious beliefs did not vary markedly between the two groups.

In summary, then, a comparison between career offenders and ex-offenders of approximately the same age showed the ex-offenders to be more likely to be married, to have had at least some college education, to be engaged in white collar work, to have more money, and to belong to professional organizations and/or social clubs. The men who had seemingly not terminated their criminal careers at roughly the same point in their lives were likely to be divorced, to have had no more than a twelfth-grade education, to have had incomes of $\$ 10,000 /$ year or less from employment in blue collar jobs, and to belong to no professional or social organization.

\section{Criminal Histories}

Men in both groups were asked "What were the main reasons that you first got involved in crime?" Inmates named "High Living" more often than any other reason as contributing to their becoming involved in crime. One 


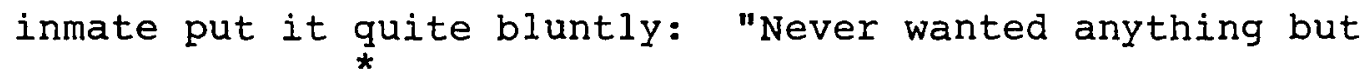
money" $(035)$. The ex-offenders, on the other hand, cited "Way of Life" more than any other single reason. As one exoffender described it: "Never thought about myself as a bad guy. I wanted to be normal. I don't want holes in my clothes or to feel hungry" (EO 06). "Support for Family and Self" and "Excitement" were offered among the top four reasons by both groups of participants, as shown in Table IV.

One might very tentatively speculate from these responses that the men who are now ex-offenders were more likely to have found themselves growing up in an environment of crime and becoming participants in that life style than the men who have not yet discontinued their criminal activities. The latter appear to have entered a criminal career for such reasons as "High Living" and "Excitement." In other words, men who are now ex-offenders may have done little more than adapt their behavior to their environment, while the men who are currently incarcerated may have entered the criminal environment to meet needs they were not able to meet using noncriminal means.

(0 15) refers to the fifteenth offender interviewed for this study. (EO 06) refers to the sixth ex-offender interviewed. 
TABLE IV

REASONS FOR INVOLVEMENT IN CRIME, EX-OFFENDERS VS. INMATES

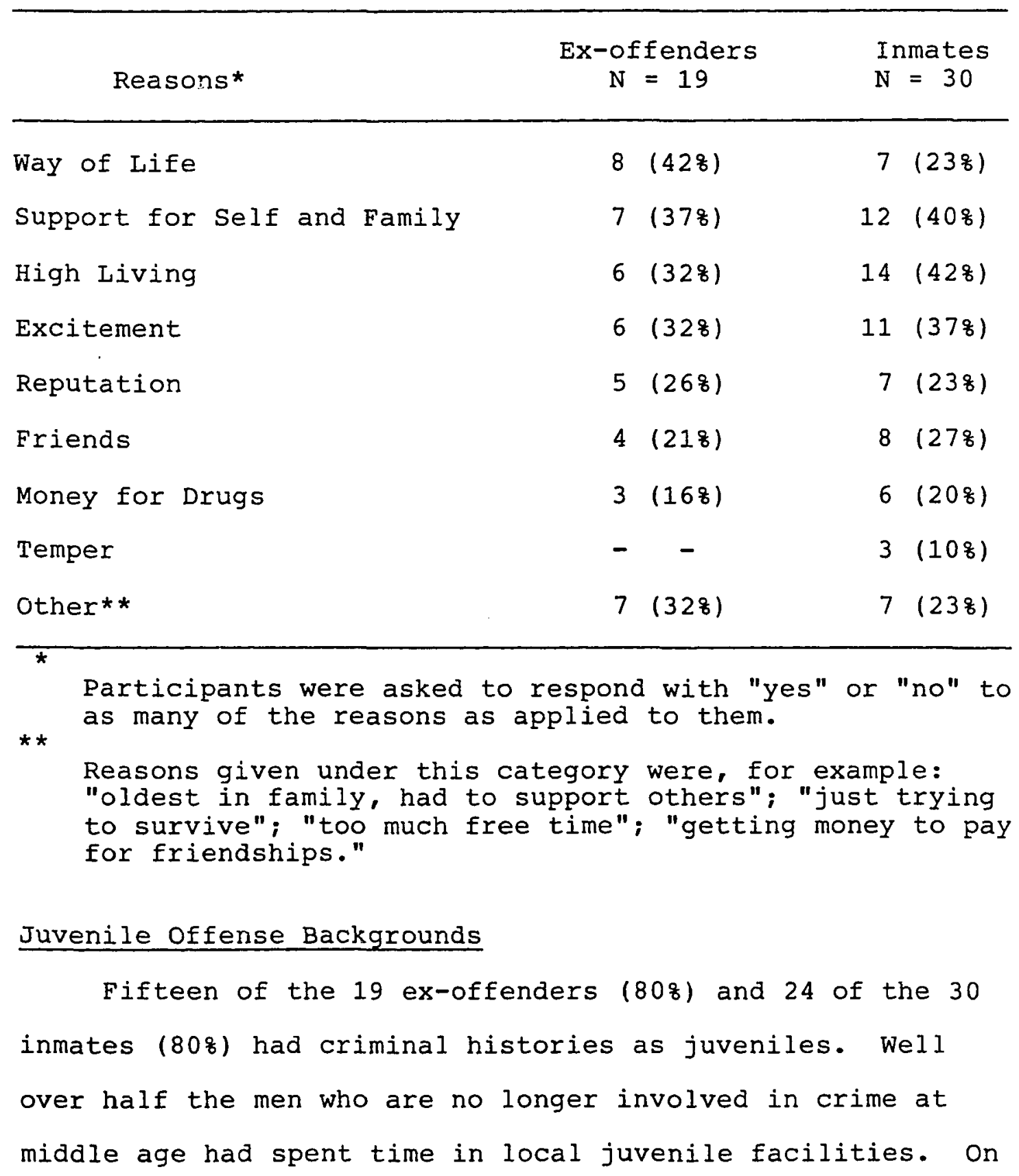


the average, this amounted to 6.8 times. Less than half the inmates reported having been held in local juvenile facilities; their average number of detentions was 3.8 . The majority of ex-offenders had never been sent to statewide or federal juvenile institutions, yet well over the majority of inmates had spent time there. Men in both groups who had been detained in statewide or federal juvenile institutions had been detained at roughly equal rates.

On the average, little difference emerged between the ex-offenders and the inmates as far as involvement in juvenile property crimes, crimes against persons, or drug use was concerned (see Table V).

The picture of juvenile criminal histories that emerged from this information depicts men in the ex-offender group and men in the inmate group as equally likely to have accumulated juvenile records based upon quantitatively and qualitatively similar criminal behavior and, as a consequence, similar detention rates in juvenile facilities. At this point, the picture changes. The men who today are ex-offenders were more likely to have been sent to local juvenile facilities than to statewide or federal juvenile

Two men reported more than 25 such detentions; the next most frequent detention rate was 6 times. 
TABLE V

CRIMINAL HISTORIES AS JUVENLIES, EX-OFFENDERS VS. INMATES

\begin{tabular}{|c|c|c|c|}
\hline Criminal History & $\begin{array}{l}\text { Ex-offenders } \\
N=19+\end{array}$ & & $\begin{array}{l}\text { Inmates } \\
\mathrm{N}=30+\end{array}$ \\
\hline \multicolumn{4}{|l|}{ Juvenile Detention } \\
\hline \multicolumn{4}{|l|}{ Iocal: } \\
\hline $\begin{array}{l}\text { Yes } \\
\text { No }\end{array}$ & $\begin{aligned} 12 & (638) \\
7 & (378) \\
\bar{x} & =6.8\end{aligned}$ & & $\begin{array}{r}13(468) \\
15(548) \\
\bar{x}=3.8\end{array}$ \\
\hline \multicolumn{4}{|l|}{ Statewide or Federal: } \\
\hline $\begin{array}{l}\text { Yes } \\
\text { No }\end{array}$ & $\begin{array}{r}8(448) \\
10(568) \\
\bar{x}=2.1\end{array}$ & & $\begin{array}{r}19(688) \\
\frac{9}{x}=1.5\end{array}$ \\
\hline $\begin{array}{l}\text { Number Involved in } \\
\text { Juvenile Property crime* }\end{array}$ & $\bar{x}=9(448)$ & $\overline{\mathbf{x}}=1$ & $13(428)$ \\
\hline $\begin{array}{l}\text { Number Involved in } \\
\text { Juvenile Crime Against } \\
\text { Persons** }\end{array}$ & $\bar{x}=5(278)$ & $\bar{x}=$ & $7(228)$ \\
\hline $\begin{array}{l}\text { Number Involved with } \\
\text { Juvenile Drug Use }\end{array}$ & $\bar{x}=3(108)$ & $\overline{\mathbf{x}}=$ & $5(188)$ \\
\hline
\end{tabular}

The N's for each group of respondents may not always add up to 19 or 30 , respectively, either because respondents failed to answer a given guestion, or because subcategories of variables were anitted from presentation in this table.

Includes burglary, car theft, theft, and forgery. Credit card theft was onitted because opportunities for this cohort as juveniles to camit this crime were very Iimited.

$\star$

Includes robbery, assault with a weapon, threat with a

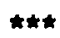
weapon, and rape.

Includes marijuana, uppers, downers, heroin, and cocaine. 
institutions.

The reverse was the case for those men who are currently incarcerated. In other words, more of the inmates than ex-offenders in this study experienced detention in facilities for serious juvenile offenders. This suggests that more of the inmates might resemble what Irwin (1974) called "state-raised youth," whose world view is almost entirely determined by "their world--the prison world" (29).

\section{Involvement with the Criminal Justice System}

The ex-offender criminal career spanned an average of 20.5 years, the shortest being 11 years and the longest 37 years. Inmates, on the average, had criminal careers lasting 28 years, with the shortest being 12 and the longest 49 years.

As Table VI shows, the average age at first arrest was the same for men in both groups. An average of two years went by between age at first arrest and age at first conviction for the ex-offender group, while for the inmates an average of one year elapsed between first arrest and first conviction.

The ex-offenders and the inmates did not differ on frequency of arrest in the course of their careers. On the average, men in either group had been arrested between 11 and 15 times. Ex-offenders averaged more felony convictions $(x=5$ vs. $x=3)$, fewer terms in the penitentiary $(x=3$ 
TABLE VI

INVOLVEMENT WITH THE CRIMINAL JUSTICE SYSTEM, EX-OFFENDERS VS. INMATES

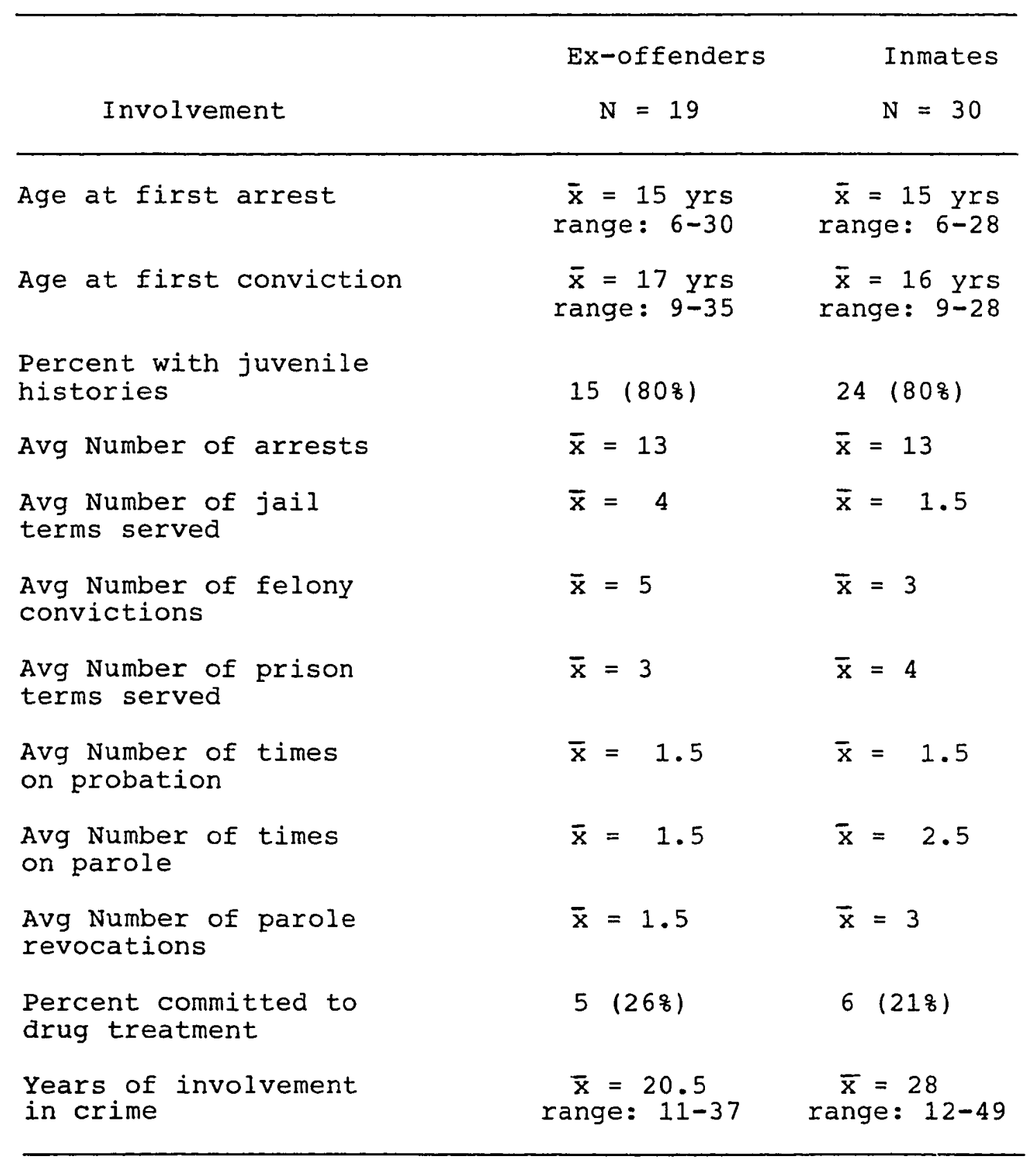


vs. $\bar{x}=4)$, but more terms in jail $(\bar{x}=4$ vs. $\bar{x}=1.5)$. Ex-offenders and inmates had been on probation with about equal frequency. The inmates had been on parole somewhat more often than the ex-offenders $(x=2.5$ vs. $x=$ 1.5) and were twice as likely to have had their parole or probation revoked.

There was virtually no difference in commitments to drug treatment programs between the two groups. While the ex-offenders and the inmates differed little in each of the categories showing involvement with the criminal justice system, a slightly different picture nevertheless emerges for the two groups. The men who today seemingly have discontinued their criminal involvement appear to have been treated somewhat differently by the system than the men who are today incarcerated.

When the ex-offenders were first arrested, an average difference of 2.4 years elapsed from first arrest to first conviction; for inmates this difference was 1.1 years. For $8(408)$ of the ex-offenders, the first arrest led to conviction; this occurred for $23(76 \%)$ of the inmates.

As noted above, upon adjudication the ex-offenders were sent to local rather than state or federal juvenile institutions; the reverse was the case for inmates. While ex-offenders and inmates averaged the same number of arrests in their adult lives, ex-offenders were sent more often to 
jail and less often to prison, even though they showed a higher average felony conviction rate. Once paroled, ex-offenders had their parole revoked at a lower rate than did inmates. While this slightly different entanglement pattern with the criminal justice system may not warrant disparate treatment charges, it does appear that once the men entered the criminal justice system, today's exoffenders as a group received less harsh treatment than did today's inmates.

Use of Accomplices in the Commission of Crimes

Ex-offenders and inmates were equally likely to have been without an accomplice when they committed the crime that led to their first conviction, as shown in Table VII. The majority of both groups, however, had been with others, rather than having committed the crime alone. Roughly the same is true for the commission of juvenile offenses. As adults, however, the inmates were less often accompanied by others when they committed crimes.

\section{Perceived Success in Crime}

The men in both groups were asked: "Overall, in the past, how successful do you think you were in committing crime?" By far the majority of men in both groups saw themselves as either very unsuccessful, or at least somewhat unsuccessful. Notwithstanding the frequency and length of 
TABLE VII

CRIME WITH/WITHOUT ACCOMPLICES, EX-OFFENDERS VS. INMATES

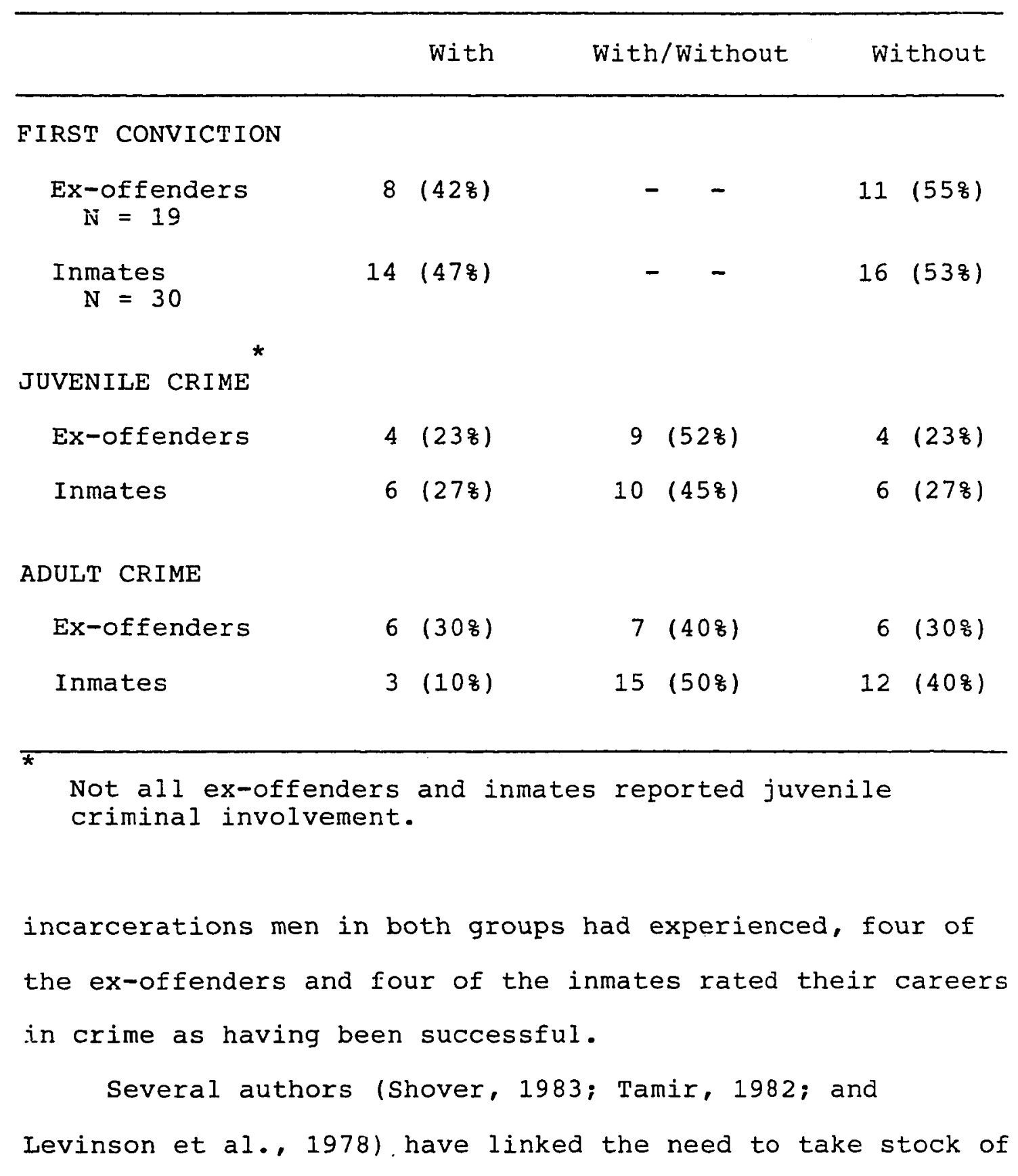


one's life to middle age. In fact, Shover lists the recognition that "their criminality had been an unproductive enterprise" (210) as one of the contingencies associated with criminal career termination. The information from this study showed roughly equal recognition of a lack of success at crime for those men who had discontinued their criminal careers as well as for those for whom career termination had yet to be achieved.

\section{Going Straight: Inmates and Ex-offenders Looking Back}

The ex-offenders were asked to think back to their last incarceration and then to answer two questions: "What did you think the chances were that you would TRY to make it going straight?" and "What did you think the chances were that you would ACTUALIY make it going straight?" The inmates were asked these same questions with reference to the present. Table VIII presents a summary of their responses.

It can be seen that the men who are now ex-offenders were generally somewhat less certain in their prediction of an impending straight life than were today's inmates. The inmates' responses clearly did not reflect a sense that they have given up hope--that they have resigned themselves to a continued unsuccessful existence.

One could argue that, taken together, the social background differences between the ex-offenders and the 
TABLE VIII RETROSPECTIVE IMPRESSIONS OF GOING STRAIGHT,
EX-OFFENDERS VS. INMATES

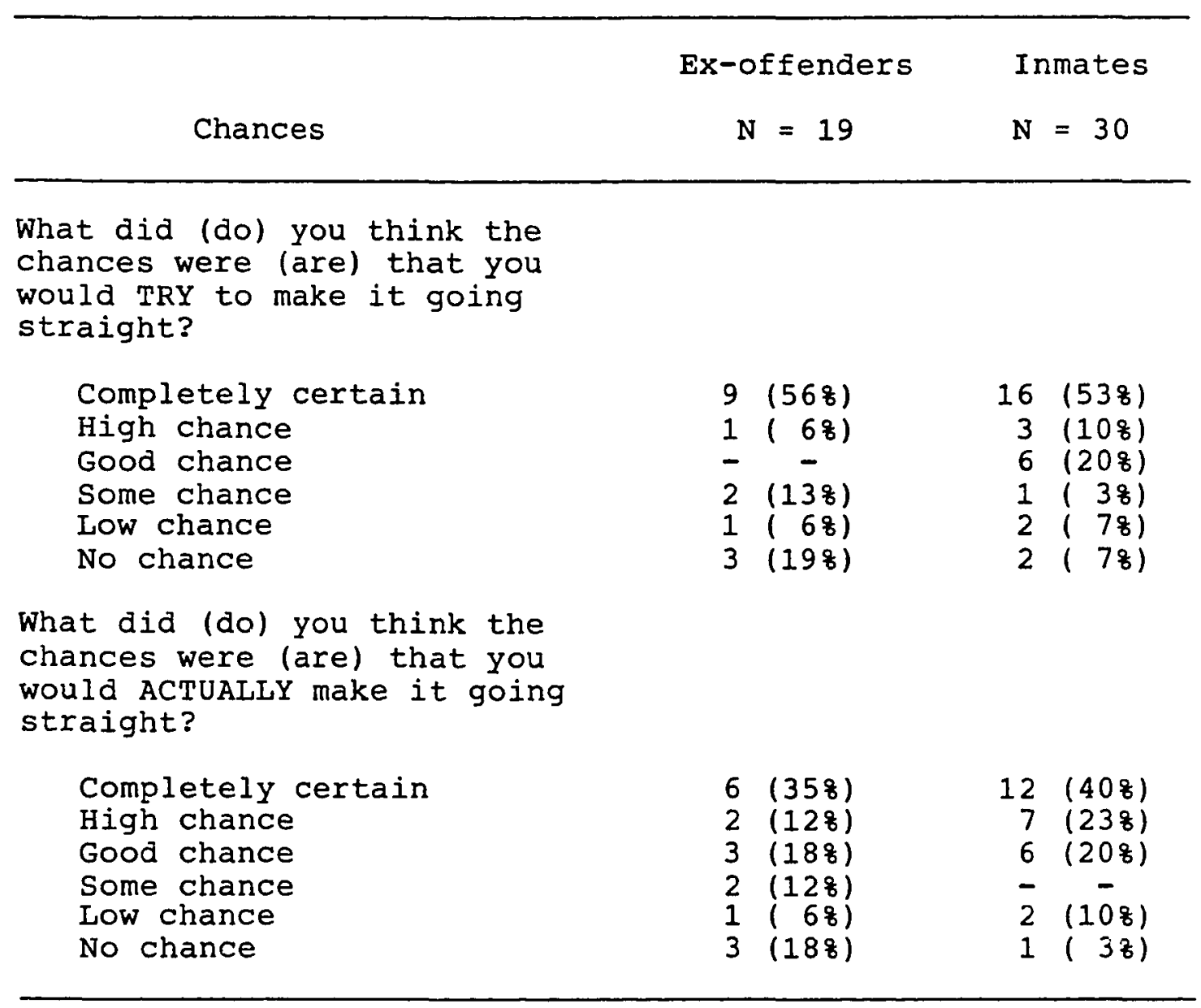

inmates indicate that the ex-offenders are more tied into the conventional social order than are their inmate counterparts. Shover (1983) cites an unpublished study by Meisenhelder (1977) that indicated that a "meaningful bond to the conventional social order" (209) was one of the 
motivating forces linked to temporary criminal career termination. On the other hand, one could argue that being married, having more years of formal education, better employment, more money, and belonging to more clubs or organizations could simply be a function of having spent less time in the penitentiary and/or of not being incarcerated at the time of the interview. Iikewise, the criminal histories of the ex-offenders and the inmates are by and large more noteworthy for their similarities than for their differences. Men in the two groups had nearly the same degrees of juvenile involvement in crime. Journeys through the system appear to have been somewhat less harsh for men in the ex-offender group. The two groups' subjective assessments of success in crime as well as predictions of disengagement from crime were quite similar.

Having taken up the nature of the two "samples," let us now examine some life areas in somewhat greater detail utilizing the information obtained from the Life Satisfaction portion of the questionnaire. An analysis of the Life Satisfaction data will be presented in the following pages. 


\section{CHAPTER III}

\section{WORK, SOCIAL RELATIONSHIPS, AND SOCIAL WELL-BEING}

IN THE LIFE OF CAREER OFFENDERS

In this chapter, desistance from crime at middle age is examined within the social-psychological framework of adult development. Several authors (Erikson, 1963; Neugarten, 1968; Levinson et al., 1978; Tamir, 1982) have argued that men at middle age experience a common developmental transition. This transition is accompanied by more major Iife changes than the adult male experiences at any other time in his life. These changes may be external, such as career or marital relationship changes, or they may be internal, such as the changing of one's values and attitudes about the world.

While Levinson et al have developed a relatively comprehensive theoretical explication of adult development, their work was not based upon a representative national sample of men spanning a broad age range. Lois Tamir remedied this situation with her detailed analysis of agerelated changes in the life spheres of men. She employed a more adequate sample than the Levinson researchers, and she studied men of varying ages. Taken together, the work of Levinson and Tamir provide a good deal of information on 
the developmental changes of men in the general American population.

The research reported herein had to do with two particular groups of American males: (1) older ex-offenders who have apparently terminated a career in crime and have entered the "straight life," and (2) older prison inmates, at least some of whom appear to be moving away from criminality. The main question posed in this study centers on the the extent to which these "deviant" males have not only switched from one mode of economic support (crime) to another (various law-abiding occupations), but have also been involved in changes in friendships, daily routines, and social behavior. In short, this research investigates the degree to which desistance from crime can be accounted for within the developmental transition framework that has been applied by Levinson and others to males within the general population.

\section{THE DATA}

How should one go about studying "maturational reform" on the part of ex-offenders within an adult developmental framework? Ideally, research ought to focus on a large, representative sample of males, following them for an extended time from early adulthood into old age. A cohort design involving a large sample of males would allow the 
researcher to separate those who followed law-abiding pathways through life from that smaller number who committed an occasional crime, and to that even smaller sample of males who became "career criminals."

Further, such a design would allow the researcher to partial the study sample into general population males, who exhibit differing age transitional experiences, as well as allowing for the identification and study of those career criminals who have matured out of crime separate from those who have continued to be involved in lawbreaking beyond middle age.

Finally, a research design of this kind would allow the researcher to probe in depth the adult developmental similarities and differences between "straight" and "crooked" American males.

A research design of this complexity was obviously beyond the scope of the exploratory investigation described in this report. The primary study data came from a small sample of ex-offenders and a similarly small group of older prisoners. These men were quizzed about events and experiences at earlier points in their lives; thus, their reports were retrospective, provided during an interview in the relatively recent past. Accordingly, it cannot be argued that the data on either ex-offenders or on inmates provide a full account of their developmental changes. 
However, Tamir's work on men in the general population can be utilized as a benchmark against which to examine both the ex-offenders and the prisoners. Put another way, if the middle-aged ex-offenders ultimately resemble Tamir's middleaged general population, less weight will have to be given to the complaint that a single set of interviews with exoffenders and inmates cannot determine much, if anything, about the ingredients of maturational reform (desistance from crime). Instead, it can be argued that findings of this sort suggest that offenders and men in the general population go through similar adult developmental experiences. On the other hand, if the offenders, exoffenders, or inmates ultimately differ from the males in Tamir's research, a different set of conclusions about criminal maturation would appear to be in order.

\section{WORK RELATIONSHIPS}

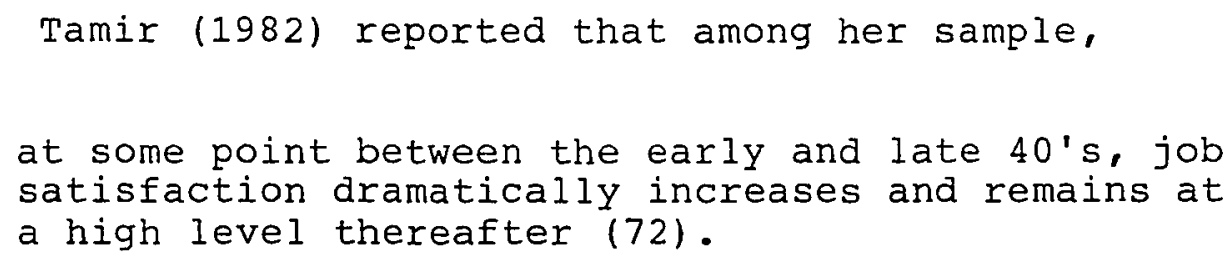

However, while most men in their $40^{\prime} \mathrm{s}$ indicated that they intended to stay with their present jobs, Tamir also found that job satisfaction was only reached after the men had considered a job change. Stated another way, the mid-40's 
was a period during which many men, particularly noncollege men, gave serious consideration to changing jobs. Tamir argued that by the mid-40's, the less-educated men find themselves locked into their jobs with little chance for change and that "the early 40's is where the man becomes aware that this is his last chance for a break--now or never" (p. 75). If he decides to stay with his job, he will most likely become reconciled to what he has in the way of employment.

Work-related issues for the men in the present study must be examined in two spheres: straight jobs and criminal occupations. In the case of the offenders, the focus of this study is upon a mid-life job change for people who have been identified as career criminals.

As has been shown, several authors (Tamir, Gould, Levinson et al.) have argued that during midale age men become increasingly aware that they may never reach goals to which they have been aspiring, such as becoming a millionaire, or becomeing famous, or even more modest goals. But what can be said about those who have worked at lawbreaking endeavors? Do they give up the quest for the "big score?" Do they take a close look at where they are today and where they might reasonably...e able to go in the future, with the result that they withdraw from criminality? The ex-offenders and inmates who were interviewed in 
this study were asked to respond to several questions about their views of the world of work. One asked the men to judge how successful they had been in crime. Almost 808 of the ex-offenders and $70 \%$ of the inmates indicated that they had come to the realization that their criminal careers had been largely unsuccessful. As one ex-offender put it: "I was never successful as a thief; I decided I was going to do what society wanted me to do" (EO 02).

The ex-offenders were asked to think back to their last incarceration and try to remember how likely they thought it was at that time that they would change to a noncriminal life. The majority of ex-offenders recalled that they thought that the chances were quite high that they would at least try to go straight. Many of the ex-offenders recalled that they were less certain that they would succeed in staying "clean," but the majority still thought the chances were at least good (see Table VIII in chapter II). The majority of ex-offenders was employed in white collar or professional jobs. As Question B in Table IX shows, almost $80 \%$ reported getting at least some satisfaction from work. The ex-offenders' mean levels of

Two ex-offenders each had come to conclude that they had been very or somewhat successful. Four inmates thought that they had been very successful in crime, and five judged their criminal involvement as having been somewhat successful. 
TABIE IX

ASPECTS OF WORK

\begin{tabular}{|c|c|c|c|c|}
\hline Questions* & Tamir & $\begin{array}{c}\text { Ex-offenders } \\
N=19 * \star\end{array}$ & $\begin{array}{l}\text { Innates } \\
\mathrm{N}=30^{\star \star}\end{array}$ & $\begin{array}{l}\text { Ex-offenders } \\
\text { Retrospective }\end{array}$ \\
\hline
\end{tabular}

a) Is your type of work:

$\begin{array}{lcrrr}\text { Blue collar? } & \mathrm{n} / \mathrm{a} & 7(358) & 17(568)^{\star \star \star} & \mathrm{n} / \mathrm{a} \\ \text { White collar? } & \mathrm{n} / \mathrm{a} & 12(608) & 11(378) \star \star \star & \mathrm{n} / \mathrm{a}\end{array}$

Mean Levels of Job Satisfaction:

b) How much satisfaction

have you received

from work at a job?

$\bar{x}=3.6 \quad \bar{x}=4.3 \quad \bar{x}=4.2 \star \star \star \quad \bar{x}=4.0++$

c) Taking all aspects

of your job into

consideration, how

satisfied are you?

$\bar{x}=3.3 \quad \bar{x}=3.7 \quad \bar{x}=3.6++\quad \bar{x}=3.8++$

d) Regardless of how much you like your job, is there any other work you'd rather do?

$\begin{array}{lrrlll}\text { Yes: } & \text { n/a } & 11(618) & 10(368)++ & 4(218) \\ \text { No: } & \text { n/a } & 7(398) & 18(648) & 15(798)\end{array}$

\footnotetext{
Some of the questions are paraphrased. The exact wording can be found in the appendix.

**

The N's for each group may not add up to 19 and 30 respectively because some respondents failed to answer a given question.

$\star \star \star$

The inmates were asked about jobs they held prior to their incarceration (i.e., "straight" jobs).

$+$ Mean scores are based on Likert responses from 1 to 5, No Satisfaction to Great Satisfaction.

$++$

Here the innates responded to work they did in prison.
} 
reported job satisfaction were quite similar to those of Tamir's general population of men. However, almost twice as many ex-offenders as general population men gave an affirmative response to the question: "Regardless of how much you like your present job, is there any other work you'd rather be doing?" (see Question D in Tabie IX).

The findings indicate that both groups of men are reasonably well-satisfied with their work, but the exoffenders more often said that they would rather do something else. Probably this is a consequence of these mens' extensive involvement in crime, which curtailed work options and opportunities in straight life.

In response to being asked about the job they held prior to their present imprisonment, the majority of inmates indicated having been employed in blue collar jobs. The majority of inmates indicated having been largely satisfied with those jobs. Their mean level satisfaction scores were very similar to those of Tamir's general population men and the ex-offenders in this study. Regarding their current work inside the penitentiary, less than half of the men said that they would rather be doing other work (see Question D in Table IX).

Does the expressed willingness of the ex-offenders to consider other work indicate that they might be willing to revert back to crime? Two questions asked the ex-offenders 
to estimate the chances that they would continue to go straight. Seventeen (908) thought that the chances would at least be good; in fact, 15 of the 19 ex-offenders were completely certain that they would continue with their straight lives.

Recall Tamir's (1982) contention that men disengage themselves from work during middle age, so that this aspect of life becomes less salient to them (93). Perhaps the shift from crime to law-abiding behavior is easier for older ex-offenders than it would have been at earlier times in their lives. And, because the shift from a lawbreaking to a straight life involves so much more than just a change in one's means of income generation, ex-offenders are loath to lose highly valued life style aspects such as "warm relations with others." Thus, these become compelling factors in keeping ex-offenders on the straight and narrow. The fact that all of the ex-offenders have been free from any type of supervision by the criminal justice system for at least five years provides additional support for this argument. That is, their avoidance of crime cannot be attributed to surveillance and other control measures.

SOCIAL RELATIONSHIPS

\section{Marriage}

The majority of Tamir's (1982) middle-aged men reported 
being satisfied with their marriages (98-99). Interestingly, the mean scores on marital satisfaction were slightly higher for the ex-offenders and the inmates (see Question $A$ on Table $X)$. The majority of men in Tamir's study reported that both partners derived about equal satisfaction from marriage, although roughly one-fourth of those in the age categories 35-39 and 55-59 reported getting more out of marriage than their wives (Tamir, 1982: 100). Similarly, roughly one-fourth of the ex-offenders reported enjoying more benefits from the marriage than did their wives. While the majority of inmates (57\%) reported that both spouses derived about equal benefits from the marriage, this percentage was considerably smaller than that of either the Tamir group or the ex-offender group.

None of the ex-offenders, but eight (298) of the inmates, felt that their wives got more out of the marriage than they did (see Table X, Question B). A 47-year-old inmate said this: "I am too good a husband. I feel men are not the kings. Marriage is a partnership" (0 29).

Tamir's general population men, the ex-offenders, and the inmates agreed that at times they had had problems getting along with their spouses, even when otherwise the marriage was a happy one (see Table X, Question A). Along with admitting to past marital problems, the majority of Tamir's men acknowledged that they weren't as good husbands 
TABLE $x$

SOCIAL RELATIONSHIPS: MARRIAGE, PARENIHOOD, AND FRIENDSHIP

\begin{tabular}{|c|c|c|c|c|}
\hline Questions & Tamir & $\begin{array}{l}\text { Ex-of fenders } \\
N=19^{\star}\end{array}$ & $\begin{array}{l}\text { Innates } \\
N=30^{*}\end{array}$ & $\begin{array}{l}\text { Ex-offenders } \\
\text { Retrospective }\end{array}$ \\
\hline
\end{tabular}

MARRIAGE* *

a) How much satisfaction have you gotten from marriage?

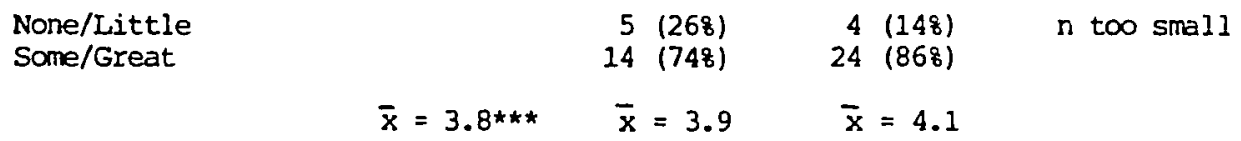

b) All in all, who would you say gets more out of being married, you or your wife, or both about equal?

Equal

Wife

Self

$\begin{array}{llll}\begin{array}{c}\text { college: } \\ 82.98\end{array} & \text { i4 }(798) & 16(578) & \text { n too small } \\ \begin{array}{c}\text { noncollege: } \\ 89.28\end{array} & & & \\ & -\overline{(228)} & 8(298)\end{array}$

c) Many men feel that they are not as good husbands as they would like to be. Have you ever felt this way?

Yes

No

$$
\begin{gathered}
58.58+ \\
\text { college: } \\
61.48 \\
\text { noncollege: } \\
55.58
\end{gathered}
$$

$13(768)$

$16(628)$

$n / a$

d) Taking all things together, would you describe your marriage as:

Very happy/ above avg

Avg/not too happy
$+$

$10(678)$

$5(338)$
$11(408)$

$\pi$ to small 
TABLE X (CONTINUED)

e) Even . . . when married couples are happy, there are times when they have problems getting along. Has this ever happened to you?

Yes

No

f) How much

satisfaction have

you gotten from

being a father?

\section{None/Little \\ Some/Great}

638 college:

70.28

noncol lege: 57.38
11 (798)

$22(798)$

$\mathrm{n}$ too small

$3(218)$

$6(218)$

n too small

$$
\bar{x}=3.7 \star \star \star \quad \bar{x}=4.3 \quad \bar{x}=4.2
$$

g) Many men feel that they are not as good fathers as they would like to be. Have you ever felt this way?

Yes $\begin{gathered}588 \star \star \star \\ \text { college: } \\ 668 \\ \text { noncollege: } \\ 488\end{gathered}$

$12(808)$

$14(648)$

n too small

No

$3(208) \quad 8(368)$

\section{FRIENDSHIP}

h) No one cares what happens to me.

Very True Not True

$n / a$

2 (118)

17 (898)

7 (248)

$23(768)$

$10(538)$

$9(478)$

i) I often wish that people would listen to me more.

Very True Not True

$n / a$

9 (478)

17 (578)

$10(538)$

13 (438)

$10 \quad(538)$

9 (478) 
TABLE X (CONTINUED)

j) I often wish that people liked me more than they do.

Very True

Not True

k) These days, I really don't know who I can count on for help. $\mathrm{n} / \mathrm{a}$

$\mathrm{n} / \mathrm{a}$

Very True

Not True

1) Do you feel that you have as many friends as you nould want, or would you want more?

\section{Want more}

Have enough

m) How many friends and relatives do you have to discuss problems with or to ask for advice? [Paraphrased]

None/Few

Several/Many

n) How often do you talk with them about problems or ask them for advice?

Never/Rare
Sometimes
Often/Very Often

$\mathrm{n} / \mathrm{a}$

$\begin{array}{ll}7 & (378) \\ 9 & (478) \\ 3 & (168)\end{array}$
7 (378)
$12(638)$

$\begin{array}{rr}7 & (248) \\ 22 & (768)\end{array}$

9 (478)

$10(538)$ 
as they would like to be. This same sentiment was expressed by the ex-offenders and to a slightly lesser degree by the middle-aged inmates in this study (see Table X, Question C). The ex-offenders, by and large, resembled Tamir's general population men in their responses to marriage questions. The observed differences between ex-offender and inmate responses may be explained by incarceration. Being currently in prison probably places serious strains on many marriages. Cordilia (1983) notes, for example, that "many wives and girlfriends abandon inmates once they go to prison" (31). The fact that fewer inmates than exoffenders attributed their marital problems to their own inadequacies may possibly be related to their rather passive roles in the relationships while they are imprisoned.

On the whole, the findings of the current study suggest that the ex-offenders resemble Tamir's general population men for whom marriage "becomes an increasingly crucial component of life in midale age" (105).

\section{Fatherhood}

The majority of Tamir's general population men reported deriving satisfaction from fatherhood, although somewhat surprisingly, the ex-offenders and the inmates showed somewhat higher mean scores on this question (see Table $\mathrm{X}$, Question F). While the majority of Tamir's men admitted that they had not been as good parents as they would like to 
have been, relatively more ex-offenders ( $80 \%$ ) said that they felt the same way (see Table X, Question G). Somewhat fewer (648) of the inmates questioned their competency as parents. Among Tamir's sample, perceptions of adequacy as a parent were not related to perceptions of adequacy as a husband (101)

The findings of this study suggest that ex-offenders and inmates, taken together, admit to somewhat greater inadequacies as husbands and fathers than do general population men. Again, incarceration may be the key factor in these self-perceptions inasmuch as these men have been cut off from opportunities to develop and exercise skills at husbanding and parenting.

\section{Friends}

Tamir's middle-aged men did not appear to differ significantly from men of other age groups when their responses to individual friendship questions were examined. A different picture emerged when Tamir analyzed the interaction patterns of these same responses. For example, noncollege middle-aged men appeared to derive much of their self-esteem from social contacts and from feeling socially connected (Tamir, 1982: 112).

Among the men in this study, this relationship was most clearly expressed by the ex-offenders looking back at their last incarceration. As a group, these men had the lowest 
average self-esteem score (see Table XI), and they also indicated feeling less, rather than more, social connectedness (see Table X, Questions h through k). For example, "I often wish people liked me more than they do" was to be judged as either very true, pretty true, not very true, or not true at all. The majority of ex-offenders answered these questions in the direction of greater, rather than lesser, social connectedness.

In response to the question, "Do you feel you have as many friends as you want, or would you like to have more friends?" more ex-offenders than inmates stated their desire for friends (see Table X, Question 1). Again, Tamir's men in their 40's did not differ from men of other ages (109). Only half as many inmates as ex-offenders expressed a desire for more friends. The majority of ex-offenders indicated having few friends or relatives with whom they discussed problems; and if they did discuss their concerns, it was more likely to happen rarely than often. Fully 25 of the 30 inmates stated having few or no close friends or relatives, and almost half reported never or rarely discussing problems with friends or relatives (see Table $x$, Questions $M$ and $N$ ). When the responses of only those

The middle-aged men in Tamir's study did not differ significantly from men of other age groups on the social connectedness items. 
TABIE XI

SEIF-ESTEEM

AVERAGE SELF-ESTEEM INDEX SCORE

(Aggregate responses to a, b, c below)

$\begin{array}{llll}\underline{\text { Tamir }} & \text { Ex-offenders } & \underline{\text { Inmates }} & \begin{array}{l}\text { Ex-offenders } \\ \text { Retrospective }\end{array} \\ \overline{\mathbf{x}}=13.7 & \overline{\mathbf{x}}=14.0 & \overline{\mathbf{x}}=13.8 & \overline{\mathrm{x}}=11.5\end{array}$

college: 13.9

noncollege: $13.4^{*}$

$\star$

Self-esteem scores for Tamir's men are only significant for noncollege men between the ages of 45-49. The mean index score for this sub-group is 12.6 .

\begin{tabular}{|c|c|c|c|}
\hline Questions & $\begin{array}{c}\text { Ex-offenders* } \\
N=19\end{array}$ & $\begin{array}{l}\text { Inmates* } \\
N=30\end{array}$ & $\begin{array}{l}\text { Ex-offenders } \\
\text { Retrospective }\end{array}$ \\
\hline
\end{tabular}

a) I feel that I an a person of worth at least as much as others.

Never/Rarely

Some/Often

b) I am able to do things as well as most other people.

Never/Rarely some/Often

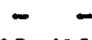

19 (1008) $\begin{array}{rr}2 & (68) \\ 28 & (948)\end{array}$

$6(328)$

18 (958)

c) On the whole, I feel good about myself.
Never/Rarely
Some/Often

$$
\begin{array}{r}
2(118) \\
17(898)
\end{array}
$$

$\begin{array}{rr}3 & (108) \\ 27 & (908)\end{array}$

3 (168)

16 (848)

$\star$

Observed responses did not differ notably for men aged 35-59(61) and men aged 4050 . 
inmates 40 - to 50-years old were examined, $83 \%$ said they never had personal conversations with friends.

Of the ex-offenders who recalled their last incarceration, even fewer expressed having wanted friends than did today's inmates. They also had fewer close friends and reported feeling considerably less socially connected than did either today's inmates or they themselves today. Overall, the ex-offenders, more than the inmates, sought out friends, talked with them about their concerns, and indicated feeling socially connected. It does not appear surprising that the inmates and the ex-offenders during their last incarceration, showed less positive attitudes toward friends and friendships.

Several ex-offenders and inmates commented on the notion of friendship in prison. One ex-offender said: "You don't have friends in prison; you have people you rap with" (EO 16). Another stated: "Friends in the pen is gamesmanship; you never know who your friends are" (EO 01 ). Summarizing the findings for marriage, fatherhood, and friendships, it was found that the ex-offenders resembled general population men in their attitudes toward marriage, which, according to Tamir takes on increased importance for the middle-aged man. The ex-offenders tended to rate themselves lower on parenting skills than did middle-aged general population men. Feelings of inadequacy were 
expressed equally often about being a good parent and being a good husband. The ex-offenders, more often than the inmates, said that they wanted friends and that they looked for and found more close friends. They also rated themselves more socially connected than did the inmates.

External aspects of life such as jobs, marriage, parenthood, or friendships affect psychological well-being during middle age, as well as at other stages in life. What are the sources of psychological well-being and how, if at all, are they related to the termination of criminal careers at mid-life? These questions will be addressed in the following pages.

PSYCHOLOGICAL WELL-BEING AT MID-LIFE

Self-Esteem

Tamir (1982) reported that among lower class men, those between the ages of 45 and 49 displayed the lowest self esteem (43). The relatively small number of participants in this study did not allow for stratification by education and age groups of 5-year intervals. Thus, the findings were compared with those from Tamir's men based upon a wider age span than 45 to 49 .

Three items from Rosenberg's (1965) Self-Esteem Scale formed the measure used in the Tamir study. 
It was found that Tamir's reported average self-esteem scores for men aged 35 to 59 were virtually identical to scores obtained for the ex-offenders and inmates of this study (see Table XI). Not only did career criminals, both ex-offenders and inmates, show the same level of self-esteem as noncriminal men, the men who were still incarcerated at middle age reported feeling equally good about themselves as did the men who had seemingly discontinued their criminal activities at middle age and who were generally quite well integrated into straight society. In other words, middleaged career criminals resembled middle-aged general population men quite closely regardless of whether or not they were still incarcerated.

Quite a different picture emerged, however, when exoffenders were asked these same questions about the time during their last incarceration. The men reported having felt considerably less good about themselves then as compared with today, or as compared with the feelings expressed by the currently-incarcerated men. Table XI, for example, shows responses to one of the questions that made up the self-esteem measure: "On the whole I feel good about myself." Eighty-nine percent of today's ex-offenders and 978 of current inmates responded with "sometimes" or "often" rather than with "rarely" or "never." Quite a few (42\%) exoffenders remembered "rarely" or "never" feeling good about 
themselves during their last incarceration. In fact, the average self-esteem score (for the questions taken together) for this group of men was 11.5 lower than any self-esteem score reported by any of Tamir's age groups (46). It appeared that these men remembered themselves as feeling significantly more worthless than any of the comparison groups.

\section{Zest}

This index is based upon the zung Depression Scale (1965). The items are phrased positively and thus, at least on the surface, give an indication of "zest."

As for Tamir's general population men, the only significant difference on this measure was found for the subgroup of college-educated men between the ages of 45 and 49 (44). The average zest score for this subgroup was $22.9^{*}$ (see Table XII). The ex-offenders and inmates between the ages of 40 and 50 had average zest scores 122.0 and 21.4) almost identical to Tamir's college-educated men in their late $40^{\prime} \mathrm{s}$. As noted earlier, the participants in this study could not be stratified by education and 5-year age intervals because the resultant $\mathbb{N}^{\prime}$ s would have become too

The average zest score for 40-49 year old men was 24.5 . Scores on this measure could range from a high of 30 to a low of 6 . 
TABLF, XII

ZLST OR ABSENCE OF DEPHLSSION

AVERAGE ZEST INUEX SCORE: This is a composite measure made up of items a through $f$ below.

\begin{tabular}{|c|c|c|c|}
\hline TAMIR & EX-OFFH NDERS & INMATES & $\begin{array}{l}\text { EX-OFFLINDEILS } \\
\text { RLTIXOSPECTIVE }\end{array}$ \\
\hline$x=24.4$ & $x=21.9$ & $x=21.9$ & $x=17.1$ \\
\hline Questions & $\begin{array}{c}\text { Ex-offenders } \\
\qquad N=19 \star \star\end{array}$ & $\begin{array}{l}\text { Inmates } \\
N=30^{*}\end{array}$ & $\begin{array}{l}\text { Bx-offenders* } \\
\text { Retrospective }\end{array}$ \\
\hline
\end{tabular}

a) My mind is as clear

as it has always

been.

$\begin{array}{lrrrrr}\text { Little/Sone Time } & 7(378) & 5(178) & 7(378) \\ \text { Part/Most Tine } & 12(638) & 24(838) & 12(638)\end{array}$

b) I find it easy to do the things I used to do.

Little/Some Tine Part/Most Time

c) My life is interesting.

Little/Some Time Part/Most Time

d) I feel that I an useful and needed.

Little/Some Time Part/Most Time

e) My life is pretty

full.

Little/Some Time Part/Most Tine
$5(268)$

$14(748) * *$
$10(348)$

20 (668)

$7(378)$

$12(638)$

I feel hopeful about the future.

$\begin{array}{llrrr}\text { Little/Some Tine } & 4(218) & 5(378) & 13 & (688) \\ \text { Part/Most Time } & 15(798) & 25(838) & 6(328)\end{array}$

The questions referred to present or past status as inmate.

'The N's for each group of respondents may not always add up to 19 or 30 respectively because some respondents fajled to give an answer to some questions.

*

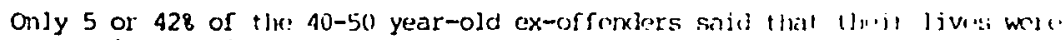
irrity intrerislim. 
small.

Thus, while not perfectly matched with Tamir's group, ex-offenders and inmates, by virtue of the average zest scores obtained, appeared to differ from the general population men, older or younger. More of the ex-offenders and inmates appeared to be more depressed than men of all other ages, save college-educated men between 45 and 49 . A glance at the individual questions that made up the zest measure (Questions a through $f$ on Table XII) showed virtually no differences in responses between ex-offenders and inmates. The only exception was that inmates were somewhat more inclined than ex-offenders to declare that their mind was as clear as it had always been. While the ex-offenders' and the inmates' zest scores showed them to be significantly more depressed than general population men of all other ages, this was true to an even greater degree for the ex-offenders when they were asked to

\footnotetext{
$\star$

Roughly half of the ex-offenders $(9 \mathrm{men})$ and one-third of the inmates ( 8 men) had some college. Only 5 of the 29 ex-offenders were in the age category 45-49.

Individual item results for Tamir's men were not available.

When only the responses of ex-offenders and the inmates between the ages of 40-50 were examined, one notable difference emerged from a comparison of all exoffenders and those aged 40-50. The men in this subgroup were considerably less likely to judge their lives as being interesting.
} 
think back to their last incarceration. The average retrospective zest scores were substantially lower than those obtained from the same men today and from the currently incarcerated men. The individual items that contributed most to this difference indicated a relative absence of feeling useful and needed, an empty life and decreased hopefulness about the future (see questions d, e, and $f$ on Table XII).

\section{Psychological Immobilization}

While the men in Tamir's study varied on the measure of psychological immobilization, only college-educated men in their late $40^{\prime}$ 's differed significantly from other age groups in this respect, with an average score of 8.0 (with the highest possible score being 20 and the lowest 5) (Tamir, 1982: 48). Table XIII shows that among the men in this study, the inmates reported being the least immobilized psychologically $(\bar{x}=8.5)$, while the ex-offenders' responses yielded an average score of 9.4 .

Both the ex-offenders and the inmates reported greater psychological immobilization than did general population men of the same ages. In fact, none of Tamir's age groups had as high an average score as did the ex-offenders and inmates. In other words, the ex-offenders and the inmates resembled each other more closely than either group resembled the general population men of the same ages. 
TABTE XIII

PSYCHOTOGICAL IMADBITIZATION

AVERAGE INUEX SOORE: This measure is made up of the combined scores for questions a through $e$.

$\begin{array}{cccc}\text { TAMIR } & \text { EX-OFEENDERS } & \text { EX-OFERNDERS } \\ \bar{x}=7.0 & \bar{x}=9.4 & \bar{x}=8.5 & \bar{x}=10.3 \\ \text { college: } 8 & & & \\ \text { RETROSPECTIVE }\end{array}$

\begin{tabular}{ccl}
\hline Ex-offenders* & Inmates* \\
$N=19$ & $N=30$ & $\begin{array}{l}\text { Ex-offenders } \\
\text { Retrospective }\end{array}$ \\
\hline
\end{tabular}

a) Do you find it difficult to get

up in the morning?

Never/Not Much

often/AlI Time

b) Are you ever bothered by nightmares?

Never/Not Much

16 (848)

3 (168)

$27(908)$
3 (108)

14 (748)

Often/AlI Time

c) Do you . . lose

welght when ...

something impartant

is bothering you?

Never/Not Much Often/All Time

d) Are you bothered by your hands sweating so that they feel damp and clanny?

Never/Not much

19 (1008)

$27(908)$

$14(748)$
$5(268)$

e) Have there ever been

times when you

couldn't take care

of things because

you couldn't get

going?

Never/Not much

often/All Time 
The greatest degree of psychological immobilization was reported by the ex-offenders looking back upon their last incarceration. Their average score of 10.3 placed them well above the average score of 7.0 reported by Tamir's men of the same ages.

A review of the five questions that made up the psychological immobilization index (see Questions a through e on Table XIII) showed this difference to be due to greater psychological immobilization across all items rather than to any one particularly differentiating response.

Drinking Problems

Tamir's results showed college-educated men between 45 and 49 to admit to more drinking problems than men of all other ages.

The inmates in this study admitted to greater troubles with alcohol than did the ex-offenders, either at the time of the interview or when they recalled their last incarceration.

As can be seen from Table XIV, the majority of the middle-aged men interviewed for this study indicated little or no difficulties with alcohol. The least difficulties were reported by today's ex-offenders. This was true even though two of the ex-offenders interviewed had alcoholrelated difficulties that determined to a large extent their residency in Portland's Skid Road district. 
TARIE XIV

ALOANO ANO DRUG USE

AVERAGE RUDXX SOORE: This moasure is composed of the combined responses to questions a through c below.

\begin{tabular}{|c|c|c|c|}
\hline $\begin{array}{l}\text { PAMIR } \\
x=4.2 \\
\text { Dllege: } 4.5 \\
\text { ancollege: } 4.0\end{array}$ & $\begin{array}{c}\text { EX-OFFENDERS } \\
x=4.9\end{array}$ & $\begin{array}{l}\text { INMATES } \\
x=6.7\end{array}$ & $\begin{array}{l}\text { EX-OFFENDERS } \\
\text { RETROSPECTIVE } \\
\qquad x=5.5\end{array}$ \\
\hline Questions & $\begin{array}{c}\text { Ex-offenders } \\
N=19 * *\end{array}$ & $\begin{array}{r}\text { Inmates } \\
N=30\end{array}$ & $\begin{array}{l}\text { Ex-offenders } \\
\text { Retrospective }\end{array}$ \\
\hline
\end{tabular}

a) Do you ever arink

more than you should?

$\begin{array}{lrrr}\text { Never/Not often } & 17(898) & 19(638) & 14(788) \\ \text { Often/Always } & 2(118) \text { *t* } & 11(378)+ & 4(228)\end{array}$

b) When you feel warried

- do you ever

drink . to help

you handie things?

Never/Not often often/Always

$17(948)$

$21(708)$

$12(758)$

c) Have there ever been problers between you and anyone in your family because you drank?

Never/Not Often often/Always

d) When you feel worried - do you take inedicines or drugs to help you handle things?

Never/liot often often/Aiways
$15(798)$

4 (218)
22 (738)

B (278) $\mathrm{n} / \mathrm{a}$ $\mathrm{n} / \mathrm{a}$

AVERACE SOORES

$\begin{array}{lclr}\text { TAMIR } & \text { EX-OFFENOERS } & \text { INAATES } & \text { RETROSPDCT } \\ x=1.4 & x=1.3 & x=2.6 & x=2.0 \\ \text { college: } 1.5 & & & \end{array}$

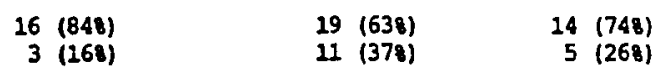

lege: 1.3

Tamir reported significant findings on the alcohol measure only for college men ages 45-49.

The $N$ for the ex-offender group does not always add up to 19 because not all respondents answered all questions.

본

Ex-offenders between 10-50: 4 (338).

Inmates between 40-50: 3 (17v). 


\section{Drug Use}

Tamir's analysis of the responses to a single question about the use of drugs or medicines to help handle tension again showed college-educated men to differ significantly from men in all other age groups, as well as from noncollege men. Middle-aged, college-educated, general population men were significantly more likely than others to use drugs or medicines to help them deal with tension or nervousness.

Question $d$ on Table XIV shows that the ex-offenders' average score resembled that of 40-49 year old men in Tamir's sample, indicating roughly equal reliance on drugs or medicines to handle nervousness and tension. This means that today's ex-offenders used more drugs than general population men of all age groups, except for 40-49 year old college-educated men. The average drug use score for inmates was considerably higher than that for any of the other groups.

\section{Summary}

In matters of psychological well-being, a notable pattern of differences emerged only for the ex-offenders when they were asked to recall how they felt during their last incarceration. Compared with general population men, inmates, and themselves today, the ex-offenders reported having been more depressed, having had lower self-esteem and having experienced greater psychological immobilization. In 
their responses, the inmates tended to resemble today's exoffenders rather than, as one might have expected, the exoffenders during their last incarceration.

Perhaps it is the passage of time that allows one to acknowledge lacking psychological well-being, or perhaps it is an actual lack of awareness on the part of middle-aged inmates that is instrumental in keeping them incarcerated at that particular stage in life, while those men who indicated having "suffered" during their last incarceration, as indicated by this group's greater average depression score, are free today.

This argument implies that the awareness of one's lack of psychological well-being supplies at least some of the motivation that may be instrumental in effecting the change away from crime and its associated life style. One of the ex-offenders recalled: "This time [meaning the last incarceration] I could put it all together. I had reached rock bottom, was better motivated to get away" (EO 10).

It appears, then, that how depressed men are, how badly they feel about themselves, and to what degree psychological factors impede their functioning does not depend on whether they are "former" or "current" career offenders, in other words, on whether they are free or incarcerated. While general population men tended to be less depressed and less psychologically immobilized than men in 
either of the offender groups, there was virtually no difference in self-esteem between middle-aged, general population men, ex-offenders, and inmates. This finding that in mid-Iife, men who have lived a "normal" life and those who have consistently been punished for living on the outside or on the periphery of "normal" existence see themselves as equally worthy people calls for a closer look at self-protective mechanisms and their role in the effectiveness of punishment for rehabilitative ends.

\section{Value Orientation}

Tamir (1982: 68) found that a change in value orientation occurred for general population men at middle age. The men were asked to choose from a list of nine values, such as self-fulfillment, accomplishment, security, etc., the two that were most important to them; subsequently, they were to determine the most important of the two. General population men in their 40's chose selfrespect as the most important value in their lives (see Table XV). Ex-offenders of the same age elected warm relationships and security equally often as their most important value. Recalling their last incarceration, today's ex-offenders remembered that respect from others was what they had valued most. Inmates in their $40^{\prime} \mathrm{s}$ most often selected accomplishment as the value of primary importance. 
In the choice of second most important value, current inmates resembled Tamir's middle-aged men inasmuch as both sets of men listed accomplishment. Today's ex-offenders, on the other hand, selected warm relationships as the second most important value to them. Recalling their last incarceration, the ex-offenders recalled that a sense of belonging was an important value.

As noted earlier, the data were analyzed for men aged 40-50, as well as for the entire sample of men aged 35-61. As shown above, this separate analysis left the resultant distribution virtually unchanged on most variables. This was not the case in the choice of most important value. Table XV documents that general population men, ex-offenders (today as well as during their last incarceration), and inmates aged 40-50 chose different most important values than they did when the age ranges were expanded to $35-$ $59(61)$.

Forty- to fifty-year-old inmates, as well as the exoffenders looking back, chose security as being of greatest value. For today's ex-offenders between 40-50, accomplishment ranked highest. Neither security nor accomplishment surfaced as a most important value for

The men in the ex-offender group ranged in age from 3559; the men in the inmate group ranged in ages from 3561; this difference is represented in the component listing $35-59(61)$. 
Tamir's men of that age group. They chose self-respect instead.

As a group, the ex-offenders placed greatest importance on warm relations and accomplishment. The inmates were virtually unanimous in casting their votes for accomplishment as their first and second most important values.

It is perhaps noteworthy that the values excitement, fun and enjoyment, and self-fulfillment were not ranked first or second by any of the groups. Except for the value placed on self-respect, the ex-offenders and the inmates did not differ greatly from their general population counterparts. In fact, even this difference was noteworthy only in comparing general population men and innates. For several of the ex-offenders, self-respect was of importance, only fewer of these men chose self-respect than accomplishment.

\section{CONCLUSIONS}

To summarize the findings from the Life Satisfaction portion of this study, it can be said that as far as work, marriage, parenthood, and friendships are concerned, the middle-aged ex-offenders in this study largely resemble general population men at mid-life. While the satisfaction gained from work increases in mid-life, this is also a time, 
more than any other, when men often contemplate changing jobs. For the ex-offenders, this contemplation appeared unlikely to involve changing back to crime.

Marriage appeared to be of equal importance to general population men and ex-offenders, which means that in midlife, marriage becomes increasingly important. The exoffenders tended to judge their adequacy as husbands and fathers lower than did Tamir's men. As far as friends and Iriendships were concerned, the ex-offenders showed greater inclinations toward social connectedness than did the inmates.

On the whole, most of the differences that emerged between middle-aged "straight" men and middle-aged past- or present-career criminals appeared attributable to the fact that the men in the latter groups have spent many years in an environment where learning and practicing how to be a good father and husband was not possible and where friendships had such different meaning that they can't legitimately be compared with friendships experienced by general population men.

On measures of psychological well-being, the general population men at mid-life showed somewhat greater zest, or absense of depression, and reported feeling less psychologically immobilized than did either today's exoffenders or inmates. In spite of this lessened sense of 
psychological well-being, the middle-aged ex-offenders and inmates did not appear to differ from the general population men in self-esteem. Unfortunately, it is not possible to determine from the information obtained for this study whether comparatively lesser degrees of psychological wellbeing precede or follow a life in crime. However, if one views the use of alcohol and drugs as methods of coping with psychological discomfort, then the data from this study provide some support for the notion that alcohol and drug use are associated with psychological discomfort inasmuch as they appear associated with incarceration for the men in this study.

Work, marriage, and friendship differences between today's ex-offenders and inmates appear attributable to the state of incarceration at the time of the interview. There is the possibility that these differences are temporary and may, in fact, disappear once the inmates are free and can participate more fully in life. As far as the measures of psychological well-being are concerned, the ex-offenders and the inmates did not differ.

So far, the search for the ingredients of maturational reform has not revealed many factors in the areas of work, relationships, or psychological well-being that clearly distinguish the middle-aged ex-offender from the middle-aged inmate. Attention will now be turned to the examination of 
those transitional tasks which Levinson et al. (1978) say must be mastered by the middle-aged male. 


\section{CHAPTER IV}

\section{THE MID-LIFE TRANSITION IN THE LIFE OF THE EX-OFFENDER}

This chapter continues the examination of the dimensions of "maturational reform" in the lives of career or long-term criminals. The major share of the discussion has to do with the extent to which Levinson's (1978) portrayal of a mid-life transition in the lives of men applies to former lawbreakers.

Levinson's theory, it will be recalled, contends that the mid-life transition forms the bridge between early and middle adulthood. As during any of the other transitional periods, a man "must come to terms with the past and prepare for the future" (191). This requires that a man accomplish three tasks: 1) review the preceding life period, in this case early adulthood, and reappraise what he has done with it; 2) begin to change the negative aspects of the early adulthood period and try out ways of dealing with them differently; 3) confront and reintegrate four basic polarities: Young/Old, Destruction/Creation, Attachment/Separateness and Masculinity/Femininity.

In the pages which follow, Levinson's argument will be further elaborated. Additionally, the data from the current study will be examined in order to evaluate the degree to 
which the Levinson argument applies to older ex-offenders and prisoners.

\section{REAPPRAISING LIFE BEFORE MIDDLE AGE}

In his reappraisal of the past, a man seeks to answer the question, "What have I done with my life?" The reappraisal involves all aspects of life: social relationships, work, values, talents, and desires. A 59year-old ex-offender put it this way: "I was going through a period of questioning that was not there before or after" (EO 04)

One's reappraisal commonly reveals that many of the long-held beliefs and assumptions about oneself and the world are based on illusions. While Levinson et al. do not specify exactly how a man comes to decide that certain aspects of the self and the world are illusory and others are not, the goal of the "de-illusionment" process is not to get rid of illusions altogether. Instead, reappraisal leads to the recognition that certain aspects of one's life may be illusory and therefore must be reassessed in a more realistic fashion.

A 59-year-old ex-offender offered a remark about friends that revealed aspects of the de-illusionment process. In response to the question, "Since middle age, have friends become more important to you?" he answered: 
"Not sure, [they] were always important. During the transition [they were] not so important [and I] questioned the value of friendship. After the change, I became more flexible, had fewer unreasonable expectations of people" (EO $04)$.

A 51-year-old inmate, in response to a question about his physical health, said, "I always believed that I couldn't get sick" (0 07). It was not until he had a heart attack in his late 40's that he reassessed his physical vulnerability.

The process of de-illusionment was described by a 41year-old inmate who talked about his changing relationship with women: "Well, I am not jumping around from woman to woman. I am not the stud of the year. I am satisfied with my old lady. I am through chasing" (0 25).

A reappraisal of one's dream or life goal frequently results in the recognition that the dream may have been illusory and must therefore be given a new, less powerful place within the life structure or must perhaps be abandoned altogether. A 44-year-old inmate reflected on his dream of being a famous baseball player: ". . my goals have changed--being a baseball player is really not so important any more" (10 05).

Remembering his last incarceration, one of the exoffenders said: "Yes, I changed then. I decided I never was 
successful as a thief [he had committed primarily armed robberies]. I was a failure, and I was going to do what society wanted me to do" (EO 02 ).

In fact, few of the men in this study who indicated having had a dream actually lived out that dream. Three men who said it was their dream to be a "good thief" (EO 04), a "very successful criminal" (0 24), or a "big-time drug dealer" (O 28) had entered the life arena where they might have achieved their dreams. By middle age, however, each one of these men had to admit to himself that his efforts had fallen short of the desired goal. Two were current Oregon state Penitentiary inmates; the third had abandoned his dream of being a good thief and entered the straight Iife.

\section{PLANNING A NEW LIFE STRUCTURE DURING THE MID-LIFE TRANSITION}

As men proceed through the mid-life transition, their attention gradually moves from a reappraisal of the past to planning for the future. According to Levinson et al. (1978),

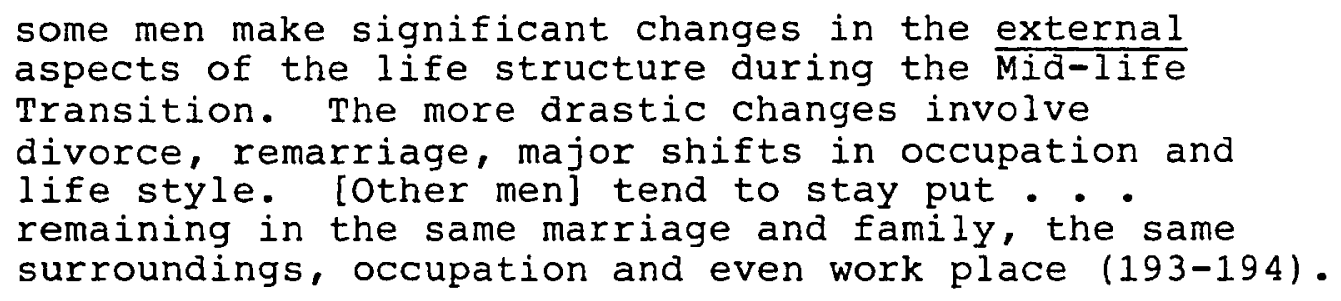


In line with this argument, the change from a life of crime to a straight life can be taken as evidence of at least one significant change in the external aspects of the life structure.

In addition to this clearly visible change, some of the ex-offenders also reported less noticeable changes. For example, one described his changed attitude toward marriage in these words: ". . [I] was 37 when I got married. The first three to four years were not too good. I didn't feel the way I feel now. Every day we get closer" (EO 02). A 46-year-old ex-offender put it this way: " . . even my wife says in the past five years I have become more stabilized. I am home more with my wife. We do more things together. I appreciate my wife more. I want to make her happy and let other people know I care" (EO 11).

In addition to more or less noticeable external life structure changes, the mid-life transition also entails

significant changes in the internal aspects of a man's life structure. . - He may change appreciably in social outlook, in personal values, in what he wants to give the world, in what he wants to be for himself (Levinson et al., 1978: 194, emphasis in the original).

One of the ex-offenders said: "I began to look at [the] future in terms of what I could contribute rather than what I could take" (EO 04). A 43-year-old inmate experienced a shift in values which he described as follows: 
". - more security-oriented, I am not influenced by what someone else has got, am more independent, single minded" (O 06).

In looking at his future, a 47-year-old inmate has a better idea of how he wants to go about life: "... [I am] more determined to accomplish what I set out to do. I set goals more now" (0 12). A 41-year-old inmate described yet another shift in values: ". . I just want peace and quiet now. I am done hassling with the authorities" (0 25).

Several of these internal changes were experienced by a 47-year-old ex-offender who said: ". . attitude has changed, probably for the best. I don't need the insane kind of excitement. I go about things a little slower. I don't do 100 miles per hour. I am extremely patient now. Going out and partying doesn't mean a whole lot to me any more. You learn to try to understand others even if they are against you. It [mid-life] feels like you go through the second half of a football game. You change your strategies" (EO 20).

"Individuation" is the underlying process that links the termination of one life period, namely early adulthood, to initiating another--middle adulthood. According to Levinson et al. (1978), "individuation" is the process by which a man gives up aspects of himself and his life arena while at the same time adopting new ways of being (195-197). 
The mid-life transition entails the application of the individuation process to four specific tasks. Levinson et al. (1978) indicate that

each task requires a man to confront and reintegrate a polarity; that is, a pair of tendencies or states that are usually experienced as polar opposites, as if a person must be one or the other and cannot be both. As he becomes more individuated in middle adulthood, a man partially overcomes the divisions and integrates the polarities $(196-197)$.

The men who participated in this study were asked several questions pertaining to each of the polarities postulated by Levinson et al. Their responses will be discussed in the following pages.

THE YOUNG/OLD POLARITY AT MID-LIFE

A major developmental task of the Mid-life Transition is to confront the Young and the old within oneself and seek new ways of being Young/old (Levinson, 1978: 210-213).

While these authors argue that young/old thoughts and feelings must be reintegrated at other transition periods in life (for example, during adolescence), middle adulthood is a time when young and old forces confront each other with equal force. In early adulthood, for example, the young is normally stronger, and in late adulthood the old takes on predominance. 
In the Mid-life Transition, the Young/old polarity is experienced with special force. . . a man is assailed by new fears of the 'loss of youth.' He feels that the Young--variously represented as the child, the adolescent and the youthful adult in himself--is dying. The imagery of old age and death hangs over him like a pall.

These authors assert that there are a number of changes that commonly occur around age 40 which intensify this sense of aging. In the most general sense, the changes force men to face their own mortality. This concern was expressed in the words of a 45-year-old ex-offender as follows: " . . [I] had reached a point [of realizing] that I would not live forever, had a heavy number on my head for about a year-just fear of death" (EO 18). Somewhat less emphatically, a 43-year-old inmate observed: " . . you learn to think of what things will be when you get old. I don't look at it to last forever" ( 0 0 04$)$.

Declining physical and psychological powers account for a number of these often only grudgingly-acknowledged changes with age. A man may find that he cannot run as fast, drink as much, or remember as well as in his younger years. He may find that more people around him have heart attacks, that deaths are more frequent, that alcoholism and depression are increasing--in general, that there is more suffering of all kinds.

One 56-year-old inmate described his decline in physical and psychological powers in these words: "I. . . 
couldn't jump around like I used to--like skiing--can't do things as good; thinking is not as strong either" (0 23).

The growing recognition of one's own mortality in midlife collides with and intensifies a man's wish for immortality. Levinson et al. (1978) argue that this wish for immortality leads to a greater concern with meaning and, as such, plays an important part in the reappraisal of life at 40 .

He often feels his life until now has been wasted. Even if, in cooler moments, he finds some redeeming qualities, he is still likely to feel that his life has not enough accrued value. He has not fulfilled himself sufficiently and has not contributed enough to the world... . In his remaining years he wants to do more, to be more, to give his life meaning that will live after his death (216).

A statement made by a 47-year-old ex-offender reflects this assertion by Levinson et al. ". . don't have muich time left when you ruined your life as I did. You think about a lot of things that you didn't do when you were younger" (EO 03).

Tamir (1982) provides empirical support for several aspects of the Young/old mid-life polarity. She reported that men in their $40^{\prime}$ 's differed from younger men in that they reported äeclining health (50) and increased depression, as weli as increased use of alcohol and drugs. Furthermore, her study contained support for Levinson's contention that during the mid-life transition, a shift away 
from transitory toward more lasting values occurs as men become increasingly concerned with immortality. She reported findings that indicated that relationships with spouses and children took on greater importance in the late $40^{\prime} \mathrm{s}$. Additionally, self-respect became the most important value to the middle-aged male, whereas security and accomplishment were most highly valued by men younger and older, respectively.

By and large, the ex-offenders resembled Tamir's general population men in aspects of the Young/old developmental tasks discussed above. Thus, they chose more lasting, rather than transitory, values (see Table XV in Chapter III), indicating a decline in psychological wellbeing and physical prowess (shown in Table XVI), and reported concern about alcohol and drug use. On measures of psychological well-being and alcohol and drug use, the middle-aged ex-offenders differed more from men of other age groups than did middle-aged general population men (see Tables XI - XIV).

The middle-aged inmates resembled the ex-offenders on measures of physical and psychological well-being. Their choices of important values, on the other hand, were more like those made by younger general population men. The middle-aged inmates also differed from the middle-aged exoffenders and general population men in that they reported 
TABLE XVI

HEALTH

$\begin{array}{cccc} & \text { Ex-offenders } & \text { Innates } \\ N=19 & N=30 & \text { Ex-offenders } \\ \text { Retrospective }\end{array}$

a) Do you feel you are bothered by all sorts of pains and ailments in different parts of your body?

$\begin{array}{lrl}\text { Yes } & 3 & (168) \\ \text { No } & 16 & (848)\end{array}$

b) For the most part, do you feel healthy enough to carry out the things you would like to do?

Yes

No

c) Do you have any particular health problems?

Yes

No
18 (958)

1 (58)

$10(538)$

9 (478)
$3(108)$

27 (908)

$19(1008)$
$29(978)$

1 (38)

$18(958)$

$1(58)$

$4(218)$

11 (338)

$19(638)$
$15(798)$ 
greater problems with alcohol and drug use in spite of the fact that they were in prison. This greater use of drugs and alcohol appeared not to be related to poorer physical health. In fact, as Table XVI shows, fewer of the inmates than ex-offenders reported having any particular health problems.

The greater use of drugs and alcohol in the absence of the relative lack of psychological and physical well-being suggests two possible explanations: 1) the currently incarcerated men simply use more drugs and alcohol, and this is a behavioral habit which is unrelated to underlying psychological and physical discomfort; or 2) the inmates deny or are not aware of the state of their psychological and physical well-being, and the use of alcohol and drugs serves to maintain the state of denial.

The ex-offenders and inmates were also asked to respond to items that dealt directly with aspects of the Young/old polarity as it has been set forth by Levinson et al. It was anticipated that middle-aged ex-offenders and inmates would indicate concern with getting older and with such related matters as estimating how much time they have left to do the things they want to do.

As shown in Table XVII, more inmates than ex-offenders showed concern about their disappearing youth, about not having enough time left in this world to do the things they 
TABLE XVII

THE YOUNG/OLD POLARITY AT MID-LIFE

\begin{tabular}{ccc}
\hline Questions & $\begin{array}{c}\text { Inmates* } \\
\mathbf{N}=19\end{array}$ & $\begin{array}{c}\text { Ex-offenders } \\
\mathbf{N}=30\end{array}$ \\
\hline
\end{tabular}

a) I often think about my disappearing youth.

\begin{tabular}{|c|c|c|c|}
\hline Agree & $5(268)$ & $18(608)$ & $10(538)$ \\
\hline Uncertain & 2 (118) & $-\overline{-}$ & $1(58)$ \\
\hline Disagree & $12(638)$ & $12(408)$ & $8(428)$ \\
\hline
\end{tabular}

c) I worry about not having enough years

left in my life to do what I want to do.

$\begin{array}{lrr}\text { Agree } & 5 & (268) \\ \text { Uncertain } & 4 & (218) \\ \text { Disagree } & 10 & (538)\end{array}$

$13(438)$

1 ( 38$)$

$5(268)$

$\begin{array}{rr}4 & (218) \\ 10 & (538)\end{array}$

$16(548)$

$1(58)$

13 (588)

d) I wonder whether $m y$

life will be more

worthwhile in my

remaining years.

Agree

Uncertain

Disagree $\begin{array}{rr}10 & (538) \\ 5 & (268) \\ 4 & (218)\end{array}$
$24(808)$

$2(78)$

4 (138)
$14(748)$

$1(58)$

$4(218)$

e) I often wonder whether

I am too old to make

a fresh start.

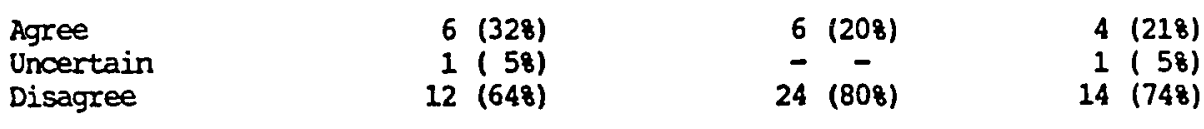

Observed differences between men 35-59(61) and men 40-50 were negligible. 
want to do, and about the worthwhileness of their future. Only in response to the item "I often wonder whether I am too old to make a fresh start" did the number of inmates expressing agreement with this pessimistic assessment lag behind the number of ex-offenders. Both groups of men disagreed with this statement. Overall, the inmate responses to questions concerning the Young/old polarity suggested that these men, at the time of the interview, experienced more conflicts about aging than did the exoffenders.

A 43-year-old inmate had this to say about getting older: ". . half my life is over with. I've got to settle down, quit that bullshit, if I want to do any of the things I want in life" (10 22).

While the ex-offenders as a group showed less conflict about getting older, they did recall how they felt during their last incarceration. From their recollections, it can be seen that their responses to the Young/Old questions were much like those of the currently incarcerated inmates.

Being middle-aged and in prison may intensify feelings of "getting older" and of "time running out" because each day of incarceration only serves to compound the perceived problem. However, it may also be the case that the exoffenders confronted Young/old related developmental tasks at a younger age than did the inmates. At the time of the 
interview, the mean ages for the two groups were roughly the same. Given that the ex-offenders' recollections of their last incarceration yielded responses that more often resembled the responses of the prisoners, one might conclude that the ex-offenders confronted the developmental taks of the Young/old polarity at an earlier age than did the inmates. The results tend to give some support to this line of argument (see Table XVII), but the support is not consistent across all the Young/old items. One of the ex-offenders remembered how he felt about getting older during his last incarceration: " . . because I was getting older, it was more difficult--[I] saw lots of old men there, but [I] didn't want to be an old man in the pen" (EO 15). THE DESTRUCTION/CREATION POLARITY AT MID-LIFE According to Levinson et al. (1978),

In the Mid-life Transition, as a man reviews his life and considers how to give it greater meaning, he must come to terms in a new way with destruction and creation as fundamental aspects of life. His growing recognition of his own mortality makes him more aware of destruction as a universal process. knowing that his own death is not far off, he is eager to affirm life for himself and for the generations to come. He wants to be more creative.

The developmental task facing the middle-aged male is to understand more deeply the destructiveness in his own life and in society at large (Levinson et al., 1978: 223- 
228). Men must seek and find a balance between power and love and must learn to exercise power with wisdom and compassion. The mid-life transition process requires that men acknowledge unintentional as well as intentional destructiveness on their part; that they come to understand the tragic sense of life based on the recognition that their own failures have not merely been imposed on them but are largely the result of unfortunate flaws in themselves; and that they accept the burdens as well as the pleasures of responsibility.

The learning that is required in the course of the mid-life transition is likely to occur during intense periods of suffering. One of the inmates reflected on the event that caused him to look more closely at his own destructiveness: "When I realized that I was even somewhat responsible for ending a person's life, even before I was arrested (I was free for some five months), during that time I couldn't commit a crime even though I was in bad financial shape. I couldn't do it. I just didn't want to. With prior crimes I dian't care. I had no thoughts of victims. Somewhere along the line you find you have a conscience. It was also the first time I had been involved in a crime where I was right with the victim" (0 01$)$.

Unfortunately, Levinson et al. do not provide quantitative empirical evidence in support of their 
theoretical conceptualizations. They do provide examples to illustrate their points, and these can be compared with examples obtained from the men in the current study. However, Tamir's data do supply some limited empirical evidence for some of Levinson's arguments. For example, Levinson et al. argue that learning about one's own and others' destructiveness during the mid-life transition period is likely to involve intense suffering. Tamir's survey included several measures of psychological well-being which reveaied that middle-class men, particularly those in their late forties, differed from other men in that they experience greater psychological discomfort. The exoffenders as well as the inmates indicated lacking psychological well-being to the same or greater degree as Tamir's general population men. Thus, there is some empirical indication of greater suffering during mid-life. This psychological discomfort may be related to Levinson's idea of learning about one's own destructiveness. Several questions were designed to tap the Destruction/Creation dimension. They were based on the above-described aspects of the developmental tasks specific to this polarity. On the whole, more inmates than exoffenders acknowledged their own as well as others' destructiveness (see Table XVIII). 
TABLE XVIII

THE DESTRUCTION/CRLATION POLARITY AT MID-LIFE

\begin{tabular}{|c|c|c|c|}
\hline Questions & $\begin{array}{c}\text { Ex-offenders } \\
N=19\end{array}$ & $\begin{array}{l}\text { Inrates* } \\
\mathrm{N}=30\end{array}$ & $\begin{array}{l}\text { Ex-offenders } \star \\
\text { Retrospective }\end{array}$ \\
\hline
\end{tabular}

a) I have failed in my responsibilities

toward many of those

who are closest to me.

\begin{tabular}{|c|c|c|c|}
\hline Agree & $8(428)$ & $21 \quad(708)$ & $14(748)$ \\
\hline Uncertain & $-\quad-$ & $1(38)$ & $(58)$ \\
\hline Disagree & $11(588)$ & $8(278)$ & (168) \\
\hline
\end{tabular}

b) I have failed and destroyed many of my own possibilities.

$\begin{array}{lll}\text { Agree } & 9 & (478) \\ \text { Uncertain } & 2 & (118) \\ \text { Disagree } & 8 & (428)\end{array}$

$23(778)$

$\overline{7}(238)$

$13(688)$

- $(\overline{328})$

c) I rarely think about the harm I have cone to others.

$\begin{array}{lrc}\text { Agree } & 8 & (428) \\ \text { Uncertain } & - & - \\ \text { Disagree } & 11 & (58 \overline{8})\end{array}$

$\overline{11}(\overline{588})$

$21(708)$

- $(398)$

$9(488)$

$10(5 \overline{8})$

d) I realize more and more that the failures and misfortunes I experience are not the fault of others but are mostly the result of unfortunate flaws in myself.

$\begin{array}{lrl}\text { Agree } & 14 & (748) \\ \text { Uncertain } & 2(118)\end{array}$

Disagree

3 (168)

$23(778)$

$1(38)$

6 (208)

7 (398)

1 ( 58$)$

10 (558)

e) Others around me, even my loved ones, have at times hurt me badly.

$\begin{array}{lrl}\text { Agree } & 11 & (588) \\ \text { Uncertain } & 2 & (118) \\ \text { Disagree } & 6 & (318\end{array}$

Uncertain

$\begin{array}{ll}2 & (128) \\ 6 & (318)\end{array}$

$18(608)$

$\overline{12}(\overline{408)}$

$12(678)$

$\overline{6}(348)$ Observed differences between men 35-59(61) and men 40-50 were negligible.

** The $\mathrm{N}$ for this group does not always add up to 19 because one respondent faileu to answer all questions. 
For example, while 708 of the inmates said that they had failed in their responsibilities toward others who were close to them, only 428 of the ex-offenders concurred. A related difference between ex-offenders and inmates emerged in response to the question about having destroyed many of their own possibilities in that the majority (778) of the inmates and less than half $(47 \%)$ of the ex-offenders agreed. An explanation that comes readily to mind is that today's ex-offenders may feel that they have made good. While their views of themselves during their last incarceration resembled those of currently incarcerated inmates, they clearly have changed since that time.

Another difference between the ex-offenders and the inmates emerged from their responses to the question: "I rarely think about the harm I have done to others." While the majority of ex-offenders, then and now, indicated that they did think about the harm they had caused others, only 238 of the inmates responded affirmatively. While generally taking responsibility for destructiveness toward others and themselves, the middle-aged inmates did not seem to contemplate the effect of their acknowledged destructiveness on others.

Some of the inmates had trouble with this question because it was phrased negatively but required an "agree" response. Thus, to answer the question correctly, either the question or the response had to be transposed. 
In Levinson's terms, the majority of ex-offenders as well as inmates appeared to have become aware of the tragic sense of life inasmuch as they attributed their own failures to flaws in themselves and not in others. Agreement between the ex-offenders and inmates was found as well in that the majority of men in either group reported having been hurt badly by a loved one.

With the exception of contemplating harm done to others and having failed in one's responsibilities toward others, the ex-offenders and the inmates tended to resemble each other in their general support for the argument that the mid-life transition involves greater acknowledgement of one's own and others' destructive forces.

In response to a question about mid-life change, one of the ex-offenders reflected upon this change: " . . I don't know if there is any one thing. It's more maturity, caring more about people and things. I used to think a lot about the things I liked, stealing, etc., but now I also think of the consequences and what effect it will have on me" (EO 08).

The ex-offenders did not remember feeling quite the same way during their last incarceration, as shown in Table XVIII. 


\section{THE FEMININE/MASCULINE POLARITY AT MID-LIFE}

In their usage of the terms feminine and masculine, Levinson et al. (1978) go beyond the "purely biological to the social and psychological differences between male and female" (228). At mid-life, an important developmental task revolves around the establishment of a more balanced co-existence between feminine and masculine values in man. Earlier times in a man's life course are characterized by his efforts to make it in a man's world, which means

to live in accord with the images, motives and values that are most central to his sense of masculinity, and he tends to neglect or repress the feminine aspects of his self (Levinson et al., 1978: 230).

Levinson et al. further assert that

most men get to the late thirties with roughly the same balance of masculine and feminine they had in the early twenties (236).

It is not until mid-life that a major qualitative reintegration of the two roles is required. When in midIife the feminine and masculine aspects become less rigidly divided within a man, he may be able to augment openly masculine concerns of doing, making, and having with aspects of the opposite pole such as being concerned with feelings, being sensitive, dependent and soft (233-234).

One ex-offender recalled how he had changed during his 
last incarceration, declaring that: " . . [I] had a change between going in and coming out--less driven by excitement. [Before,] I always had to be doing something. I couldn't BE; I had to DO" (EO 12).

The mid-life developmental task requires that a man "come to terms in new ways with the basic meanings of masculinity and femininity" (Levinson et al., 1978; 230). Several personal qualities are part of this Feminine/Masculine polarity. These qualities were used to develop the questions included in this study (see Table XIX). If Levinson et al. are correct, responses to these questions should reflect the struggle inherent in the process of integrating opposing feminine/masculine characteristics. In concrete terms, the masculine/feminine responses of the men in this study might be expected to be about evenly distributed between the categories of "agree" and "disagree."

With the exception of one question that asked about working with women or having a woman boss, the majority of ex-offenders gave responses that affirmed masculine rather

It is quite likely that the responses to this question were influenced by the fact that the personal interviews were conducted by a woman who clearly was in charge of the situation and who had expressly asked for the men's cooperation. In this case, the situational factors of the interview may sufficiently confound the responses to the question to render them of questionable accuracy. 
TABLE XIX

THE FEMININE/MASCULINE POTARITY IN MID-LIFE

$\begin{array}{cccc} & \text { Ex-offenders* } & \text { Inmates } & \text { Ex-Offenders } \\ \text { Questions } & \mathrm{N}=19 & \mathrm{~N}=30 & \text { Retrospective }\end{array}$

a) I can undertake long, grueling work and endure severe bodily stress without quitting.

$\begin{array}{lrrr}\text { Agree } & 11(588) & 14(478) & 17(898) \\ \text { Uncertain } & 2(118) & 7(238) & 1(58) \\ \text { Disagree } & 6(328) & 9(308) & 1(58)\end{array}$

b) A man's first responsibility is to provide for his family's financial and physical well-being.

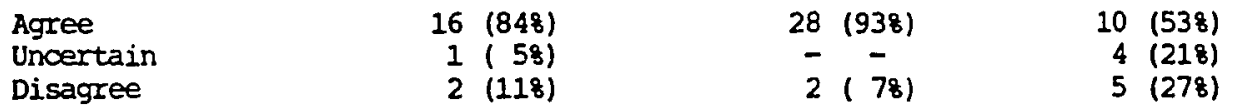

c) I can do nearly anything as long as I put my mind to it.

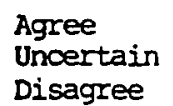

d) If I am part of a group, we usually get things

done.

$\begin{array}{lrl}\text { Agree } & 15 & (798) \\ \text { Uncertain } & 1 & (58) \\ \text { Disagree } & 3 & (168)\end{array}$

Disagree

e) Others usually do what I want them to do.

$$
\begin{aligned}
& \text { Agree } \\
& \text { Uncertain } \\
& \text { Disagree }
\end{aligned}
$$

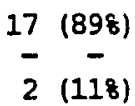

$\begin{array}{rr}26 & (878) \\ 2 & (78) \\ 2 & (78)\end{array}$

$14(748)$

2 (118)

3 (168)
19 (638)

6 (208)

5 (178)
12 (638)

2 (118)

5 (278)

(CONTINUED) 
TABLE XIX (CONTINUED)

f) If I want to do $m y$ work well, I can't let my feelings interfere.

$\begin{array}{lrl}\text { Agree } & 12 & (638) \\ \text { Uncertain } & 2 & (118) \\ \text { Disagree } & 5 & (278)\end{array}$

20 (678)

$1(38)$

$10(538)$

(118)

9 (308)

6 (328)

Disagree

g) I don't mind working

with women, but I

wouldn't want to

have a woman boss.

\begin{tabular}{lrrrrr} 
Agree & 2 & $(118)$ & 6 & $(208)$ & $9(478)$ \\
Uncertain & 2 & $(118)$ & - & - & $2(118)$ \\
Disagree & 15 & $(788)$ & 24 & $(808)$ & $8(428)$ \\
\hline
\end{tabular}

Observed differences between men 35-59(61) and men 40-50 were negligible. 
than feminine role characteristics. The majority of exoffenders affirmed 1) their ability to undertake long grueling work; 2) their responsibility in supporting their families; 3) their ability to overcome obstacles with will power; 4) their leadership capabilities as well as their concessions that feelings would interfere with quality work performance.

On the whole, neither ex-offenders nor inmates, nor the ex-offenders during their last incarceration differed notably in their responses to feminine/masculine questions. Members of all three groups showed a somewhat greater inclination to affirm masculine rather than feminine values in themselves, as shown in Table XIX.

Levinson et al. (1978) discuss the concept of mentoring in conjunction with the mid-life integration of feminine and

\footnotetext{
Note that relatively fewer inmates (478) than exoffenders (638) agreed with the statement "Others usually do what I want them to do." Perhaps feelings of personal power are somewhat reduced during incarceration, for obvious reasons.

Recalling how the felt during their last incarceration, considerably nore of the ex-offenders than currently incarcerated inmates stated that they could endure long grueling work. But during their last incarceration, these men were at least five years younger than those currently in prison. Hence, decreased abilities to endure physically grueling work may be a function of the documented (Tamir, 1982: 48) decline in physical health at mid-life, rather than a particularly strong endorsement of masculine values.
} 
masculine values. One of the results of this newlydeveloped balance between feminine and masculine values is that being a mentor becomes easier and more rewarding. The heretofore rigid "division between work (thinking, performing, achieving) and personal relationships (loving, caring, fostering development)" is relaxed for the middleaged man who now

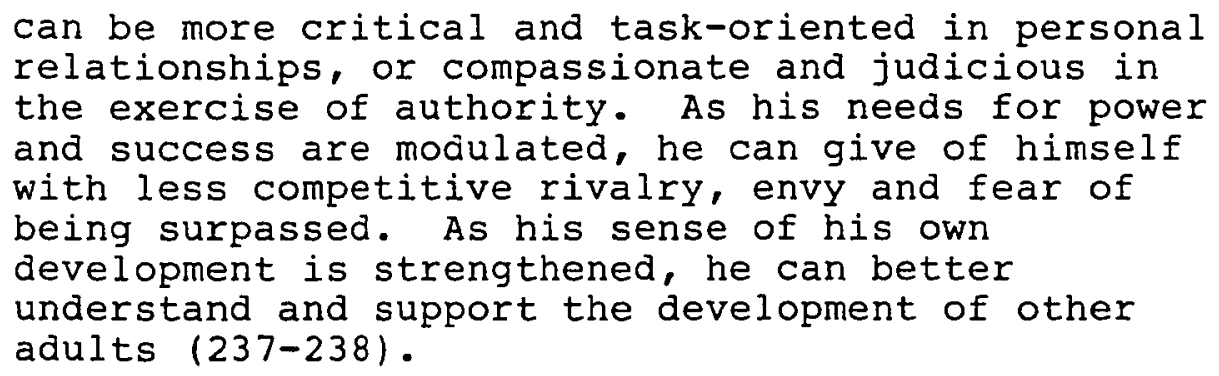

Most of the ex-offenders and inmates endorsed mentoring as an important function in their lives (see Table XX). But retrospectively, fewer of the ex-offenders agreed that being a mentor was important to them.

THE ATTACHMENT/SEPARATENESS POLARITY AT MID-LIFE

Levinson et al. (1978) use the term attachment to mean everything that connects the person and his environment. Thus,

to be attached is to be engaged, involved, needy, plugged in, seeking, rooted... . I am attached when I am trying to adapt to, participate in, or master the external world (239). 
TABLE $X X$

THE IMPORTANCE OF BECOMING A MENTOR AT MID-LIFE

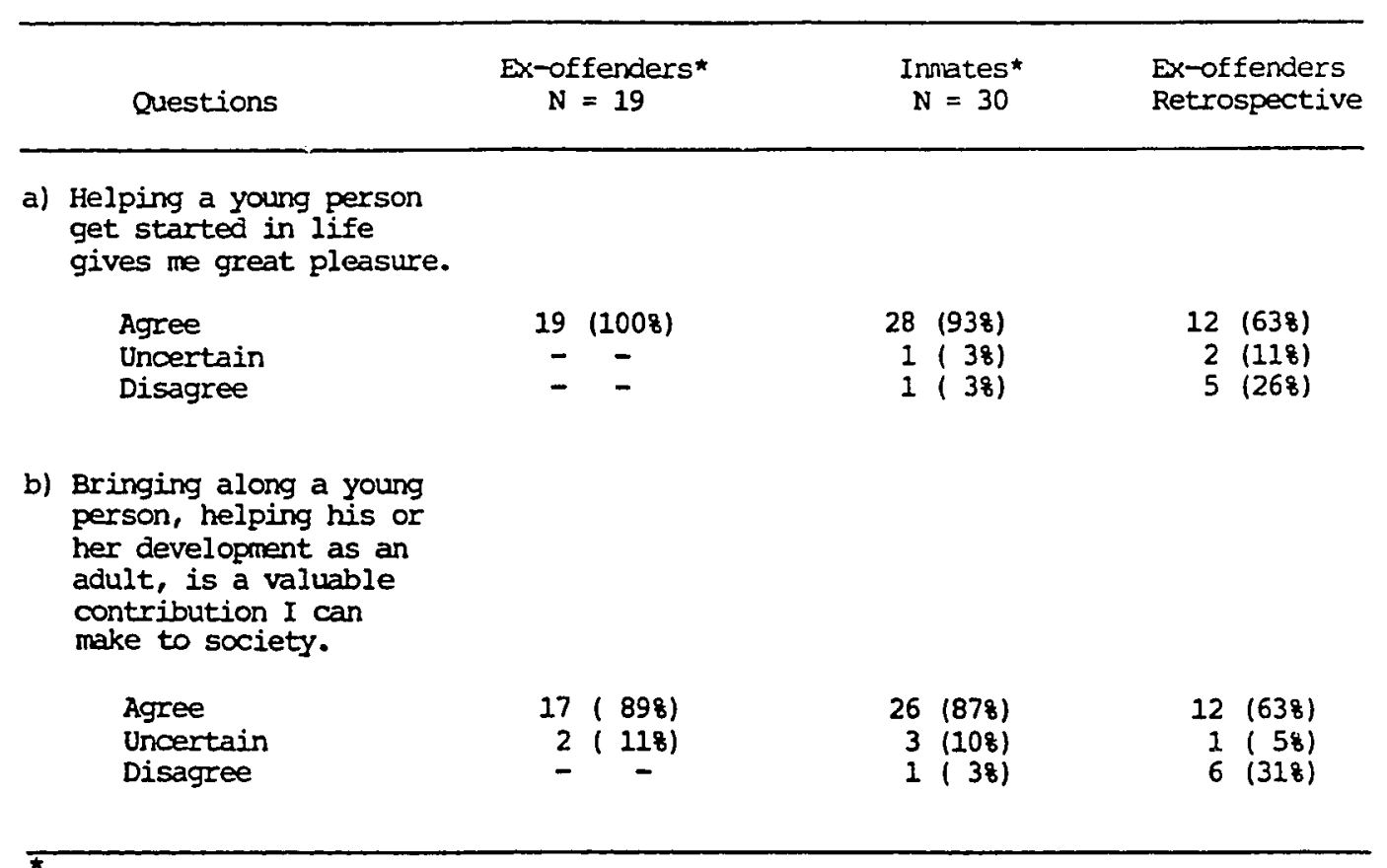

Observed differences between men 35-59(61) and men 40-50 were negligible. 
"Separateness," on the other hand, does not mean isolation or aloneness, for a person can be alone and at the same time be actively engaged in the surrounding world. Instead, separateness, according to these authors, refers to a person's involvement primarily with his inner world.

His main interest is not in adapting to the 'real' world outside, but in constructing and exploring an imagined world, the enclosed world of his inner self.

While this sort of separateness fosters individual growth, it can be harmful when carried to an extreme, as illustrated by the separate and private world often entered by the schizophrenic.

As with the other mid-life transitional tasks, the Attachment/Separateness polarity must be confronted and reintegreted at each developmental transition. Levinson et al. (1978) note that in early adulthood, the balance between attachment and separateness moves strongly in the direction of attachment at the expense of separateness.

During the twenties and thirties, a man is tremendously involved in entering th adult world and doing his work for the tribe... . It is difficult to find time for separateness--for solitude, play and quiet self-renewal (241).

However, during mid-life, a more equal weighing of the two forces becomes necessary when the cumulative impact of experience reminds men that favoring attachment at the 
expense of separateness does not guarantee success, eternal health and happiness. No matter how much effort is spent in the pursuit of external success, it is hollow if it is not accompanied by internal growth.

During the mid-life transition, so say Levinson et al. (1978), a man needs to reduce his heavy involvement with the extneral world and begin to listen to his inner self. He will find it necessary to ask himself, "What do I really want?" or "How do I feel about my life?" As the mid-life transition progresses, the "self acquires an importance for him roughly equal to that of the external world" (214-242). The developmental task, then, is to find a "better balance between the needs of the self and the needs of society." In reference to this mid-life change, a 47-year-old exoffender offered this thought: "I . . went from a scared person, afraid of not having enough security [material things]--from being motivated by fears to motivating myself to achieve an ideal self" (EO 12).

In their choice of self-respect and accomplishment as the two most important values (see Table XV), Tamir's middle-aged, general population men illustrated quite well the dual importance of attachment and separateness in midlife. The ex-offenders and the inmates, on the other hand, more often chose attachment values rather than separateness values, inasmuch as their choices were security, 
accomplishment, and warm relationships with others.

The men in this study were asked to respond to three questions designed to address the Attachment/Separateness mid-life developmental tasks. As middle-aged men try to balance the push and pull of the Attachment/Separateness forces, one would expect that an individual's responses would also be about equally divided between Attachment and Separateness concerns.

The responses of the ex-offenders, as well as those of the inmates, were in the direction of greater separateness, although not markedly so (see Table XXI). The greatest rejection of attachment, by both the ex-offenders and the inmates, was registered in response to the question, "I am so caught up in everyday concerns that I rarely sit back and reflect on what's going on." Fourteen (748) of the exoffenders and $24(80 \%)$ of the inmates disagreed with this statement. This response, for the inmates at least, could simply reflect a lack of things to do in prison.

The closest balance between attachment and separateness was reflected in the retrospective accounts. In reflecting upon his change from a criminal career to straight life, one

Most of the values listed in Table XV are representative of attachment aspects as Levinson et al. might interpret the term. 
TABLE XXI

THE ATTACHMENT/SEPARATENESS POLARITY AT MID-LIFE

$\begin{array}{cccc} & \text { Ex-offenders* } & \text { Inmates* } & \text { Ex-offenders } \\ \text { Questions } & \mathbf{N}=19 & \mathbf{N}=30 & \text { Retrospective }\end{array}$

a) I am so caught up in everyday concerns that I rarely sit back and reflect on what's going on.

$\begin{array}{lccrcc}\text { Agree } & 5 & (268) & 3 & (108) & 9 \\ \text { Uncertain } & - & - & 3 & (108) & - \\ \text { Disagree } & 14 & (748) & 24 & (808) & 10\end{array}$

b) Without people or things to keep me busy, I usually feel

lost.

\begin{tabular}{|c|c|c|c|}
\hline Agree & $6(328)$ & $10(338)$ & $8(438)$ \\
\hline Uncertain & 3 (168) & $3(108)$ & $1(58)$ \\
\hline Disagree & $10 \quad(538)$ & $17(578)$ & $10(528)$ \\
\hline
\end{tabular}

c) To own things and to be seen as successful are most important in my life.

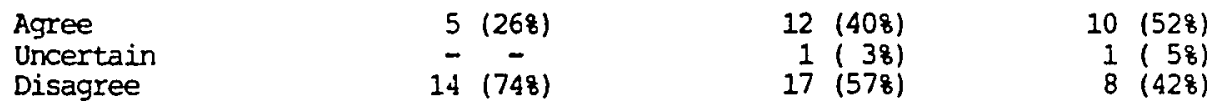

Observed differences between men 35-59(61) and men 40-50 were negligible. 
of the ex-offenders alluded to the detachment from his previously all-important reference group: "It was fear that I would be locked up again. Before, I didn't care, wasn't aware. I began to care more about myself and more for people, the public in general and what they thought of me. I used to only care about my peer group" (EO 19). One of the inmates offered a statement that bespoke his attachment to external aspects of life: "What's important to me when I get out--100 dollar bills, Cadillacs and 16-year-old girls" $\left(\begin{array}{ll}0 & 17\end{array}\right)$.

THE DREAM OR LIFE GOAL AND THE MID-LIFE TRANSITION

Most men in the Levinson et al. study had a discernible dream or life goal. This dream, Levinson et al. (1978) argue,

derives in part from normal omnipotence fantasies of early childhood, when the distinction between wish and reality is poorly established. [It generally] contains an imagined self having a variety of goals, aspirations and values . . . and [involves the man] pursuing his quest within a certain kind of world. A man's dream is his personal myth, an imagined drama in which he is the central character (246-248, emphasis in original).

This dream represents a youthful illusion of how a young man sees himself living the good life. It is the illusory aspect that comes under attack during the mid-life transition. A man may discover that even after having been 
successful in attaining his dream, this does not necessarily mean that he will live happily ever after, that he is invincible, or that the result of pursuing his dream is either a total success or a total failure. The task of the mid-life transition is to modulate the extreme, illusory demands of the dream. The desired outcome of this transitional task is that the dream no longer has absolute power

\footnotetext{
- - to make its demands less absolute; to make success less essential and failure less disastrous; to diminish the magical-illusory qualities.
}

Levinson et al. (1978) reported that while most of the men in their study had a discernible dream, there were nevertheless variations among the men in the four occupational groups (245).

The early Dream played an important part in the
choice of occupation for many biologists and
novelists. Only a few of the ten executives,
however, were impelled by a youthful Dream, [and
while most of the workers] had a Dream relating to
occupation.. - they chould not live it out (95).

The men in this study were asked whether or not they had formed an identifiable dream in their earlier years. The majority of ex-offenders (63\%), as well as inmates (608), said that they had had no goal (see Table XXII). While more than half of the ex-offenders agreed that their Iife without a dream lacked purpose and meaning, only 388 of 
TABIE XXII

THE IMPORTANCE OF THE DREAM OF LIFE-GOAL IN MID-LIFE

\begin{tabular}{ccc}
\hline Questions & $\begin{array}{c}\text { Ex-offenders* } \\
\mathrm{N}=19\end{array}$ & $\begin{array}{c}\text { Innates* } \\
\mathrm{N}=30\end{array}$ \\
\hline
\end{tabular}

a) Starting in adolescence, many men report having a goal in mind in life that they

want to reach. They have a clear picture of how they are going to live their adult

lives. Do you have such a goal?

$\begin{array}{lrrr}\text { Yes } & 7 & (378) & 12(408) \\ \text { No } & 12 & (538) & 18\end{array}$

IF THE ANSWER WRS YES:

al) In order to achieve this life goal, all important choices must be made to fit the goal.

\begin{tabular}{|c|c|c|}
\hline Agree & $3(428)$ & $10(838)$ \\
\hline Uncertain & $\begin{array}{ll}2 & (288) \\
2 & (288)\end{array}$ & $\overline{2}(178)$ \\
\hline
\end{tabular}

a2) One can either succeed or fail at achieving one's life goal. There is no in-between.

\section{Agree \\ Uncertain \\ Disagree}

a3) To fail to reach one's life goal means to fail at life.

\section{Agree \\ Uncertain}

Disagree
1 ( 148)

$\overline{6}(\overline{868})$
4 (338)

$1(88)$

7 (588)

IF THE ANSWER WAS NO:

b) Without a life goal, my life

lacks purpose and meaning.

\begin{tabular}{|c|c|c|}
\hline Agree & $7(588)$ & $6(388)$ \\
\hline Uncertain & $1(88)$ & $-\quad-$ \\
\hline Disagree & $4(338)$ & $10(638)$ \\
\hline
\end{tabular}

$1(88)$

$\overline{11}(\overline{928)}$
-

$\overline{7}(1008)$ 
the inmates felt this way.

Several questions were asked of the men who had indicated having a dream in order to assess the extent to which the mid-life transitional task of loosening the illusory grip of the dream had been accomplished. Table XXII shows that the majority of ex-offenders disagreed with the statements which reflected absolute adherence to a dream.

Thus, for those ex-offenders who did have a dream, at mid-life this dream was not a force exacting total adherence. Apparently, the majority of ex-offenders had accomplished their mid-life transitional task as postulated by Levinson et al.

The inmates' responses suggested that the dream still had stronger pull, for 838 of the inmates who did have a dream agreed that "in order to achieve this life goal, all important choices must be made to fit the goal." Yet only one of them agreed that: "To fail to reach one's life goal means to fail at life." While many of the inmates viewed the dream as reachable if one meets its demands, they seem to consider quite realistically the likelihood and impact of failing this dream.

Several of the men in this study commented on their dreams. Individual ex-offenders reported dreams of wanting to be a famous athlete or entertainer, a successful 
criminal, a politician, or a police officer. The dream most often named by the inmates involved athletic achievement and being a successful criminal.

Yet, the more noteworthy finding from this inquiry about career criminals' dreams or life goals was the fact that relatively few of these men had any dreams or life goals at all. One of the ex-offenders commented that he " . was too involved with immediate survival to think ahead" (EO 19).

Some of the inmates who said that they did not have a dream as such reported instead having had diffuse wishes such as the one described by this inmate: "I wanted to Iive secure. I didn't want to pick shit with the chickens, just wanted to be good at what I did" (0 07), and another inmate stated: "Always wanted to live, have a good job, not have to worry about doing without" (0 29).

It must be noted that the ex-offenders and inmates, while reporting considerably fewer dreams than general population men, were about equally likely not to have had a dream or life goal (see Table XXII). Of those who had had a dream, the ex-offenders at mid-life appeared somewhat less caught up in the dream's demands than did the inmates.

\section{MID-LIFE CHANGE}

To this point, inferences have been drawn about the 
occurrence of mid-life changes on the part of ex-offenders and inmates. These surmises were based upon their responses to questions about a variety of life areas and internal psychological processes. In addition to asking general questions presumed to be related to the mid-life transitional process, this study also asked participants directly about certain changes that Tamir and Levinson et al. have identified as part of the mid-life transition.

The responses to these open-ended questions were recorded on the interview schedule and later analyzed to determine whether the respondents indicated that: YES, there was definitely change; YES and NO, there was perhaps some change; or No, there was no change compared with earlier times (see Table XXIII).

The majority of ex-offenders (89\%), as well as the majority of inmates (798) said yes, their middle-aged years were different from other times in their lives. Five exoffenders attributed the difference more or less directly to no longer being involved in crime. As one ex-offender expressed it, he ". . quit crime, quit serving time, quit getting in trouble with the law" (EO 01). Another noted the importance of no longer doing crime, but found that middle age was different for other reasons as well: "Yes, [once I had anl extended period of freedom, not just the lack of incarceration, mental freedom [or] not getting caught for 
TABLE XXIII

MID-LIFE CHANGE: SUMMARIZED RESPONSES TO OPEN-ENDEU QUESTIONS

\begin{tabular}{ccc} 
Questions & $\begin{array}{c}\text { Ex-offenders* } \\
N=19\end{array}$ & $\begin{array}{c}\text { Innates } \\
N=30 * *\end{array}$ \\
\hline
\end{tabular}

a) Did you find that your middle-aged years were different from other times in your life?

$\begin{array}{lrrrr}\text { Yes } & 17 & (898) & 23 & (798) \\ \text { Somewhat } & 1 & (58) & 1 & (38) \\ \text { No } & 1 & (58) & 5 & (178)\end{array}$

b) Overall, do you think that you have changed during or after your middleaged years?

\begin{tabular}{|c|c|c|}
\hline Yes & $18(958)$ & $24(838)$ \\
\hline Somewtzat & $-\quad-$ & - - \\
\hline No & $1(58)$ & $5(178)$ \\
\hline
\end{tabular}

c) Since middle age, so you view the future äifferently?
Yes
15 (798)
$25(868)$
Somewhat
$1(58)$
$\overline{4}(148)$
No
3 (168)

* The oiserved differences between men 35-59(61) and men 40-50 were negligible. One innate did not answer these questions. 
something, [I] began to question both myself and society, [which is] something I had not done before. [I felt a] concern about how much time I have left, [I experienced] a maturity in general terms, a change in [my] value system" (EO 16).

While termination of criminal behavior patterns was frequently cited as at least one of the reasons for experiencing mid-life differently, most ex-offenders named attitudinal and personality changes as well. For example, the men described their middle years as "more stable, more constructive, and more fulfilling" (EO 07), as involving "more questioning" (EO 04), as including "doing something positive" (EO 09), as allowing for "greater willingness to be alone and being more serious" (EO 04), as a time in life that required "needing less excitement, where going out and partying doesn't mean a whole lot to me any more" (EO 20). Roughtly the same proportion of inmates as ex-offenders felt that mid-life had been different for them than other times in their lives. As noted above, about one-fourth of the ex-offenders attributed this difference to no longer doing crime. The inmates most frequently named declining physical health and increasing rationality as reasons for experiencing middle age differently from other times. For example, one described his decline in physical prowess in these words: "Sure, this is different now. Well, I was 
able to do more things when I had youth on my side. Now I have to be careful about my health, what I eat" (0 29).

Many inmates made reference to thinking more rationally and acting less impulsively. One 43-year-old inmate put it this way: "Yes, you know, I am able to reason better than when I was younger, [I am] more mellow. [I have a] different perception. Things are more clear to you" (0 05). Another inmate, aged 45, concluded: ". . . Now it's a whole new ballgame, not just to react [but] to stop and think" (0 11).

A closely-related question asked: "Overall, do you think you have changed during or after your middle-aged years?" Those who responded affirmatively were asked to describe how they thought they had changed. Fully 958 of the ex-offenders acknowledged having changed during or after mid-life as did $83 \%$ of the inmates.

The reasons given for the mid-life changes included thinking differently or more rationally, valuing relationships more, feeling more responsible, being more patient, listening more, caring more about people and things, mellowing, liking oneself better, being disillusioned with oneself, and gaining more strength and becoming more self-assured. There were virtually no differences in the reasons given by the ex-offenders and the inmates for the change. 
One of the ex-offenders who reported not having changed during mid-life said: "No, I [have] always been kind of ambiguous; I'd like to do something" (EO 07). This statement came from a man with a college degree, who, at the time of the interview, was employed part-time as a counselor in an alcohol rehabilitation center. He was quite unhappy with his life situation. rie desperately wanced a woman friend--someone he could care for and who would care for him, in the absence of which he was afraid he would resume his heroin habit.

Several of the inmates indicated that they had not changed during mid-life. A 59-year-old inmate, for example, had this to say: "No, I've been Leroy ever since I've known Leroy--the only thing you are [is] older" (0 10). A 42year-old inmate admitted, "I think that's the problem; I haven't changed. Certainly, I haven't gotten any wiser, I don't think" (0 03).

\section{SUMMARY}

The developmental process outlined in Levinson's conceptualization of the transitional period is called individuation. It involves reappraising the past and, based

This man was recently arrested for theft. He was reportedly stealing to support his heroin habit. 
on this reappraisal, planning for the future. According to Levinson et al., individuation during the mid-life transition centers on four aspects of a man's life: age, power, gender role, and the concept of self in society. The mid-life transition requires that a man find a new balance between opposing forces in each of the four life areas. Thus, as far as age is concerned, the man at midlife finds that the polar opposites of Young and old confront each other with almost equal force, making it necessary that he find a new way to integrate them in order to create a viable new life structure for himself. The middle-aged male confronts a similar transitional task in having to reintegrate the polarities of Attachment/Separateness (concept of self in society), Destruction/Creation (power), and Masculine/Feminine (the gender role).

The results of this study have been discussed as they apply to Levinson's developmental concepts. It was argued that the process of individuation encompasses setting up a new life structure, which means leaving behind aspects of the old one. Often, particularly in conjunction with the mid-life transition, this new life structure is characterized by significant external changes such as divorce, or a change in occupation or life style.

The men who were the central focus of this 
investigation were selected because they had made significant external changes in their lives, i.e., they hac. seemingly ended a career in crime and had begun a straight life. Perhaps this external change is accompanied by other aspects of the individuation process. If so, new insight might be gained about criminal career termination.

In general, the ex-offenders, as well as the inmates, who took part in this study acknowledged that mid-life was different for them than earlier times in their lives. For many, this meant questioning their past and looking at the future in new ways. How then did the ex-offenders and inmates deal with the tasks of confronting and reintegrating each of the four polarities?

For the Young/old polarity, the majority of exoffenders said they were not overly concerned about their disappearing youth. Yet it should be noted that a fair number of ex-offenders did voice concern about their disappearing youth, about the time they have left in this Iife, and similar issues.

Regarding the Destruction/Creation polarity, the majority of ex-offenders reported that they did not feel that they had failed in their responsibilities toward those who are closest to them. They believed that any misfortunes they had experienced in their lives were largely the result of unfortunate flaws in themselves rather than in others. 
Their responses to the Masculine/Feminine questions showed that more of these men affirmed masculine rather than feminine values. Hence, the majority of them affirmed that they could undertake long, grueling work without quitting, etc. Thus, the masculine gender identification for middleaged ex-offenders was fairly strong.

Responses to the Attachment/Separateness questions indicated that the majority of ex-offenders leaned in the direction of separateness and away from attachment. More than two-thirds of them said that they do sit back and reflect on what is happening in their lives.

Unlike the majority of ex-offenders, the inmates tended to be concerned with Young/old matters. They said that they often think about their disappearing youth and about how much time they have left in this world.

Most of the inmates admitted their own and others' destructiveness. Also, masculine values received endorsement from the majority of them. The inmates' responses to Attachment/Separateness questions paralleled those of the ex-offenders. On balance, the ex-offenders and inmates resembled each other in matters of mid-life development.

What shall we make of these results? How well do career criminals' maturational paths resemble those of straight men? Are there aspects of adult development that 
distinguish the middle-aged ex-offender from the middle-aged inmate? How well does the adult developmental model serve to illuminate changes in criminal behavior? These and other questions will be addressed in the concluding chapter. 
CHAPTER FIVE

CONCLUSIONS

This concluding chapter includes a brief recapitulation of the purpose and design of this study as well as some notes on its limitations.

The usefulness of the theoretical framework of adult development for the explanation of desistance from crime will be examined. The major focus will be on a comprehensive description of the middle-aged ex-offender, with special attention given to his similarities and dissimilarities with middle-aged general population men and current inmates.

In addition to describing the middle-aged ex-offender, an attempt will be made to identify possible social and personal characteristics that can be linked to desistance from crime at middle age, i.e., to tentatively identify ingredients of maturational reform.

The original question leading to this study was straightforward: Why do many criminals appear to stop committing crimes when they get older? This, of course, was not a novel question. One of the earliest investigations along these lines was conducted by quetelet in 1833 . Since that time, the age-crime relationship has been noted by many 
different authors (Glueck \& Glueck, I930; Bromley, 1974;

Riley and Foner, 1968; Cormier et al., 1950, 1961; Rubin, 1984; McCreary \& Mensh, 1977; Greenberg, 1983; Seiden, 1981; Rowe and Tittle, 1977; Hoffman \& Beck, 1984). While this question suggested itself from a mere glance at the annual FBI arrest reports, the crime-age relationship quickly turned out to be considerably more complex than these official figures suggested. A closer look at the data showed, for example, that the relationships varied widely with the type of crime under consideration (Greenberg, 1983; Bromley, 1974).

The strongest association which was found to exist between increasing age and decreasing criminal behavior was for predatory or garden variety crimes, including the majority of offenses identified by the FBI as Index Crimes. The question then became: Why do some of those who commit burglaries, robberies, rapes, etc., appear to desist from those acts as they get older?

The area of concern was further narrowed to those men who had committed many crimes, who by middle age had spent a good part of their lives in lawbreaking and in dealing with the consequences of their criminal activities. In short, these were men who had made a career of crime. Career criminals were chosen for two reasons primarily. First, findings from recent studies which have shown that a 
relatively few felons are responsible for a disproportionately large number of garden variety crimes (Petersilia et al., 1978; Chaiken \& Chaiken, 1982) have prompted a number of research efforts designed to learn more about these men (Peterson et al., 1981; Petersilia et al., 1978, 1980; Moore et al., 1985). Thus, it was reasoned that a study of desistance from crime for career offenders could be expected to yield a greater return with respect to potential crime reduction than a study of desistance from crime for the less criminally-active offenders.

secondly, if it. could be shown that career offenders do, in fact, change, not only in terms of a switch in income-generation, but also in terms of lifestyle, then maturation on the part of the less serious offenders might be assumed to occur with even greater likelihood.

Criminology had little to offer in the search for theoretical guidance. Most criminological theorizing centered on questions of etiology and not on maturational reform, or even on desistance from crime. The theory of adult development set forth by Levinson et al. ultimately provided the most useful theoretical framework to account for age-related changes in criminal behavior. The following explanation for mid-life desistance from crime was thus constructed using Levinson et al. as a basis.

At mid-life men go through a developmental phase called 
the mid-life transition. This transition (see chapter I for a detailed account) involves identifying and relinquishing those aspects of the past that are considered negative and replacing them with more positive ones. It is in the course of this transition that men are more likely to attempt to bring about major changes in their lives than at any other time. Desistance from crime can be viewed as a mid-life change growing out of mid-life transitional processes in men.

The following questions about the relationship between mid-life development and desistance from crime came to mind: (1) do the mid-life experiences of ex-offenders and inmates differ from those of general population men? (2) Do the mid-life experiences of ex-offenders differ from those of inmates? (3) Are there specific mid-iife experiences that are 1 inked to desistance from crime?

In part due to considerable uncertainty about actually being able to locate former career offenders who had been free from any form of correctional supervision for at least five years, and in part because of the somewhat tenuous link between desistance from crime and the theoretical framework, the research was conceived of as exploratory rather than hypothesis-testing.

The methodological limitations of the sampling procedures used here clearly restrict the generalizability 
of the findings. The small samples and the descriptive nature of the data analysis do not permit the testing of specific hypotheses, nor can the information be used for predictive or policy purposes. On the other hand, it can be argued that evidence which tentatively identifies changes in the areas of work, social relations, and personal well-being (areas which seem to comprise elements of maturational reform in the career offenders) is well worth assembling. While the concept of maturational reform has frequently been invoked by criminologists to explain desistance from crime, little is known about its ingredients or how they combine to effect desistance in the midale-aged criminal.

THE EX-OFFENDER AT MID-LIFE: A COMPREHENSIVE PICTURE

Chapters II, III, and IV offered descriptions of the

The decision to include current OSP prisoners in a study on desistance from crime deserves some comment. There were several reasons for doing so, some theoretical, others practical. (1) As anticipated, only a small number of ex-offenders who fit the study's criteria for inclusion could be located. Therefore, the inclusion of inmates of like age and criminal background provided a greater information base for the examination of maturational processes among career criminals. (2) The inclusion of innates would permit comparing them to the ex-offenders on a comprehensive array of social and personal characteristics which may be linked to desistance from crime. (3) If, in fact, ex-offenders and inmates share mid-life transition experiences with general population men and if those experiences generally reflect the postulations of Levinson et al., this would lend support to Levinson's (1978) rather than Dannefer's (1984) theoretical contentions. 
ex-offenders and inmates in the areas of criminal and noncriminal work activities, social relationships, and personal well-being. In the following pages, the findings reported in those chapters will be combined in order to present a complete description of ex-offenders as they emerged from this study.

The average age of the ex-offenders at the time of the interview was 46 years. A number of them had some college education, had been employed in white collar or professional occcupations, and had upward of $\$ 20,000-a-y e a r$ incomes. It was most common for ex-offenders to have found work within the criminal justice system. The remainder listed their occupations as cook, mechanic, dishwasher, sales representative, and janitor. Most ex-offenders indicated deriving at least some satisfaction from their work, even though many said that they considered changing jobs. But the likelihood that the ex-offenders would return to crime appeared quite low. Instead, most of the men asserted that they intended to continue with their straight lives.

Two men were employed as parole and probation officers; several were involved with nonprofit ex-offender organizations, which, save for one, were well-established organizations; two men worked as drug and alcohol rehabilitation counselors, one full-time and the other part-time; one was a trial assistant for an urban public defender's office; and yet another worked as a crime prevention specialist. Two men were self-employed. One owned and operated an $\$ 80,000$ truck, and the other owned a janitorial service franchise. 
As for their criminal backgrounds, four-fifths of the ex-offenders began their life in crime as youths; they were generally first arrested at about age 15. Most of the juvenile offenses involved property crimes; fewer than onethird of these men committed offenses against persons, and a small number were involved with drugs. In adulthood, these persons were involved on the average in a dozen arrests, five felony convictions, and four jail and three prison terms. During their last incarceration, most of the exoffenders were in their mid-thirties. Stated differently, most of the ex-offenders in this study had spent 20 years between their first arrest and their last incarceration. Petersilia et al. (1978) charted virtually identical career paths for the 49 men who participated in their study of armed robbers:

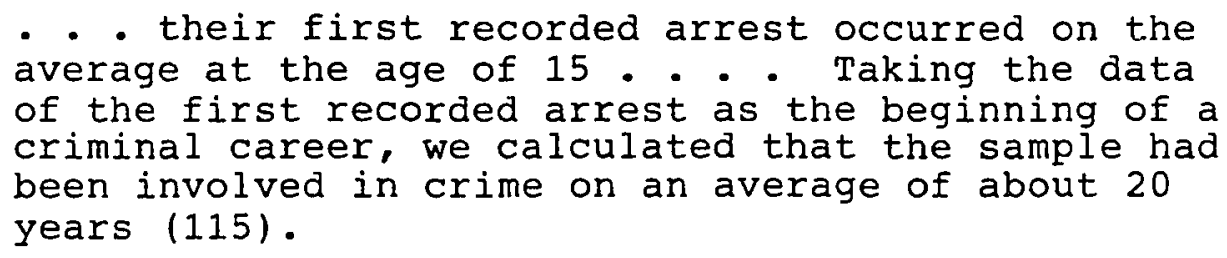
of the first recorded arrest as the beginning of a criminal career, we calculated that the sample had been involved in crime on an average of about 20 years (115).

The men in this study were asked whether their careers in crime had been successful, to which they overwhelmingly responded in the negative. One of the ex-offenders who summed up his criminal career as "very successful," remarked: "I always made lots of money, but I also had a high profile and got caught" (EO 15). By middle age, most 
men had come to the firm conclusion that their criminal work life had not been successful.

Social relationships in the lives of middle-aged exoffenders also form an important part of the comprehensive picture. At the time of the interview, the majority of exoffenders were married and said that they were generally satisfied with their marriages. Most of them reported that both spouses benefitted equally from the relationship, although they saw it as their responsibility to provide for the financial and physical well-being of their families. Probably not unlike other married men, the ex-offenders did report that there had been problems in their marriages on occasion. The majority admitted not being as good husbands as they thought they should have been, but even so, the majority rejected the notion that they might have failed in their responsibilities toward those who are closest to them. Overall, by middle age, marriage had become an important part of the ex-offenders' lives. Four out of five ex-offenders were fathers. Most reported deriving satisfaction from parenting, even though they did not always perform as well in their role as they wished they had. Levinson's concept of "mentoring," i.e., of helping a young adult get started in life is related to parenting. Almost all ex-offenders agreed that they derived great pleasure from this activity and considered it to be a valuable 
contribution that they could make to society.

Most of the ex-offenders felt socially connected, meaning that they thought people liked them, cared about them, respected them, and would help them if need be. But in spite of this subjective assessment, two-thirds of them said that they would like to have more friends and that they had either few or none at the present time. severai reported a qualitative mid-life change in their views of friendship. In the words of one man: "r=al friends are more important [now]; just people to hang out with are less important" (EO 10).

At middle age, the majority of ex-offenders reported increased concerns about their physical well-being, even though most of them said that they felt healthy enough to carry out the things they wanted to do. Most reported few problems with alcohol or drug use. In matters of selfesteem, the ex-offenders said that they felt of equal worth with others, although they reported occasional feelings of depression and of being psychologically immobilized.

On the whole, lack of psychological well-being did not

Thinking back to before their criminal career termination, the majority of ex-offenders reported feeling considerably less socially connected than they are today. Yet four out of five recalled having no desire for more friends, even though almost nine out of ten said that they had either none or few friends with whom they could talk. 
seem to loom large in the lives of the majority of exoffenders.

Generally, the middle-aged ex-offenders appear quite well adjusted to straight life. They are married and have children. Their families, for whom they feel responsible, are important to them. They earn reasonably good money, belong to organizations, show concern for their physical well-being, and seem to feel psychologically healthy. But how closely do they resemble middle-aged general population men on the above-mentioned characteristics?

While most ex-offenders, like most middle-aged general population men, were married and fathers, they had somewhat higher levels of formal education than the men in Tamir's sample.

Even though reported mean levels of satisfaction from work at mid-life were the same for both sets of men, the exoffenders were somewhat more inclined to entertain thoughts

The ex-offenders reported good physical health during their last incarceration, but did recall having had psychological, alcohol, and drug problems. The exoffenders were in better physical health near the end of their criminal careers than they reported at the time of the interviews, but verbalized indications that they were lacking psychological weli-being at the earlier time. Today, about 21 years later, they claim more health $\star \star$ problems but are in better psychological shape.

Tamir (1982) reported that 478 of the men in her study (aged 35-59) had no college education. The same was true for only 428 of the ex-offenders (26). 
of switching jobs. Perhaps those who experience long periods of noninvolvement in "straight" work will ultimately show restricted opportunities for regular work, with the result that middle-aged ex-offenders may find themselves working at a job they would rather trade in for another one. Or, perhaps the majority of ex-offenders had not formed conventional occupational goals early in their lives and may still be trying to decide what it is they really want to do in the way of earning a livelihood.

Both groups of men reported similar experiences with marriage and parenthood at mid-life, but the ex-offenders judged their skills as husbands and fathers somewhat lower than did the general population men. They also felt in greater need of friends. As several ex-offenders remarked during the interview, quitting crime also means giving up one's friends. Indeed, continuation of friendships with former crime partners was seen by them as a real threat to going straight and staying straight. By mid-life, many of the ex-offenders had left behind their friends from the past, which would be unlikely for many middle-aged general population males.

Growing older is accompanied by increased concern for one's physical health, regardless of one's status as exoffender or as a straight person. While middle-aged exoffenders and middle-aged nonoffenders felt equally good 
about themselves, more of the former reported being depressed and pychologically immobilized. However, this somewhat lower level of psychological well-being did not translate into greater reliance on alcohol or drugs.

Overall, middle-aged ex-offenders resembled middle-aged general population men in that both groups differed from men older or younger on many aspects of work, social relationships, and personal well-being. By implication, this means that they had undergone a change at mid-life. When asked directly about this matter, nearly all of the exoffenders said that they had, in fact, changed during midlife.

The pages to follow examine the extent to which the exoffenders' mid-life change occurred in accordance with the developmental processes postulated by Levinson et al. (1978)

THE MID-LIFE TRANSITION AMONG EX-OFFENDERS

As noted in Chapter IV, quantified comparisons between the ex-offenders and Levinson's men were not possible because Levinson et al. (1978) presented their findings mostly in narrative form (see Chapter I for notes on the methodology employed by Levinson et al.). While they did caution that their insights and generalizations were hypotheses in need of testing, they went on to assert that 
developmental periods were

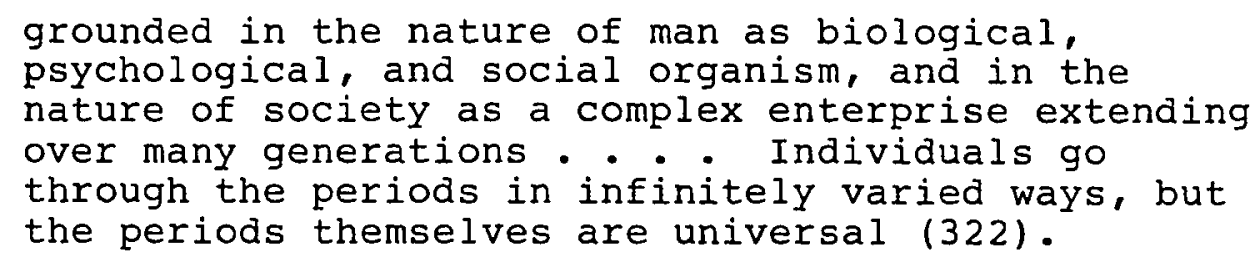

Accordingly, one should expect ex-offenders to have passed through the mid-life transitional period. More specifically, they should have completed the following three tasks: (1) review and reappraise the life period preceding the mid-life transition; (2) begin to change the negative aspects of early adulthood; (3) confront and reintegrate the four basic polarities: Young/Old, Destruction/Creation, Masculine/Feminine, and Attachment/Separateness.

The ex-offenders, simply by meeting the criteria for inclusion in this study, showed at least some evidence of having accomplished tasks (1) and (2). In addition, they provided a multitude of examples of changes in attitude, values and behaviors. For example, they reported having replaced negative behavior by "doing something positive" (EO 07); by "no longer wanting to hurt people" (EO 19); by "deferring gratification" (EO 12); by being more "mellow, understanding, listening, more patient" (EO 06); by being "more mature, having fewer illusions, [being] more willing to accept responsibility" (EO 16); by being "less aggressive and more responsive to people" (EO 19); and by "being more 
serious [and] less easily influenced by others" (EO 10). Many of these attitudes have been noted in the adult developmental literature as characteristic of middle age (Neugarten \& Gutman, 1968; Riley \& Foner, 1968; Jackson, 1974; Brim, 1975; Gould, 1978; Levinson et al., 1978; Seiden, 1981; Tamir, 1982).

As for the mid-life polarities which Levinson et al. postulate as part of the transition, the ex-offenders expressed concerns about getting older and how it affected their work life, social relationships, and person wellbeing. One ex-offender (EO 19) remarked that he felt much worse because of all the years he had wasted. Another ruminated for the first time about how his limited future would affect his children (EO 08). Still another regretted that his remaining years might not allow him to do the things he wanted to do (EO 03).

The ex-offenders were also concerned with achieving a new balance of feminine and masculine feelings in themselves. One 46-year-old individual (EO 11) stated that in setting goals for himself, he now considered whether they reflected his desire to be helpful and giving instead of just serving his own needs. Another admitted to having newly-discovered feelings of closeness and caring (EO 02), while yet another said he understood himself much better now since he became more concerned about people and things 
around him (EO 15).

Coming to terms with destructive and creative forces in mid-life was reflected in several remarks. Some men contemplated how the mistakes of their past would affect their future work lives (EO 03, EO 07), and others considered their change away from destructive actions and how it affected the way they felt about themselves (EO 11, EO 19).

The ex-offenders also attested to a gradual turning toward the self. For example, a 42-year-old man came to see the less enjoyable external aspects of straight life in light of what they do for his personal sense of well-being, i.e., he reported feeling good about himself, not because of external rewards or punishments, but because he managed to successfully negotiate the demands of straight life (EO 16).

On the whole, the study found that the majority of exoffenders offered information about changed values,

Analysis of the ex-offenders' retrospective responses indicates further support for their assertions that they are different today than they were during their last incarceration. Generally, they reported having felt less socially connected, lower self-esteem, more depressive feelings, and more symptoms of psychological immobilization, as well as having had relatively more problems with alcohol and drugs in their lives. Furthermore, they were more concerned with getting older than they are today and contemplated their own and others destructiveness more often. 
attitudes, and behaviors in addition to the external "marker" event ("a drastic change in job or occupation," Levinson et al., 1978: 61) of desistance from crime. What is most striking in reviewing the responses by the exoffenders is how much they resemble general population men in terms of their mid-life concerns and ways of dealing with them.

While it is possible that this apparent similarity is simply an artifact of the cross-sectional research design, it seems more likely that these findings may lend support to the notion that change in adulthood is relatively unaffected by social context. If this is the case, less weight may have to be given to Dannefer's (1984) contention that the adult developmental approach leads to psychological reductionism, which he calls the "ontogenetic fallacy" (109)

A look at the mid-life experiences of the inmates as compared with the ex-offenders should shed additional light on this matter. That is, if adult developmental processes are substantially affected by social contexts such as "straight" versus "criminal," then it would be reasonable to expect responses from those men who at mid-life are still incarcerated to be different from those who have since then gone straight and those who have never been caught in trouble for lawbreaking in the first place. 
THE MID-LIFE TRANSITION AMONG INMATES

This study produced two sets of "in-prison" responses. Information about work, social relationships, and personal well-being was obtained from 30 inmates and from 19 exoffenders who were queried about their last incarceration.

By and large, the inmates resembled the ex-offenders in age, racial distribution, and criminal backgrounds. However, the inmates had less formal education, were more likely to be divorced, were more likely to have been employed in blue collar jobs, had lower annual incomes, and tended not to belong to social or professional organizations.

Unlike the ex-offenders, these men did not say that they would prefer to be involved in a different line of work. Achievement, rather than warm relationships, was most frequently chosen as most important value by the inmates. They much more frequently endorsed the statement that all important choices must be made to fit one's life goal if it is to be achieved. Twice as many inmates judged their marriages as average or not too happy, and the same number said that they did not want more friends even though fourfifths indicated that they had either none or just a few

See Chapter II for a discussion of thw two groups' possible differential processing by the criminal justice system. 
friends.

In matters of well-being, fewer inmates than exoffenders reported having any particular health problems. The men resembled each other quite closely in psychological well-being; however, more of the inmates disclosed having problems with alcohol and drug use.

When the inmates were asked whether they had changed in mid-life, all but five said that they had. With one exception, their stated reasons for this change were virtually identical to those provided by the ex-offenders. The exception was that several ex-offenders attributed differences between their middle years and other times in their lives to the change from a criminal life to a straight life. The inmates, on the other hand, thought that a decline in physical health and an increase in rational thinking accounted for the difference.

One of the major differences between the inmates and the ex-offenders obviously was that the inmates' mid-life transition, if indeed it occurred, was not demonstrated by a "marker event." According to Levinson et al. (1978), for some men a drastic change marks the shift from one life structure to the next.

Other lives show no conspicuous change: life at 45 seems to be just as it was at 39. If we look more closely, however, we discover seemingly minor changes that make considerable difference. 
No matter how visible, drastic, or subtle the changes, these authors assert,

A man's life structure, we have found, necessarily changes in certain crucial respects during the course of his mid-life transition (61).

What evidence does this study provide to document a mid-life transition in incarcerated career offenders? Have the inmates gone through a mid-life reappraisal of their past? Several open-ended questions asked them to describe any changes in attitudes, values and behaviors they might have experinced in mid-life. They described several changes, such as being more rational now than in younger years $(004,005,011,012,020,025,030)$, more aware of the effects of physical decline $1001,023,024,026$, 0 29), as well as being more "mellow" (0 05), "kicked back" (0 10), "able to enjoy things, less impulsive" (0 25, 0 12), "less concerned with power" (0 24, 0 17), "more understanding" (0 20), and simply "more mature" (0 12). What about the mid-life transitional task of confronting and reintegrating the four basic polarities? More inmates than ex-offenders appeared to be concerned with issues related to "time-left-to-live" (Neugarten, 1968). Also, more inmates felt that they had failed in their responsibilities toward those closest to them and had destroyed their own possibilities. The mid-life transitional tasks concerning the polarities of 
Attachment/Separateness and Masculinity/Femininity were handled similarly by the ex-offenders and inmates in this study. Overall, the parallels between the middle-aged exoffenders and the middle-aged inmates seemed greater than the differences.

How should the various similarities and differences between the men in this study be interpreted? Before this question is answered, it should be reiterated that the terms "differences" and "similarities" are not used to refer to statistically-significant findings on individual indices or individual variables. Instead, findings of differences and similarities are based on overall patterns found among sets of possible responses.

When the most general conclusion leads, however tentatively, to the assertion that, by and large, exoffenders resemble inmates at mid-life and that both of those groups resemble general population men at mid-life, it would be difficult to assert that the necessary ingredient for looking alike in middle age is shared social context. Evidence provided by Tamir (1982) and Levinson et al. (1978) indicates that these middle-aged men look unlike either younger or older men in many aspects of life. Additional, tentative evidence suggests that the middle-aged ex-offenders looked different when they were younger and that the middle-aged inmates had apparently changed with age 
as well. Accordingly, it appears that age-related changes in men create a pattern of similarities among middle-aged men in spite of such differences as having lived in early adulthood as identified criminals versus having lived in early adulthood without such a label.

This finding of general mid-life similarity comes as something of a surprise. Even those authors who argue for shared life experiences within adult age groups seem to make allowances for age group differences for men who may

have suffered such irreparable defeats in preadulthood or early adulthood, and have been able to work so little on the tasks of the mid-life transition that they lack inner and outer resources for creating a minimally adequate life structure in middle adulthood (Levinson et al., 1978: 24).

Tamir (1982) cites a study by Andrews and Withey (1976) who note that persons who do not experience "normative lifecycle stages" show different age patterns than those persons who do. It would be difficult to argue that extensive criminal careers such as those displayed by the men in this study would lead a person through "normative life cycles." Hence, one could expect men with criminal life experiences to differ from general population men at mid-life. While academic research is not available to clarify this issue, a recent trade book by Nolen (1984) asserts that mid-life crises entail "a common feeling of discontent that cuts across all classes and social backgrounds." This rather 
broad sweep could presumably apply to the men in this study as well.

Before turning to an analysis of the differences, a brief remark about one rather striking similarity is in order. Middle-aged general population men, middle-aged exoffenders, and middle-aged inmates obtained almost identical average self-esteem scores. In other words, their subjective ratings of self-worth were seemingly uninfluenced by past or present criminal identifications. This finding is noteworthy particularly because the criminological literature has frequently linked low self-esteem to deviance, most notably to delinquent behavior (Jensen, 1980; Ferracuti \& deBrenes, 1975; Reckless \& Dinitz, 1972). Possibly, the lack of association between low selfesteem and adult career criminal's identity rests on definitional problems that have led several authors to question the low self-esteem delinquency connection (McCarthy \& Hoge, 1985; Dinitz \& Pfau-Vincent, 1982; Schwartz \& Tangri, 1965). On the other hand, it is possible that at middle age, with a rather firmly-set criminal identity, these men no longer compare themselves with straight people against whom their self-esteem might suffer; instead, they may contrast themselves with other career offenders and thus fare, on the average, as well or as badly as any general population male who evaluates himself in 
relation to other general population males.

AN ANALYSIS OF THE DIFFERENCES BETWEEN MIDDLE-AGED GENERAL POPULATION MEN, MIDDLE-AGED EX-OFFENDERS, AND MIDDLE-AGED INMATES

As noted in Chapter III, several of the differences between the men with and those without criminal experiences seem most easily explained by the effect of years of incarceration on opportunities in the realm of work and social relationships. There are, however, a few other differences that are less easily explained. For example, according to Levinson et al. (1978), general population men are more likely than not to have had a life goal since adolescence. This was not the case for either the exoffenders or the inmates.

This lack of goals or lack of purpose in the lives of identified criminals was noted as well in a study by Marks and Glaser (1980) who compared criminals, bikers, surfers, hippies, and straights. The criminals differed significantly from these other groups in "steadiness of life aims" and "lack of realism in plans for the future" (p. 189). Lack of occupational aspirations was also noted by Hirschi (1979) as important in delinquency causation.

Whether the lack of goals in adolescence predisposes a youth to become involved with delinquency or whether delinquent behavior disrupts the development of a goal is 
not clear. It is possible that for the men in this study, early economic survival imposed a day-to-day lifestyle of which life goals or dreams were not a part. One ex-offender who did not have a goal sąid "[I] was too involved with immediate survival to think ahead" (EO 19). An inmate put it this way: "Just wanted to get by and have a good time" $(0$ 02). Another said: ". - never could enjoy a teenage life. I started working when I was 13" (0 10). A look at the reasons which the men gave for first getting involved with crime showed that financial concerns were among those cited (see Table IV).

The ex-offenders shared with the inmates a difference from general population men in that those with criminal backgounds were more depressed and psychologically immobilized. The adult developmental literature contains numerous references to increases in psychological difficulties in middle-aged men (Lowenthal \& Chiriboga, 1973; Rogers, 1974; McCreary \& Mensh, 1977; Tamir, 1982). The men in this study, regardless of whether they had discontinued their life in crime or were still incarcerated appeared more depressed and psychologically immobilized than others. Incarceration apparently was not a crucial variable in self-assessed lack of psychological well-being, at least for these men.

Perhaps the mere existence of a criminal background 
weighs particularly heavily on these men during a time in their lives when reappraisal and assessment of the past become more important concerns than at any other time. or the ex-offenders and inmates may have psychological problems for different reasons. It may be that men who are incarcerated experience what Erikson $(1950,1982)$ has termed "stagnation," a state in which a person is unable to accept himself and his life and thus becomes incapable of changing. The result may possibly be psychological distress for this man, while the man who has changed from a criminal life to a straight life shows the effects of the psychological strains associated with such a radical change.

In summary, ex-offenders and inmates tended to resemble the middle-aged general population men, yet they were more likely not to have had an occupational goal in their lives. They were more depressed and psychologically immobilized, and particularly the currently-incarcerated men had considerably greater alcohol and drug dependency problems than the noncriminal males in mid-life.

While criminal background and state of incarceration did not appear to substantially alter or impede the middleage development processes, a closer look at some of the differences between those men who have made a seemingly radical work and lifestyle change and those who have not is order. 
The men who had changed away from well-established criminal careers had more years of formal education with associated higher annual incomes and employment in white collar or professional jobs. They were more likely to be married, to value warm relationships, and to seek out friendships.

The middle-aged incarcerated men tended to have had a twelfth-grade education or less and were employed in blue collar jobs with annual incomes below $\$ 20,000$. While they valued accomplishment, they did not indicate wanting to do other work. They were likely to be divorced, or if married, rated their marriages as not too happy or average. They did not generally belong to social or professional organizations and had no desire for more friends. Few reported problems with physical health, but tended to admit to alcohol and drug difficulties. At mid-life, they were concerned about getting older and about their own and others' destructiveness.

On the average, the ex-offenders had had several years more freedom than the inmates. It could conceivably be argued that less formal education, fewer skills, and lower earning power are simply the results of the inmates' having had less time in which to attain equal standing with the exoffenders. On the other hand, being divorced or having a barely average marriage relationship and no desire for 
friendships may quite possibly be a mere reflection of the state of their present incarceration. However, marriage and ensuing stability have been linked to successful adjustment to straight life (Curtis \& Schulman, 1984; Shover, 1982). It also seems plausible that in the course of the mid-life reappraisal, being incarcerated makes inmates more acutely aware of "time-left-to-live" and of human destructiveness, including their own.

The differences between ex-offenders and inmates that cannot be as easily explained by incarceration are alcohol and drug dependency. While there appears to be a welldocumented relationship between alcohol consumption and serious criminal behavior (Collins, 1981), inmates in the current study not only differed substantially from middleaged population men and from middle-aged ex-offenders, but also from the ex-offenders during their last incarceration. This study cannot determine whether difficulties in establishing a satisfactory life structure in early adulthood (for example, maintaining a marriage relationship, developing job skills, or getting an education) make it impossible for the inmate to shake his alcohol or drug dependency, or whether his alcohol and drug dependencies make it impossible for him to maintain the marriage, job, etc. Collins (1981) reviewed the literature on alcohol and crime, noting that the causal connection between serious 
crime and chronic drinking is not at all clear. It is also not clear why some men decrease their drug usage around age 40 (as reported by Drews, 1968, and by the ex-offenders in this study) and others do not.

Levinson et al. (1978) offer a description of how a man might find himself unable to change at mid-life:

A man at 40 may have been so beaten down by an oppressive environment, or so consumed in the struggle for survival, that he cannot make the developmental effort to give his life a new meaning - . He exists without hope or sense of value. Such men often die in their forties or fifties. The immediate cause of death may be illness, accident, or alcoholism. The basic cause is that neither he nor society can make a space for him to live, and he just withers away. There are too few available resources, external or internal, to sustain his life. Alternatively, he may live a long and trivial existence if he finds a protective environment and accepts a limited life (216).

Clearly, this dismal scenario may not apply to many of the middle-aged inmates, 86 percent of whom believe that life will be happier for them five or ten years from now.

\section{SUMMARY}

This study has shown that by and large career criminals go through a mid-life transition much the same way as do noncriminal men. Adult developmental theory has helped illuminate processes that accompany desistance from crime. At mid-life, some career criminals go through a reappraisal of their past, not infrequently a painful process associated 
with a lack of psychological well-being. As a result, some aspects of the past are relinquished and replaced with new ways of being.

In the case of the ex-offenders, these new ways of being mean changed attitudes, values and behaviors, with the most notable external change being that from criminal to noncriminal behavior. In the case of middle-aged inmates, these new ways of being also mean changed attitudes, values and behaviors.

Whether these behavior changes will ultimately include a changing away from criminal behavior could not, of course, be determined from this study. It appears likely that those inmates whose life circumstances at release do not converge to beat them down or consume their energies in the struggle for survival may well change away from crime. It also appears likely that finding and maintaining social relationships such as marriage, friendship, and belonging to social organizations, having academic and work skills, and shedding alcohol and drug dependencies seem to be involved in averting the convergence of factors that prevent change away from crime at mid-life. 
REFERENCES

Andrews, Frank M. and Stephen B. Withey. Social Indicators of Well Being: Americans' Perception of Life Quality. New York: Plenum Press, 1976.

Babbie, Earl R. Survey Research Methods. Belmont: Wadsworth, 1973.

Backstrom, Charles H. and Gerald D. Hursh. Survey Research. Chicago: Northwestern University Press, 1963.

Bazemore, Samuel G. Growing Out of Delinguency: The Adolescent Labeling Experience and Reform. Ann Arbor: University Microfilms International, 1982.

Becker, Howard and Blanch Greer. "Participant Observation and Interviewing: A Comparison," Human Organization, 16, 1957, pp. 28-32.

Best, Joel and David Luckenbill. Organizing Deviance. Englewood Cliffs: Prentice-Hall, 1982.

Biernacki, Patrick and Dan Waldorf. "Snowball Sampling: Problems and Techniques of Chain Referral Sampling," Sociological Methods and Research. Vol. 10 (2), 1981, pp. 141-163.

Bittner, Egon and Sheldon L. Messinger. "Curing the American Disease: The Violent Predator on the Unsafe Streets," Criminology Review Yearbook, Vol. 2, 1980, pp. $339-365$.

Braly, Malcolm. False Starts. Boston: Little, Brown \& Co., 1976.

Brim, Orville G. Jr. and Stanton Wheeler. Socialization After Childhood. New York: Wiley, $19 \overline{66 .}$

Bromley, Dennis B. The Psychology of Human Aging. 2nd ed. Harmondsworth: Pelican, 1974.

Chaiken, Jan M. and Marcia R Chaiken. Varieties of Criminal Behavior. Santa Monica: The Rand Corporation, 1982 . 
Collins, James J. Jr. "Alcohol Careers and Criminal Careers," in Drinking and Crime. Collins, James J. Jr., ed. New York: Guilford, 1981 .

Cordilia, Ann. The Making of an Inmate. Cambridge: Schenkman, 1983.

Dannefer, Dale. "Adult Development and Social Theory: A Paradigmatic Reappraisal," American Sociological Review, Vol. 49 (February), 1984, pp. 100-116.

Drew, Leslie R. H. "Alcoholism as a Self-Limiting Disease," Quarterly Journal of Studies on Alcohol. Vol. 29 (4), 1968, pp. 956-969.

Erikson, Erik H. Childhood and Society. 2nd ed. New York: Norton, 1963.

1982 . - The Life Cycle Completed. New York: Norton,

Ferracuti, Franco D., Simon Dinitz, and Esperanza A. deBrenes. Delinguents and Non-Delinguents in the Puerto Rican Slum culture. Columbus: Ohio state University Press, 1975.

Gibbens, T. C. N. "Borstal Boys After 25 Years," The British Journal?of?Criminology. Vol. 24 (1), $1984, \overline{\mathrm{pp}} .49-$ 62 .

Gibbons, Don C. Society, Crime and Criminal Careers. Englewood cliffs: Prentice-Hall, 1977.

Glueck, Sheldon and Eleanor Glueck. Later Criminal Careers. New York: The Commonwealth Fund, 1937.

Gould, Richard L. Transformations. New York: Simon and Schuster, 1978 .

Greenberg, David F. "Age and Crime," in Encyclopedia of Crime and Justice. S. Kadish et al., eds. New York: MCMillan, 1983.

Hare, Robert D. "Psychopathy and Violence." Paper presented at the symposium on violence and the violent Individual. 12th Annual Symposium of the Texas Research Institute of Mental Sciences, Houston, 1978. 
Hirsch, Andrew von. "Issues in Sentencing Offenders to Longterm Confinement," in Confinement in Maximum Custody. Wood, D. and K. Schoen, eds. Lexington: Heath, 1981.

Hirschi, Travis. Causes of Delinguency. Berkeley: University of California Press, 1969.

Hoffman, Peter B. and James L. Beck. "Burnout-age at Release from Prison and Recidivism," Journal of Criminal Justice. Vol. 12 (6), 1984, pp. 617-623.

Inkeles, Alex and David Smith. Becoming Modern. Cambridge: Harvard University Press, 1974.

Irwin, John. The Felon. Englewood Cliffs: Prentice-Hall, 1974 .

Jensen, Gary F. "Labeling and Identity," Criminology. Vol. 18 (1), 1980, pp. 121-129.

Kerlinger, Fred N. Foundations of Behavioral Research. 2nd ed. New York: Holt, 1973.

King, Harry. Box Man: A Professional Thief's Journey. As told to and edited by Bill Chambliss. New York: Harper, 1972.

Lemert, Edwin M. Human Deviance, Social Problems, and Social Control. 2nd ed. Englewood Cliffs: PrenticeHall, 1972.

Levinson, Daniel J., C. M. Darrow, E. B. Klein, M. H. Levinson, and B. McKee. "The Psychological Development of Men in Early Adulthood and the Mid-Life Transition," in Life History Research in Psychopathology. Ricks, D. , H. Thomas, and M. Roff, eds. Minneapolis: University of Minnesota Press, 1974.

Levinson, Daniel J. in collaboration with C. N. Darrow, E. B. Klein, M. H. Levinson, and B. Mckee. Seasons of a Man's Life. New York: Knopf, 1978.

Lowenthal, M. F. and D. Chiriboga. "Social Stress and Adaptation: Toward a Life Course Perspective," in Eisendorfer, C. and M. P. Lawton, eds. The Psychology of Adult Development and Aging. Washington, D.C.: The American Psychological Association, 1973. 
Marks, John B. and Edward M. Glaser. "The Antecedents of Chosen Joblessness," The American Journal of Community Psychology. Vol. $8(2), 1980, \mathrm{pp} .173-201$.

McCarthy, John D. and Dean R. Hoge. "The Dynamics of SelfEsteem and Delinquency," American Journal of Sociology. Vol. 90 (2), 1984, pp. 396-411.

McCreary, Charles P. and Ivan N. Mensh. "Personality Differences Associated with Age in Law Offenders," Journal of Gerontology. Vol. 32 (2), 1977, pp. 164167.

Matza, David. Delinquency and Drift. New York: Wiley, 1964 .

Meisenhelder, Thomas. "An Exploratory Study of Exiting from Criminal Careers," Criminology. Vol. 15 (3), 1977, pp. 319-334.

Miller, Stuart J., Simon Dinitz, and John P. Conrad. Careers of the violent: The Dangerous offender and Criminal Justice. Lexington: Lexington Books, 1982 .

Moore, Mark H., Susan R. Estrich, Daniel McGillis, and William Spelman. Dangerous Offenders: The Elusive Target of Justice. Cambridge: Harvard University Press, 1985.

Neugarten, Bernice L., Joan Moore, and John Lowe. "Age Norms, Age Constraints, and Adult Socialization," American Journal of Sociology. Vol. 70 (5), 1964, pp. 710-717.

Neugarten, Bernice L., R. J. Havighurst, and S. S. Tobin. "Personality and Patterns of Aging," in Neugarten, B. L., ed. iddle-Age and Aging. Chicago: University of Chicago Press, 1968.

Nolan, William A. risis Time! Love, Marriage and the Male at Midlife. Dodd Mead, 1984.

Petersilia, Joan. Focusing Attention on Career Criminals-An Idea Whose Time Has Come Santa Monica: The Rand Corporation, 1978 .

Petersilia, Joan. "Criminal Career Research: Review of Recent Evidence," in Crime and Justice--An Annual Review of Research. vol. 2. Morris, N. and M. Tonry, eds. Chicago: University of Chicago Press, 1980. 
Petersilia, Joan, P. K. Honig, and C. A. Hubay, Jr. The Prison Experience of Career Criminals. Santa Monica: The Rand Corporation, 1980.

Petersilia, Joan, Peter W. Greenwood, and Marvin M. Lavin. Criminal Careers of Habitual Felons. Santa Monica: The Rand Corporation, 1977.

Polk, Kenneth. "Becoming Adult: An Analysis of Maturational Development from Age 16 to 30 of a Cohort of Young Men." The Final Report of the Marion County Youth Study, Eugene: University of Oregon Press, 1981.

Quetelet, A. Recherches Sur le Penchant au Crime aux Differents Ages. 2nd ed. Brussels: Havez, 1833, quoted by Thorsten Sellin in "Maturing out of crime: Recidivism and Maturation," National Probation and Parole Association Journal. Vol. 4 (3), 1971.

Reckless, Walter C. and Simon Dinitz. The Prevention of Juvenile Delinquency: An Experiment. Columbus: The Ohio State University Press, 1972.

Robins, Lee N. Deviant Children Grown Up. Baltimore: William \& wilkins, 1966 .

Rogers, Kenn. "Crisis at the Mid-point of Life," New Society. Vol. 29 (619), 1974, pp. 413-415.

Rosenberg, M. Society and the Adolescent Self-Image. Princeton: Princeton University Press, 1965.

Rowe, Alan R. and Charles R. Tittle. "Life Cycle Changes and Criminal Propensity," Sociological Quarterly. Vol. 18 (2), 1977, pp. 223-236.

Schwartz, Michael and Sandra S. Tangri. "A Note on 'SelfConcept as an Insulator Against Delinquency'," American Sociological Review. Vol. 30, 1965, pp. 922-926.

Seiden, Richard H. "Mellowing with Age: Factors Influencing the Nonwhite Suicide Rate," International Journal on Aging and Human Development. Vol. 13 (4), 1981.

Sheehy, Gail. Passages. New York: Bantam Books, 1974.

Shover, Neal. "The Later Stages of Ordinary Property Offender Careers," Social Problems. Vol. 32 (2), 1983, pp. 208-218. 
Sutherland, Edwin H. and Donald R. Cressey. Criminology. 9th ed. Philadelphia: Lippincott, 1974.

Tamir, Lois M. Men in Their Forties. New York: Springer Publications, 1982 .

Vaillant, George E. Adaptation to Life. Boston: Little Brown, 1977.

Webster's New Collegiate Dictionary. Springfield: G. and G. Merriam Company, 1973. 
APPENDIX A

ADVERTISEMENT FOR THE STUDY 


\section{MEN OVER 40}

WHO HAVE DONE

\section{CRIME FOR MANY YEARS}

WHO HAVE BEEN

\section{FREE OF ARRESTS FOR \\ PAST 5 YEARS}

please contact

as soon as possible for research purpose:

MICHAEL STOOPS

BALONEY JOE'S

$231 \rightarrow 158$ 
APPENDIX B

INFORMED CONSENT 
INFORMED CONSENT

hereby agree to serve as a participant in the research project on criminal Career Termination conducted by Annette Jolin under the supervision of Dr. Don C. Gibbons.

I understand that the possible risks to me associated with this study are: demands on my time, possible inconvenience, and to some degree, the invasion of my privacy.

It has been explained to me that the purpose of the study is to learn about criminal career termination.

I may not receive any direct benefit from participating in this study, but my participation may help to increase knowledge which may benefit others in the future.

Ms. Jolin has offered to answer any questions I may have about the study. I have been assured that all information I give will be kept confidential and that the identity of all participants will remain anonymous.

I understand that I am free to withdraw from participation in this study at any time without jeopardizing my relationship with Portland State University.

I have read and understand the foregoing information.

Date Signature

If you experience problems that are the result of your participation in this study, please contact Victor C. Dahl, Office of Graduate Studies and Research, 105 Neuberger Hall, Portland State University, 229-3423. 
APPENDIX C

MATRIX APPLICATION--MULTIPLE OFFENSE 


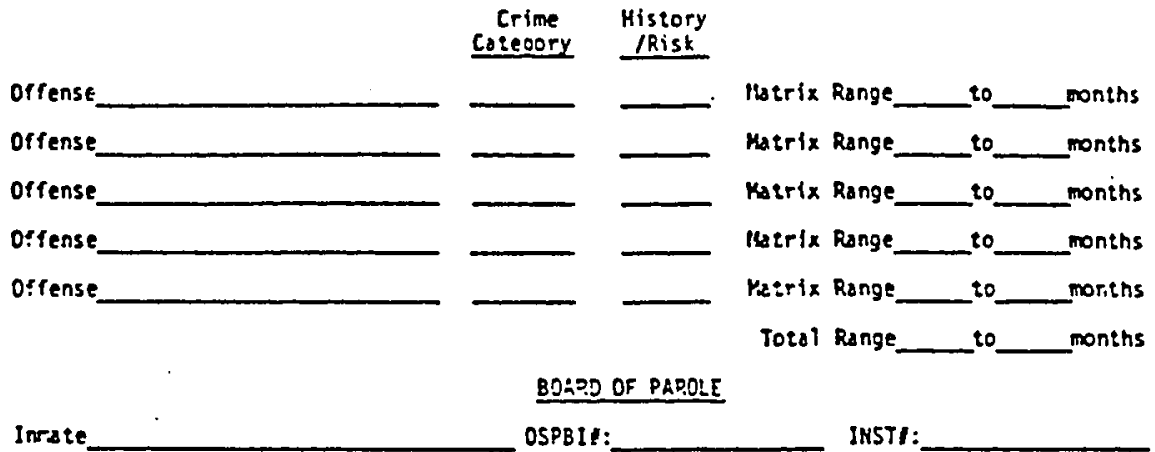

Criminal History/Risk Assessment

ITEY:

(A) No prior felony or misdeaseenor convictions as an oduit or Juvenile:

One prior conviction:

3

Two or three prior convictions:

Four or nore prior convictions:

(B) No prior incarcerations (1.e., executed sentences of 90 days or more) as an iduile or juventie:

One or ewo prior incarcerations:

Three or more prior incerserations:

2

(c) Verified period of 3 years conviction free in the co-rinity prior to present incarceration: Osherwise:

(D) Ace at comencement of behavior leading to this incarceration:

26 or oider and at least one point received in Items A. B or C:

26 or older ane no points resefved in $A$, or $C$ :

21 to under 26 and at least one point received in $A, B$ or $C$ :

21 to unser 26 and no points recelved in $A, B$ or $C$ :

Under 21:

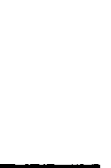

$\longrightarrow$

(E) Present comitment does rot inciude paroie, probalion. faflure to appear, reiease agreement, escape or custody violation: Present comitment involves probation. release agreement. or fallure to appear violation:

Present conmitment involves parole, escape or custody violation:

2

$\longrightarrow$

(F) Has no ad-itted or documented heroin or opiate derivative -buse probler: Othenvise:

TOTAL HISTORY RISK ASSESSMENT SCORE:

\section{Severtey}

renge

Adgutad Inceptica bete
Ireparee by Parole Aeabre

Date 
APPENDIX D

SOLICITATION LETTER 
May 7, 1984

Dear Mr. :

As part of my doctoral degree, I am doing a study that involves interviewing inmates with extensive criminal backgrounds. The purpose of the study is to find out what factors are associated with "burn-out."

I am writing to you to ask whether you would be willing to participate in this study. Taking part in this study will mean a one-hour personal interview with me. There are no further requirements. You will be informed of the results of the study in exchange for your participation.

Your participation is, of course, voluntary, which means that you and only you make the decision to take part, and furthermore, that you are free to discontinue your involvement at any time. All information provided by you is held confidential, and your participation will remain anonymous.

If you wish to be considered for this interview, please sign below and return this letter to Larry Roach.

Sincerely yours,

Annette Jolin

Portland State University 
APPENDIX E

THANK-YOU LETTER 
Annette Jolin

School of Urban and

Public Affairs

P. O. Box 751

Portland State University

Portland, Oregon 97207

July 18,1984

Dear Mr. :

I would like to take this opportunity to thank you for your willingness to participate in my research project.

The interview with you was and is of great importance to me. Without your generosity, this project would not have been possible.

I am in the process of analyzing the data from the interviews. It will be some time yet before I can actually communicate to you what I have found.

As I had told you during the interview, I will make a copy of the results available to you sometime this fall.

Again, thank you very much.

sincerely yours,

Annette Jolin 


\section{APPENDIX F}

BACKGROUND CHARACTERISTICS 
To begin with, I would like to ask you a few questions about yourself. Please answer these questions as accurately as possible.

BACKGROUND CHARACTERISTICS: PART A

1. Age

2. Race (ask only if not obvious)

Hispanic Asian American Other

3. Marital Status

$\begin{array}{lrr}\text { Divorced } & \text { Separated } & \text { Widowed } \\ \text { Never Married } & \text { Common Iaw Marriage }\end{array}$

If widowed, divorced, or separated, how long?

Iess than 1 year__ 1-3 years__ 4-7 years

Over 7 years

4. Children

Number of Children Age of Oldest Child

5. What is the highest level of education completed?

Less than high school__ High School

Vocational Training__ Associate Degree

Baccalaureate Degree__ Graduate Degree

Other

6. Would you describe yourself as a religious person?

Not at all hardly somewhat fairly very

7a. Are you employed?

No If No, skip to Question 8 .

Yes_ Part-time___ Full-time 
7b. If employed, what is your occupation?

7c. If you are not employed, when was your last job? and what was it?

8a. Can you tell me into which of these categories your yearly income falls?

Less than $\$ 5000 \quad$ Between $\$ 5000$ and $\$ 10,000$ Between $\$ 10,000$ and $\$ 20,000$ over $\$ 20,000$

8b. What are the sources of your income (e.g., job, social security, pensions, disability, etc.l?

9a. Are you a member of any group that meets regularly?

No Yes

9b. If YES, describe group (s):

10. Your current address:

11a. Type of residence House Apartment

11b. Not counting yourself, how many persons live in this residence with you?

11c. How are they related to you?

Relative Spouse Friend 
APPENDIX G

CRIMINAL HISTORY QUESTIONS 


\section{CRIMINAL HISTORY QUESTIONS: PART B}

The next questions are about your criminal history. Some of the questions ask you to think back about your life and to remember things that happened. Please think about the questions and give the most accurate answers you can.

1. How old were you when you were first arrested--that is, officially charged by the police (an adult or a juvenile arrest, other than a traffic violation)?

Years old

2. How old were you when you were first convicted of a criminal offense (an adult or a juvenile conviction, other than a traffic violation)?

Years old

2a. Were you first convicted of a crime that you had committed by yourself or with a group of others?
Alone
With Others
How many?

What crime?

3. What were the main reasons that you first got involved in crime? Check all that apply.

For excitement___ Friends got me into it___ To get money for high living--nice clothes, car, etc.

Lost my temper___ To get money for drugs--had a habit__ to get money for day-to-day living--self and family support___ For the reputation____ Everyone I knew was doing it--just a normal way of life Other What?

4. How old were you at the time? years old 
5. Were you ever sent to a local or county facility such as a county youth camp, a home, or a juvenile hall?

No Yes How many times?

6. Were you ever sent to a statewide or federal juvenile institution?

No Yes How many times?

7. Before youu were 18, did you ever do anything on this list?

Broke into some place Stole a car

Stole something worth more than about $\$ 100$

Used a stolen credit card

Forged something

If No, go to Question 10 .

8. How old were you when you first did any of these things?

_ years old

9. Before you were 18, how often did you do any of these things?

Once or twice

A Eew times

Sometimes

Often 
10. Before you were 18, did you ever do anything on this list?

Robbed someone

Threatened someone with a gun, knife, or other weapon

Hurt someone with a gun, knife or other weapon

Beat someone badly

Raped someone

If No, go to Question 13.

11. How old were you when you first did any of these things?

years old

12. Before you were 18, how often did you do any of these things?

Once or twice

A few times

Sometimes

Often

13. Before you were 18, did you use each of the things on the list below? (Circle one number on each line.)

\begin{tabular}{|c|c|c|c|c|}
\hline & Often & Sometimes & $\begin{array}{c}\text { Once or } \\
\text { Twice }\end{array}$ & Never \\
\hline Marijuana & 3 & 2 & 1 & 0 \\
\hline LSD. Psychedelics & 3 & 2 & 1 & 0 \\
\hline Uppers, downers & 3 & 2 & 1 & 0 \\
\hline Heroin & 3 & 2 & 1 & 0 \\
\hline Cocaine & 3 & 2 & 1 & 0 \\
\hline
\end{tabular}


13a. Before you were 18, did you commit crimes by yourself or with others?

Always alone Always with others

Sometimes alone, sometimes with others

Which crimes alone?

Which crimes with others?

The next questions are about your whole life, both as an adult and as a juvenile.

14. Altogether in your life, how many times have you been arrested? (Don't count traffic violations.)

Once. 2-3 times 4-6 times 7-10 times

11-15 times 16-25 times more than 25 times

15. How many different terms have you served in a local or county jail?

none 1-2 terms 3-5 terms $6-10$ terms 11-15 terms 16-25 terms more than 25 terms

16. How many times have you been on probation? times N Never

17. How many times have you served in an adult prison? (If you are now in prison, include this term. Don't count parole revocations as a different term.)
None
1 term
2 terms
3 terms
4 terms
5 terms
6 or more terms 
17a. In chronological sequence, list all the adult prisons you have served time in.

18. How many times have you been on parole? (Count each time you were released on parole.) times $\quad$ Never

19. How many times have you had probation or parole revoked?

times $\quad$ Never

20. Have you ever been committed to a drug treatment program?

Yes _ No

21. Altogether in your life, how many times have you been convicted of a felony?

Never__ Once_ 2-3 times_ 4-6 times

7-10 times_ 11-15 times___ 16 or more times

22. Overall, in the past, how successful do you think you were in doing crime?

very successful___ somewhat successful

somewhat unsuccessful

very unsuccessful 
23. (This question is to be asked only for retrospective interview and with inmates.)

What do you think the chances are that you will TRY to make it going straight when you get out?

no chance_ low chance___ some chance

good chance __ high chance

completely certain

24a. (For retrospective and inmate interviews only.)

What do you think the chances are that you will

ACTUALLY make it going straight on the outside?

no chance___ low chance___ some chance

good chance __ high chance.

completely certain

24b. (For interview with the ex-offender.)

What do you think the chances are that you will CONTINUE to go straight?

no chance ___ low chance___ some chance

good chance __ high chance

completely certain

25. (For interview with the ex-offender.)

What do you think the chances are that you will end up back in prison?

no chance low chance

some chance

good chance __ high chance

completely certain 
APPENDIX H

SATISFACTION 
The next set of questions concerns your life now and how you feel about it. Please think carefully before you answer each question.

1. How often do

$\begin{array}{lcl}\text { Little or } & \text { Some } & \text { A good } \\ \text { none of } & \text { of the } & \text { part of } \\ \text { the time } & \text { time } & \text { the time }\end{array}$

All or most of you feel? the time

a. My mind is as clear as it has always been.

1

2

4

5

b. I find it easy to do the things I used to do.

1

2

4

5

c. My life is interesting.

1

2

4

5

d. I feel that I am useful and needed.

1

2

4

5

e. My life is pretty full. 1 2

4

5

f. I feel hopeful about the future. 1

2

4

5

2. How often are these true for you. Never Rarely sometimes often

a. I feel that I am a person of worth, at least as much as others.

b. I am able to do things as well as most other people.

c. On the whole, I feel good about myself. 
3. How often has the following been true for you? Never

Not

Very

Nearly

Much

Pretty

often

All the

Time

a. Do you find it

difficult to get up in the morning?

1

2

4

5

b. Are you ever

bothered by

nightmares?

1

2

4

5

c. Do you tend to lose weight when you have something important bothering you?

d. Are you troubled by your hands sweating so that you feel damp and clammy?

e. Have there ever been times when you couldn't take care of things because you just couldn't get going? 1

2 you had the following?

Never

a. Do you ever drink more than you should?

b. When you feel worried, tense, or nervous, do you ever drink alcoholic beverages to help you handle things?
1
Not Very

often

Pretty

Often

Nearly

All the

Time
2

4 5 


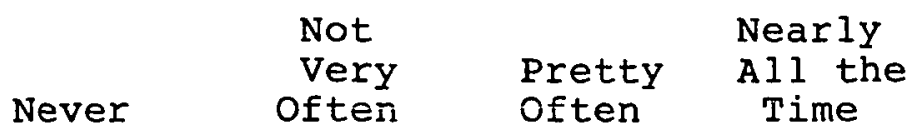

c. Have there ever been problems between you and anyone in your family because you drank alcoholic beverages?

5. How often have you had the following?

a. Do you ever have any trouble getting to sleep or staying asleep?

b. Have you ever been bothered by nervousness, feeling fidgety, and tense?

c. Are you ever troubled by headaches and pains in the head?

1

2

4

d. Do you have a loss of appetite? 1

e. How often are you bothered by having an upset stomach?

6. How often have you had the following?

a. Has any ill health affected the amount of work you do?

b. Have you ever been bothered by shortness of breath when not exercising or working hard? 


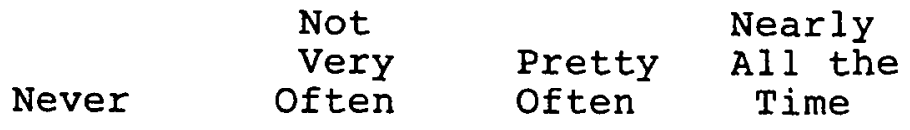

c. Have you ever

been bothered by

your heart beating hard?

1

2

4

5

7. Just answer the following questions with YES or No

a. Do you feel you are bothered by all

sorts of pains and ailments in different

parts of your body?

YES NO

b. For the most part, do you feel healthy

enough to carry out the things you would

like to do? YES NO

c. Do you have any particular health problem? YES No

8. When you feel

worried, tense,

Never

Hardly Some-

Ever times

Many

or nervous, do

you ever take

medicines or

drugs to help

you handle

things?

1

2

4

5

9. Some things in our lives are very satisfying to one person, while another may not find them satisfying at all. I'd like to know how much satisfaction you have gotten from some of these different things:

No Little
Satisfaction Some Great

a. How much satisfac-

tion have you

gotten from work at a job?

1

2

4

5 
No Little Satisfaction

b. What about being married?

c. How much satisfaction have you gotten out of being a father?
1

2

4

5

1

2
Some

Great

10. Compared to your life today, how do you think things will be 5 or 10 years from now? Do you think things will be happier for you than they are now, not quite as happy, or what?

$$
\text { More happy Same Less Happy }
$$

11. Here is a list of things that many look for of want out of life. Please study the list carefully, then tell me:

a. Which two of these things are most important to you in your life?

b. And of these two, which one is the most important to you in your life?

Sense of belonging

Excitement

Warm relationships with others

Self-fulfillment

Being well respected

Fun and enjoyment in life

Security

Self respect

A sense of accomplishment

12. Taking into consideration all the things about your job, how satisfied or dissatisfied are you with it?
Very dis-
Neutral, Ambivalent
Satisfied
Very
Satisfied 
13. Regardless of how much you like your job, is there any other work you'd rather be doing?

$$
\text { YES NO }
$$

14. Many men feel that they are not as good fathers as they would like to be. Have you ever felt this way?

$$
\text { YES NO }
$$

15. Taking all things together, would you describe your marriage as:

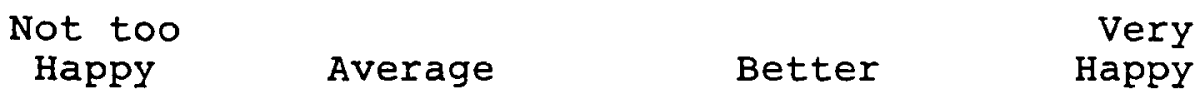

16. Even in cases where married people are happy, there have often been times in the past when they weren' $t$ too happy--when they had problems getting along with each other. Has this ever been true for you?

$$
\text { YES NO }
$$

17. Many men feel that they're not as good husbands as they would like to be. Have you ever felt this way?

$$
\text { YES NO }
$$

18. All in all, who would you say gets more out of being married-you, your wife, or both about equal?
self
about equal
wife

19. About how many of your neighbors do you know well enough to visit or call on?
none
a few
several
many 
20. About how often do you visit with any of your neighbors, either at their homes or at your own?

Less than

Once a

Month

Once a

Month

A Few times

Once a

A month Week

More

21. About how often do you get together with friends or relatives--I mean things like going out together or visiting in each other's homes?
Less than
Once a Once a
Month
Once a
Month
A Few times
Once a
A month Week
More

22. Now think of the friends and relatives you feel free to talk with about your worries and problems, or even count on for advice or help--would you say you have many, several, a few, or no such friends or relatives?
None
A few
Several
Many

23. How often, if ever, have you talked with friends or relatives about your problems when you were worried, or asked them for advice or help?

Never Rarely Sometimes Often Very often

24. Do you feel you have as many friends as you want, or would you like to have more friends?

$$
\text { enough want more }
$$


25. I have some statements here that describe the way some people are and feel. I'll read them one at a time and you just tell me how true they are for you--whether they're true for you, pretty true, etc.

$\begin{array}{cccc}\text { Very } & \text { Pretty } & \text { Not Very } & \text { Not at } \\ \text { True } & \text { True } & \text { True } & \text { All True }\end{array}$

a. No one cares much what happens to me. 1

3

4

b. I often wish that people would listen more to me. 1

c. I often wish that people liked me more than they do. 1

d. These days I really don't know who I can count on for help. 1 
APPENDIX I

SOCIAL PSYCHOLOGICAL DEVELOPMENT 
PART D: SOCIAL PSYCHOLOGICAL DEVELOPMENT

This section includes statements about people's thoughts and feelings. Think carefully about how much each of these statements applies to you and your life.

Strongly

Agree

Agree

Uncertain

Disagree

Strongly

Disagree

Y01 I often think about my disappearing youth.
1
2
3
4
5

DC2 I have failed in my responsibilities toward many of those who are closest to me.
1
2
3
4
5

MF3 I can undertake long, grueling work and endure severe bodily stress without quitting.
1
2
3
4
5

AS4 I am so caught up in everyday concerns that I rarely sit back and reflect on what's going on.
1
2
3
4
5

M 5 Helping a young person getting started in life gives me great pleasure.
1
2
3
4
5

Yo6 I often think about how much time I have left in this world. 
Strongly

Agree

Agree

Uncertain

Disagree

Strongly

Disagree

DC7 I have failed and destroyed many of my own possibilities.

1

2

3

4

5

MF8 A man's first responsibility is to provide for his family's financial and physical well-being.

$\begin{array}{lllll}1 & 2 & 3 & 4 & 5\end{array}$

AS9 Without people or things to keep me busy, I usually feel lost.
1
2
3
4
5

M10 Bringing along a young person, helping his or her development as an adult, is a valuable contribution I can make to society.
1
2
3
4
5

Y011 I worry about not having enough years left in my life to do what I want to.
1
2
3
4
5

DC12 I rarely think about the harm I have done to others.
1
2
3
4
5

MF13 I can do nearly anything as long as I put my mind to it.

1

2

3

4

5

AS14 To own things and to be seen as successful is most important in my life.

1

2

3

4

5 
Strongly

Agree

Agree Uncertain

Disagree

Strongly

Disagree

Y015 I wonder if my life will be more worthwhile in my remaining years.
1
2
3
4
5

DC16 I realize more and more that the failures and misfortunes I experience are not the fault of others, but are mostly the result of unfortunate flaws in myself.
1
2
3
4
5

MF17 If I am part of a group, we usually get things done.
1
2
3
4
5

MF19 Others usually do what I want them to do.
1
2
3
4
5

Yo20 I often wonder if I am too old to make a fresh start. $\begin{array}{llllll}1 & 2 & 3 & 4 & 5\end{array}$

MF21 If I want to do my work well, I can't let my feelings interfere.
1
2
3
4
5

DC22 Others around me, even my loved ones, have at times hurt me badly.
1
2
3
4
5

MF23 I don't mind working with women, but I wouldn't want to have a woman boss.

1

2

3

4

5 
Starting in adolescence, many men report having a goal in life that they want to reach--they have a clear picture of how they are going to live their adult lives. Do you have such a goal?

YES NO

If YES, start with Question 1.

If No, start with Question 4.

Strongly

Agree

Agree

Uncertain

Disagree

Strongly

Disagree

1. In order to achieve this life goal, all important choices must be made to fit the goal.
1
2
3
4
5

2. One can either succeed or fail at achieving one's life goal. There is no in-between.

$\begin{array}{lllll}1 & 2 & 3 & 4 & 5\end{array}$

3. To fail to reach one's life goal means to fail at life. $\begin{array}{lllll}1 & 2 & 3 & 4 & 5\end{array}$

4. Without a life goal, my life lacks purpose and meaning.
1
2
3
4
5

P1. Did you find that your middle-age years were different from other times in your life? 
P2. During middle age, did you feel better or worse about yourself than at other times in your life?

P3. Did you become more concerned about your physical health during middle age?

P4. Did your feelings about relationships with women change during middle age?

P5. Since middle age, have friends become more important to you?

P6. Since middle age, do you view the future differently?

P7. Overall, do you think you have changed during or after your middle-age years? 
APPENDIX J

SOCIAL DESIRABILITY INDEX 
SOCIAL DESIRABIIITY INDEX

Please tell me whether the following statements are true or false.

1. I have never intensely

TRUE

FALSE disliked anyone.

2. I sometimes feel resentful

TRUE

FALSE when I don't get my way.

3. I'm always wiling to admit when I make a mistake.

TRUE

FALSE

4. I sometimes try to get even

TRUE

FALSE

rather than to forgive and

forget.

5. At times, I have really insisted on having things

TRUE

FALSE my own way.

6. I have never been angered

TRUE

FALSE when people expressed ideas very different from mine. 